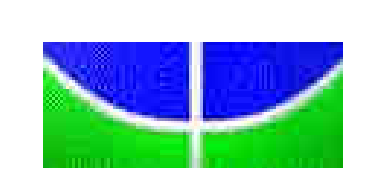

Universidade de Brasília - UnB

PROGRAMA DE PÓS-GRADUAÇÃO EM CIÊNCIA DA INFORMAÇÃO - PPGCINF FACULDADE DE CIÊNCIA DA INFORMAÇÃO - FCI

\title{
A contribuição da Arquitetura da \\ Informação na construção e utilização de Ambientes Informacionais Colaborativos \\ de Ensino/Aprendizagem
}

Ernesto Henrique Radis Steinmetz 


\section{A contribuição da Arquitetura da \\ Informação na construção e utilização de Ambientes Informacionais Colaborativos de Ensino/Aprendizagem}

Tese apresentada à Faculdade de Ciência da Informação da Universidade de Brasília, como parte dos requisitos para obtenção do Título de Doutor em Ciência da Informação.

Orientador: Prof. Dr. Cláudio Gottschalg-Duque 


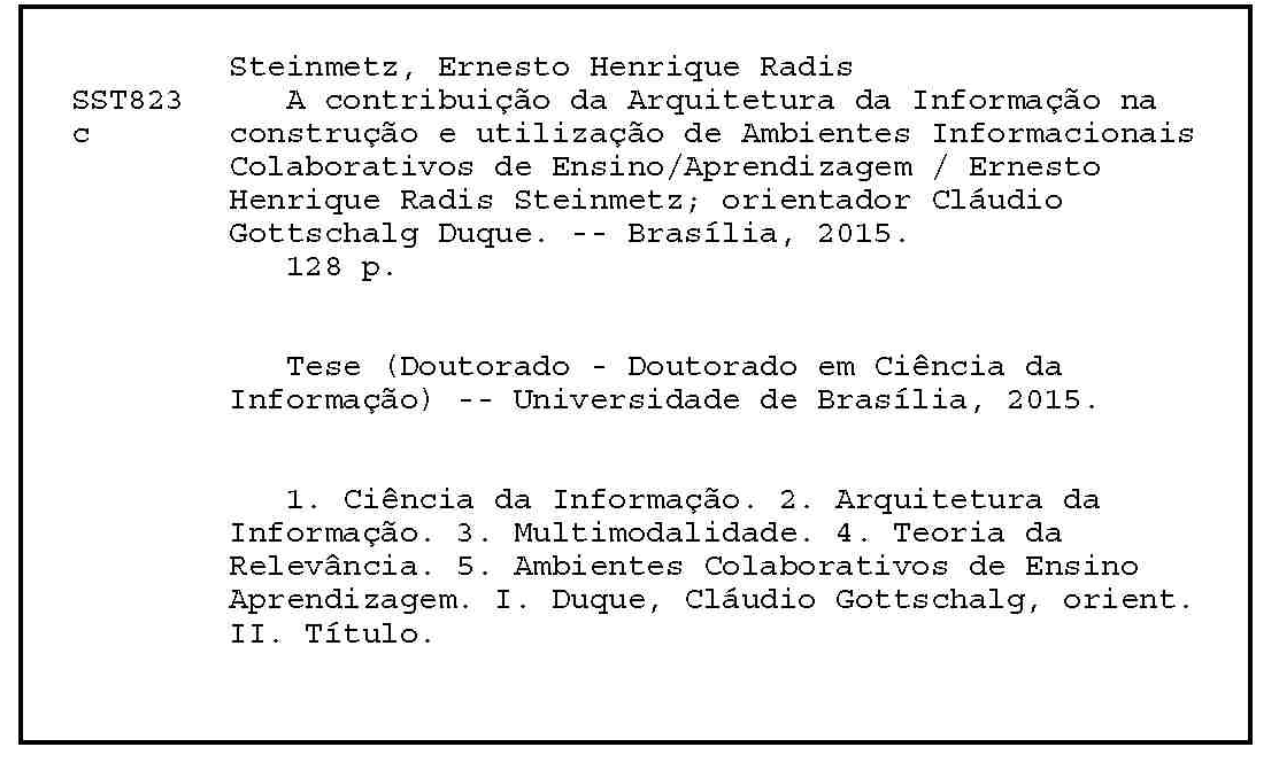


Título: "A contribuição da Arquitetura da Informação na construção e utilização de Ambientes Informacionais Colaborativos de Ensino/Aprendizagem".

Autor (a): Ernesto Henrique Radis Steinmetz Área de concentração: Gestão da Informação Linha de pesquisa: Organização da Informação

Tese submetida à Comissão Examinadora designada pelo Colegiado do Programa de Pósgraduação em Ciência da Informação da Faculdade em Ciência da Informação da Universidade de Brasília como requisito parcial para obtenção do título de Doutor em Ciência da Informação.

Tese aprovada em: 14 de dezembro de 2015.

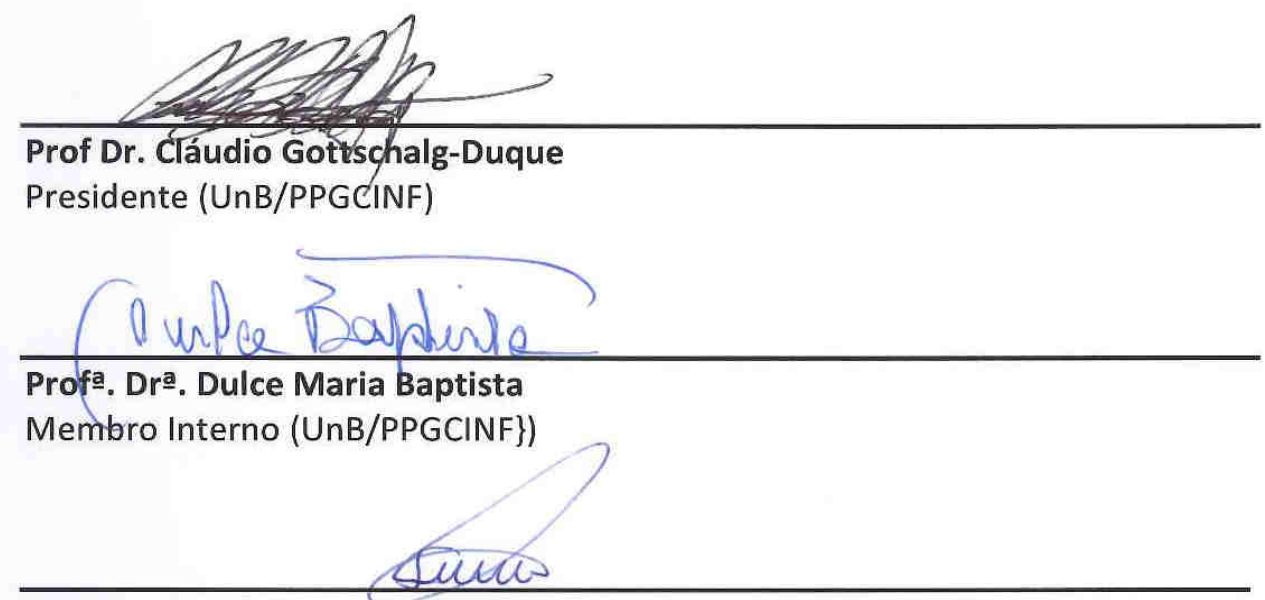

Prof. Dr. Josué de Souza Mendes Membro Externo (RIFB/IFB))

Fabiomo Cavolcoust; Fermondes

Prof. Dr. Fabiano Cavalcanti Fernandes

Membro Externo (CTAG/IFB)

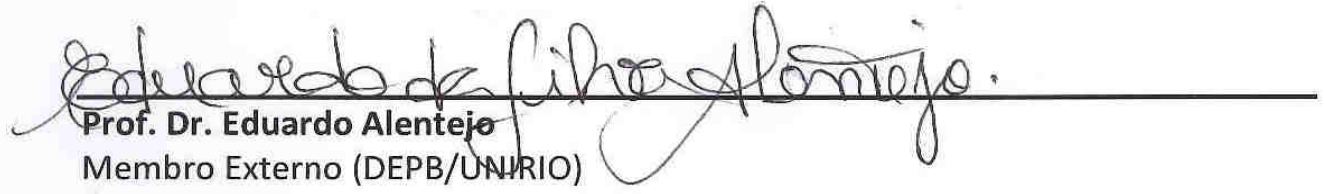

Prof. Dr. André Porto Ancona Lopez

Suplente (UnB/PPGCINF) 


\section{DEDICATÓRIA}

Aos meus filhos Thaís Helena e Henrique Rael, o que tenho de mais valioso em minha vida.

A minha Mãe Gerta Steinmetz, meus Irmãos Ligia e Ricardo pelo incentivo e apoio em todos os momentos. 


\section{AGRADECIMENTOS}

Agradeço em primeiro lugar a Deus.

Ao meu pai, Prof. Rolf Frederico Steinmetz (em memória), pelo exemplo de dedicação a vida acadêmica como professor, pesquisador e museólogo. Que sempre tentou me ensinar o valor e a importância dos estudos, mesmo quando eu não tinha maturidade para entender isso.

Ao meu orientador, Prof. Dr. Cláudio, pela confiança na minha capacidade e dedicação durante o todo o meu processo de aprendizagem e amadurecimento que me capacitaram á me tornar um doutor. Sem ele, essa tese não existiria.

Aos membros da banca Prof. Dr. Josue de Sousa Mendes, Prof. Dr. Fabiano Cavalcanti Fernandes, Prof. Dr. Eduardo Alentejo, Prof $\stackrel{a}{\text {. Dr }}$. . Dulce Maria Baptista e Prof. Dr. André Porto Ancona Lopez, pela disponibilidade em contribuir com as suas experiências na banca de defesa desta tese.

Aos colegas e amigos que se disponibilizaram a participar do grupo focal, dispondo do seu tempo e conhecimentos de maneira altruísta, provendo contribuições inestimáveis para a elaboração desta tese.

Aos colegas do PPGCInf/FCl/UnB e, principalmente, aos colegas do grupo de pesquisa R.E.G.I.I.M.E.N.T.O., pelas diversas contribuições informais nas atividades de elaboração dessa tese.

Aos professores do PPGCInf/FCl/UnB, pelos conhecimentos transmitidos e aos funcionários da UnB, sempre dispostos a ajudar e cooperar, prestando atendimento com atenção e dedicação.

A todos que colaboraram de forma direta ou indireta na realização deste trabalho. 
RESUMO: Este trabalho apresenta algumas contribuições da Arquitetura da Informação na construção de Ambientes Informacionais Colaborativos de EnsinoAprendizagem com a intenção de estabelecer um fluxo de atividades para elaboração, utilização e refinamento desses ambientes, a partir dos conceitos e fundamentos da Arquitetura da Informação, da multimodalidade e da Teoria da Relevância. Para tanto, foi realizada uma revisão de literatura a fim de identificar o estado da arte dos temas envolvidos nesta pesquisa. Após isso, foram identificados estudos sobre a relação entre a ciência da informação, a Arquitetura da Informação e a multimodalidade aplicadas em Ambientes Informacionais Colaborativos de Ensino-Aprendizagem, com o objetivo de aumentar a relevância desses ambientes para os estudantes. Foi elaborada uma proposta inicial do fluxo do modelo de Arquitetura da Informação multimodal aplicado em ambientes Colaborativos de Ensino/Aprendizagem. O método utilizado para validação da pesquisa foi o grupo focal, que compreende uma investigação exploratória para avaliar a proposta preliminar e formular questões pertinentes que possam contribuir para a evolução dessa proposta. No final, foi elaborada uma proposta de Arquitetura da Informação que apresenta um fluxo de atividades, atores e artefatos para a construção e utilização de Ambientes Informacionais Colaborativos de Ensino-Aprendizagem, sob a luz dos conceitos da Multimodalidade e da Teoria da Relevância.

PALAVRAS-CHAVE: Ciência da Informação; Arquitetura da Informação; Ambientes Colaborativos de Ensino-Aprendizagem; Multimodalidade; Teoria da Relevância.

ABSTRACT: This research presents a proposal of Information Architecture's contribution for Informational Environments in Collaborative Teaching-Learning. It is to establish a flow of activities for the preparation, use and refinement of Informational Environments for Collaborative Teaching-Learning, according to the concepts and fundamentals of information architecture and multimodality. Therefore, a literature review was conducted to identify the state of the art of the issues involved in this research. After this, studies were identified on the relationship between information science, information architecture and multimodality applied in Informational Environments Collaborative Teaching-Learning, in order to Increase the relevance of these environments for students. An initial proposal by the architectural model of the flow of multimodal information applied in Environments for Collaborative Teaching-Learning was developed. The method used to search the validation was focus group; Comprising exploratory research to assess the preliminary proposal and formulate relevant questions might to contribute to the evolution of it. In the end, it created the proposal for information architecture to provide a flow of activities, actors and artifacts for the construction and use of Informational Environments Collaborative Teaching and Learning, in the light of the concepts of Multimodality and relevance theory.

KEYWORDS: Information Science; Information Architecture; Collaborative environments Teaching-Learning; multimodality; Relevance Theory. 


\section{LISTA DE FIGURAS}

Figura 1: Usos e Necessidades da Informação (LE COADIC, 2004, p. 40).................19

Figura 2: Sistema de Informação Aberto (AUDY, ABREU e CIDRAL, 2007)...............23

Figura 3: Proposta de Modelo de Arquitetura da Informação (LIMA-MARQUES;

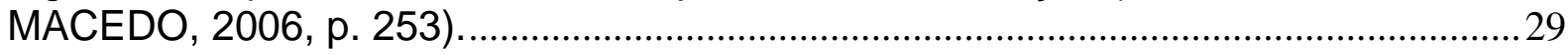

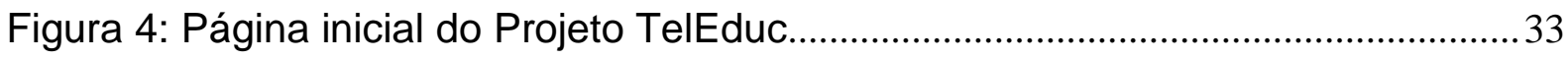

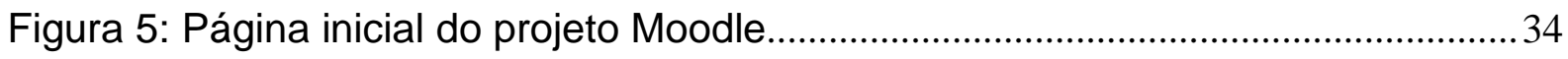

Figura 6: Diagrama do Modelo de Colaboração 3C (FUKS et al., 2004b) .....................36

Figura 7: Espectro de abordagens para um documento e suas páginas (BATEMAN, 2008, p 25)

Figura 8: Proposta de Composição de Layout (KRESS e VAN LEEWEN, 1998, $p$ 223)

Figura 9: Relação da Precisão X Revocação em SRls (Steinmetz et al. 2013, p. 13).

Figura 10: Fluxo da Informação em um Ambiente CSCL (STENMETZ e DUQUE, 2014).

Figura 11: Design centrado no humano - (ISO/IEC 13407, 1999)...

Figura 12: Principais fases dos modelos de processo de software - (Pressman, 2011).

Figura 13: Modelo de Ciclo de Vida do Desenvolvimento de Sistemas (GORDON e GORDON , 2006).

Figura 14: Diagrama de fases para concepção de uma Arquitetura da Informação Multimodal para ambientes CSCL - DAIM:CSCL. 68

Figura 15: Interseção entre o DAIM:CSCL e o Modelo de Arquitetura da Informação

Figura 16: Organização e recursos da sala para a reunião do grupo focal. .82

Figura 17: Proposta de alteração da figura do DAIM:CSCL do participante 8. 84

Figura 18: Proposta de alteração da figura do DAIM:CSCL do participantes 4 e 7. ..85

Figura 19: Novo DAIM:CSCL - Diagrama de Arquitetura de Informação Multimodal para Ambientes CSCL. 


\section{LISTA DE QUADROS}

Quadro 1: Critérios para a Ciência da Informação de acordo com o Institute of Information Science.

Quadro 2: Abordagens para a Ciência da Informação ....................................................19

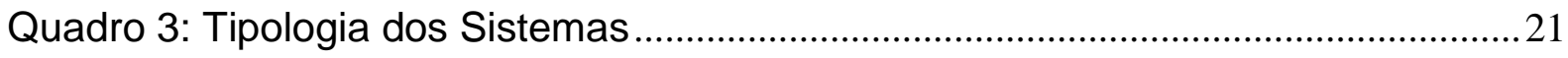

Quadro 4: Classificação dos Conceitos de Arquitetura da Informação ..........................27

Quadro 5: Serviços de comunicação, coordenação e cooperação do AulaNet...........36

Quadro 6: Requisitos e Características Comuns aos Grupos Focais.............................53

Quadro 7: Limitações de Grupos Focais e Medidas Mitigadoras .....................................53

Quadro 8: Resumo da Relação entre Arquitetura da Informação, a Multimodalidade, a Teoria da Relevância. 58

Quadro 9: Relação dos especialistas candidatos com os perfis definidos para participação no grupo focal.

Quadro 10: Formação Acadêmica dos membros dos especialistas do grupo focal...77

Quadro 11: Artefatos de entrada e saída das fases do DAIM:CSCL 91 


\section{LISTA DE SIGLAS}

Al - Arquitetura da Informação.

AlA - American Institute of Architects.

AVA - Ambiente Virtual de Aprendizagem.

ASSIT\&T - American Society for Information Science and Technology

CBIE - Congresso Brasileiro de Informática na Educação.

$\mathrm{Cl}$ - Ciência da Informação.

CSCL - Computer Supported Collaborative Learning.

CSCW - Computer Supported Collaborative Work.

DAIM:CSCL - Diagrama de fases para concepção de uma Arquitetura da Informação Multimodal para ambientes CSCL

EaD - Educação a Distância.

GF - Grupo Focal.

GD - Gêneros Discursivos.

Nied - Núcleo de Informática Aplicada à Educação.

PMBOK - Project Management Body of Knowledge

PMI - Project Management Institute

RBIE - Revista Brasileira de Informática na Educação.

SBC - Sociedade Brasileira da Computação.

SI - Sistemas de Informação.

SRI - Sistemas de Recuperação da Informação.

TGAI - Geral da Arquitetura de Informação.

TGS - Teoria Geral de Sistemas.

TIC - Tecnologia da Informação e Comunicação.

UNICAMP - Universidade Estadual de Campinas.

USP - Universidade de São Paulo.

WfMC - Workflow Management Coalition 


\section{SUMÁRIO}

1 INTRODUÇÃO

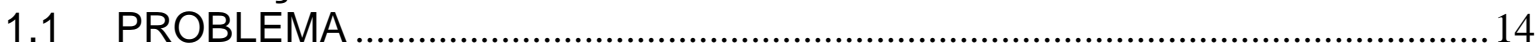

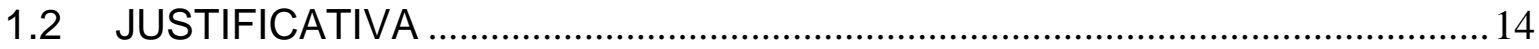

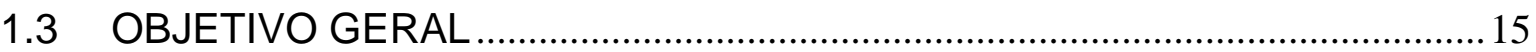

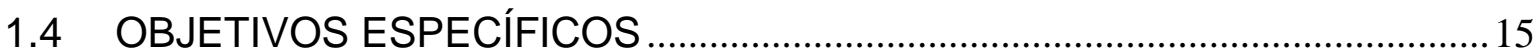

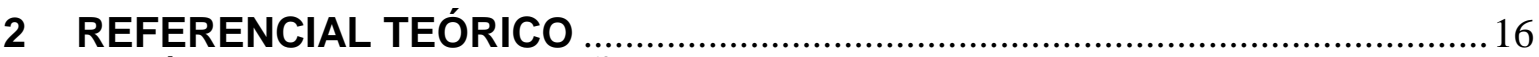

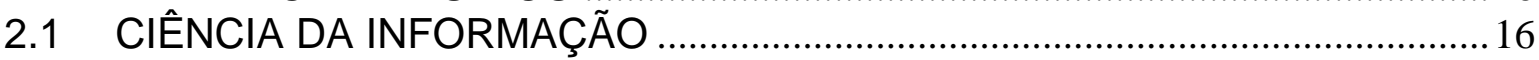

2.1.1 Usos e necessidades da Informação ……………………………………......19

2.1.2 Os Sistemas de Informação e a Teoria Geral de Sistemas - TGS ...............20

2.1.1 Dado, Informação e Conhecimento ................................................................2

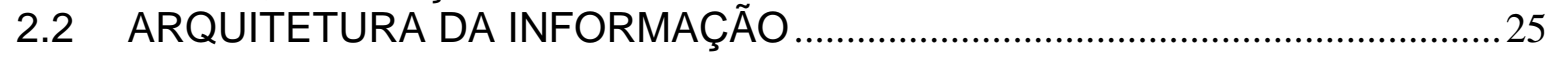

2.2.1 Proposta de Modelo de Arquitetura da Informação ………………………......28

2.3 AMBIENTES INFORMACIONAIS COLABORATIVOS DE

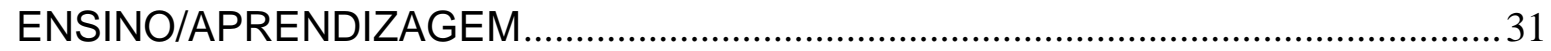

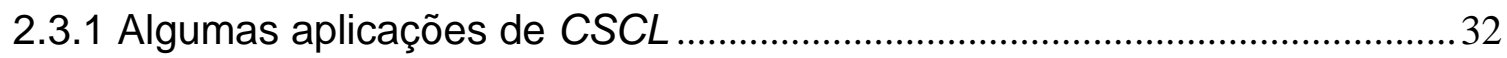

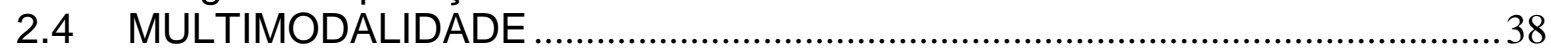

2.4.1 A Gramática Visual em Documentos Multimodais ............................................4 41

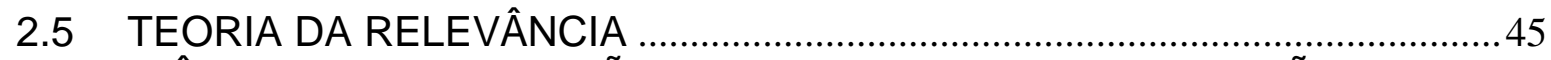

2.6 CIÊNCIA DA INFORMAÇÃO, ARQUITETURA DA INFORMAÇÃO E MULTIMODALIDADE NO PROCESSO DE ENSINO/APRENDIZAGEM...................46

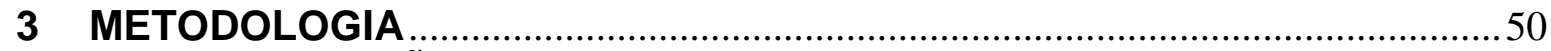

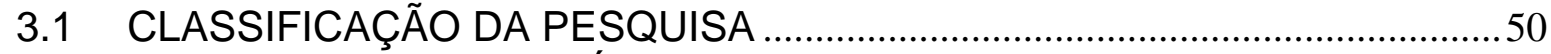

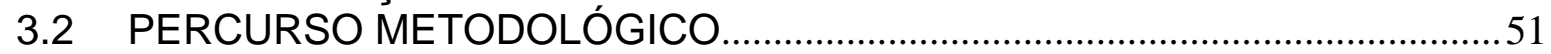

4 DESCRIÇÃO E ANÁLISE DO MODELO DE ARQUITETURA DA

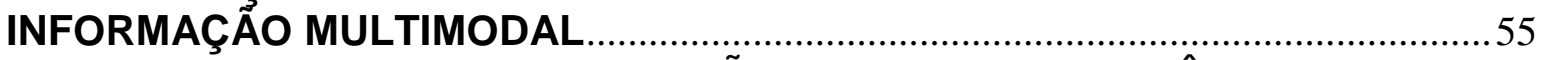

4.1 ARQUITETURA DA INFORMAÇÃO, TEORIA DA RELEVÂNCIA e MULTIMODALIDADE APLICADAS EM SITEMAS DE INFORMAÇÃO …….............55

4.2 A BASE EPISTEMIOLÓGICA DA PROPOSTA ………...................................62

4.3 PROPOSTA PRELIMINAR DO MODELO DE ARQUITETURA DA

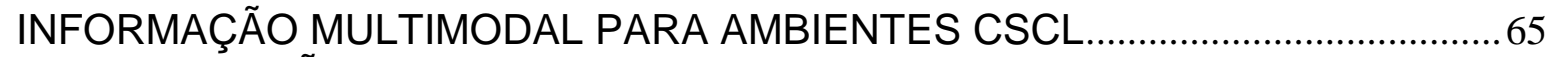

4.4 DEFINIÇÃO DO GRUPO FOCAL ………………….......................................... 71

4.4.1 Procedimentos metodológicos de aplicação do grupo focal............................78

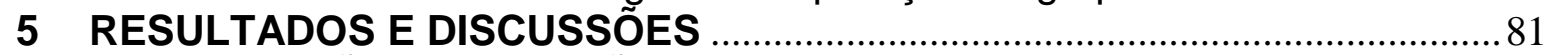

5.1 REALIZAÇÃO DA REUNIÃO DO GRUPO FOCAL...........................................81

5.2 NOVA PROPOSTA DE ARQUITETURA MULTIMODAL PARA AMBIENTES

CSCL, CONFORME RESULTADOS DO GRUPO FOCAL ……………......................... 89

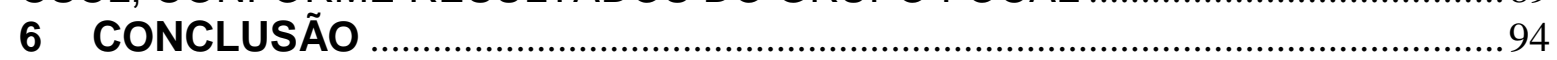

6.1 SUGESTÕES DE TRABALHOS FUTUROS ……..........................................95

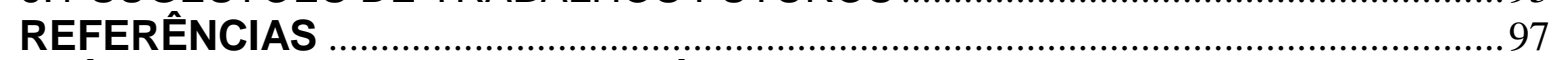

APÊNDICE A - CORREIO ELETRÔNICO ENVIADO AO GRUPO FOCAL .........104

APÊNDICE B - QUESTÕES PARA O GRUPO FOCAL ……………………............105

APÊNDICE C - O CONTEXTO DA PESQUISA …………………………………...... 106

APÊNDICE D - APRESENTAÇÃO DA PROPOSTA PARA O GRUPO FOCAL 121 


\section{INTRODUÇÃO}

O uso de ambientes de ensino e aprendizagem tem sido alvo de estudos principalmente no âmbito da Ciência da Computação, onde existem eventos científicos e acadêmicos destinados para este fim. Entre eles, podemos citar, como mais importante em nível nacional, o Congresso Brasileiro de Informática na Educação (CBIE), promovido pela Sociedade Brasileira da Computação (SBC). Bem como, periódicos especializados nesta área como a Revista Brasileira de Informática na Educação (RBIE).

Esses periódicos e eventos científicos/acadêmicos tratam de assuntos relacionados ao uso da Tecnologia da Informação aplicada à educação. Onde podemos destacar o estudo dos ambientes computacionais de apoio ao processo de ensino-aprendizagem, ou conforme nomeados no âmbito da Ciência da Computação, ambientes de Aprendizagem Colaborativa Apoiada por Computador (Computer Supported Collaborative Learning - CSCL).

Podemos entender que, do ponto de vista da Ciência da Informação e da Teoria Geral de Sistemas (TGS), estes ambientes desenvolvidos para uso de computadores são ambientes informacionais que utilizam Tecnologia da Informação e Comunicação (TIC). Assim, podemos derivar o termo "Ambientes Informacionais Colaborativos de Ensino-Aprendizagem apoiados em computador", ou ambientes que tratam a informação com o objetivo de auxiliar no processo de ensino/aprendizagem.

Hsu e Shiue (2005) observaram que a contribuição da Tecnologia da Informação ( $\mathrm{TI}$ ) como meio facilitador em ambientes de aprendizagem apresenta considerável importância, no sentido de auxiliar na comunicação apresencial e atemporal. Segundo os autores, no fim do Século XX uma expressiva quantidade de pessoas já haviam utilizado cursos de Educação à Distância, tornando esta prática bem aceita e indicando uma forte tendência de um aumento significativo desta quantidade com o decorrer dos anos seguintes.

Entretanto, atualmente tem-se a percepção de que somente o uso da TI não é suficiente para o sucesso das atividades desenvolvidas no processo de ensinoaprendizagem, sejam eles presenciais, mistos ou à distância. Steinmetz (2007) apresenta uma proposta de um ambiente de planejamento discente que permite o a 
acompanhamento destas atividades pelo docente. Esse ambiente é proposto utilizando-se conceitos de workflow e TI, para ser aplicado em atividades de ensino/aprendizagem presenciais, mistas ou à distância.

Ao olharmos para um contexto mais amplo, temos a pesquisa desenvolvida anteriormente por Neri (2009), que contou com o apoio do INEP e do MEC, onde o autor estuda os Motivos da Evasão Escolar. Ao apresentar os seus dados destacase, entre os principais motivos da evasão, a falta de interesse intrínseco dos pais e dos alunos sobre a educação ofertada, perfazendo um total de 40,3\% dos estudantes evadidos. O autor explica que, dentre vários motivos que levaram a estes números, o uso da TI e ambientes colaborativos de ensino/aprendizagem pode ser um fator relevante para diminuir esse percentual.

O estudo das contribuições da Ciência da Informação e da Arquitetura da Informação em ambientes colaborativos de ensino e aprendizagem ainda são incipientes. Sendo relevante o estudo da arquitetura de informação nestes ambientes informacionais, pois o aluno é um usuário da informação e para gerar seu conhecimento precisa recuperar informações por meio de ambientes informatizados.

Um dos trabalhos identificados sobre as contribuições da Ciência da Informação e da Arquitetura da Informação em ambientes de ensino-aprendizagem, Felipe (2011) explica que:

$\mathrm{Na}$ sociedade contemporânea, verifica-se que a informação e o conhecimento passam a ser exaltados como elementos-chave para o desenvolvimento social, visto que a humanidade está inserida num contexto em que a utilização das Tecnologias da Informação e da Comunicação (TIC) que estão desencadeando uma série de mudanças de ordem política, econômica, cultural e educacional, além de provocar impactos significativos nos modos de aprender e fazer do ser humano. Assim sendo, pode-se afirmar que o mundo será cada vez mais construído por aqueles que investem na educação, na ciência e no desenvolvimento tecnológico (FELIPE, 2011, p. 16)

Considerando que a informação é um elemento essencial no processo de ensino e aprendizagem e que Arquitetura da Informação trata da sua organização e recuperação, entende-se que ela deveria estar presente no processo de elaboração e utilização de Ambientes Informacionais Colaborativos de Apoio ao Processo de Ensino-Aprendizagem (CSCL). 


\subsection{PROBLEMA}

Podemos utilizar a Arquitetura da Informação no auxilio e entendimento dos problemas de reunião, armazenamento, organização e apresentação da informação, criando espaços informacionais que possam sanar às necessidades informacionais dos usuários. O questionamento que norteia esse trabalho é: Como melhor atender as necessidades informacionais dos usuários, criando espaços informacionais que estimulem ou limitem às interações nos Ambientes CSLC para tornar estes ambientes relevantes aos estudantes?

\subsection{JUSTIFICATIVA}

No âmbito da recuperação da informação, Bates (1999) explica a importância da estruturação das informações para a sua recuperação pelos usuários de forma eficiente e eficaz. Segundo a autora, há uma complexa relação entre a tecnologia e as questões cognitivas e sociais:

Devido à complexidade linguística, psicológica, cognitiva, social e técnica de recuperação da informação, cada aumento no tamanho da fonte de informações ou banco de dados exige soluções diferentes. A escalabilidade é um problema fundamental na ciência da informação. O desenvolvimento de cada novo meio de comunicação ou dispositivo tecnológico exige também uma mistura sofisticada de conhecimentos tecnológicos e psicossociais para produzir o melhor resultado no sistema de recuperação de informações. (BATES, 1999, p. 1044).

O uso de uma Arquitetura da Informação que atenda à necessidade do usuário dentro de um contexto específico é essencial, conforme podemos observar em Lima Marques e Macedo (2006):

A criação de uma Arquitetura da Informação bem definida, elaborada e gerenciada de forma coerente permite que todas as partes envolvidas numa organização falem a mesma língua e utilizem a informação para tomada de decisões significativas. Assim o modelo e as metodologias que a Arquitetura da Informação se baseia procuram sistematicamente documentar todas as fontes de dados importantes numa organização (por exemplo, clientes, produtos, funcionários...) e as relações entre os dados. (LIMA-MARQUES e MACEDO, 2006, p. 3). 
Para tanto, busca-se nesta tese identificar modelos existentes de Arquitetura da Informação que possam contribuir para a construção de Ambientes Informacionais Colaborativos de Apoio ao Processo de Ensino-Aprendizagem, aumentando a relevância desses ambientes para o estudante, a fim de promover a eficiência comunicativa e a participação nos referidos ambientes.

\subsection{OBJETIVO GERAL}

Esta tese tem como objetivo geral apresentar algumas contribuições da Arquitetura da Informação Multimodal para Ambientes Informacionais Colaborativos de Ensino-Aprendizagem apoiados em computador, utilizando os fundamentos teóricos da Arquitetura da Informação conjuntamente com as abordagens metodológicas desenvolvidas na Multimodalidade a partir da teoria da relevância.

\subsection{OBJETIVOS ESPECÍFICOS}

- Identificar os conceitos e fundamentos da Arquitetura da Informação, da multimodalidade e teoria da relevância, bem como, alguns ambientes colaborativos de ensino/aprendizagem, segundo critérios pré-estabelecidos.

- Estabelecer relações teóricas entre Arquitetura da Informação, Teoria da Relevância e Multimodalidade que fundamentam um modelo de Arquitetura da Informação multimodal.

- Propor e discutir um modelo preliminar de Arquitetura da Informação Multimodal para Ambientes Colaborativos de Ensino Aprendizagem. 


\section{REFERENCIAL TEÓRICO}

\subsection{CIÊNCIA DA INFORMAÇÃO}

Ao falarmos sobre a Ciência da Informação, é importante definirmos inicialmente o seu significado. Nesse sentido Borko (1968) afirma o seguinte:

Ciência da Informação é o estudo da coleta, organização, armazenamento, recuperação e disseminação da informação, a preocupação da $\mathrm{Cl}$ está voltada para o corpo de conhecimentos relacionados com a origem, a coleta, organização, armazenamento, recuperação, interpretação transmissão, transformação, utilização de informações (BORKO, 1968, p. 3).

O autor explica também que a Ciência da Informação é a disciplina que investiga as propriedades, comportamento da informação, forças que regem o fluxo de informação, meios de processamento de informação para a acessibilidade e usabilidade ideal.

Vickery e Vickery (1993) observam que o aumento da necessidade de informação na sociedade moderna leva ao surgimento do registro da informação e a evolução histórica da $\mathrm{Cl}$. Esse desenvolvimento histórico teve como reflexo a identificação de quatro áreas:

- O problema específico de comunicação da informação em ciência e tecnologia, melhor chamada de "ciência da informação";

- O usuário de tecnologia, computadores e telecomunicações, particularmente, no tratamento da informação - tecnologia da informação;

- A aplicação do método científico aos problemas de informação prática -

Estudo de sistemas de informação;

- O estudo científico da comunicação da informação na sociedade - a ciência da informação no sentido de uma disciplina acadêmica.

Vickery e Vickery (1993) remetem para a importância da interdisciplinaridade entre a $\mathrm{Cl}$ e outras áreas considerando que o uso adequado da informação é essencial em qualquer lugar, em qualquer área e em qualquer momento. 
Para Saracevic (1995) a ciência da informação tem duas orientações: a primeira trata da necessidade de informação, enquanto a segunda trata das técnicas de recuperação da informação. $O$ autor explica ainda que o seu surgimento segue a Segunda Guerra Mundial, porém seus termos entraram em uso somente nos anos 1960.

Capurro (2003, p. 04) entende que a Ciência da Informação busca estudar "a produção, seleção, organização, interpretação, armazenamento, recuperação, disseminação, transformação e uso da informação". Essa visão abrangente da ciência da informação também é defendida por Robredo (2003) quando afirma que "a ciência da informação é o estudo, com critérios, princípios e métodos da informação" e tem como objeto "a informação em todos os seus aspectos e de todos os pontos de vista" (ROBREDO, 2003. p. 23).

Robredo (2005) acrescenta ainda que:

As mais recentes abordagens epistemológicas da ciência da informação conduzem a visualizar esta não mais como uma evolução ou uma extensão das ciências e técnicas da documentação no seu sentido mais amplo, mas, pelo contrário, como sendo ela o marco geral em que se enquadram, não somente as ciências e técnicas derivadas do estudo de todo tipo de documento e de seus desdobramentos práticos e aplicados, mas também todas aquelas outras ciências que possuem como foco ou objeto de estudo, de uma ou de outra forma, a informação. (ROBREDO, 2005. p. 1).

Existem outros autores que tratam o termo Ciência da Informação, entre os quais situa-se Le Coadic (2004), que define a Ciência da Informação como uma ciência social que se apóia em uma tecnologia rigorosa, com a prática na organização e estudo das propriedades gerais da informação como natureza, gênese e efeitos. Ainda, para Le Coadic (2004, p. 27), "a informação é o sangue da ciência... sem informação, a ciência não pode se desenvolver e viver".

Duque (2005) apresenta uma revisão de literatura em que sintetiza a visão do Institute of Information Science, dividindo a Ciência da Informação em três grandes seções: a própria ciência da informação, o gerenciamento da informação e a tecnologia da informação, conforme Quadro 1. 
Quadro 1: Critérios para a Ciência da Informação de acordo com o Institute of Information Science

\begin{tabular}{|l|}
\hline \multicolumn{1}{|c|}{ Critérios para a Ciência da Informação } \\
\hline Seção 1 (Área Núcleo): ciência da informação: \\
\hline A teoria e prática de criar, aferir, acessar e validar, organizar, armazenar, transmitir, \\
recuperar e disseminar informação. \\
Informação: suas características, provedores e usuários \\
Fontes de informação \\
Armazenamento e recuperação de informação \\
Análise da informação \\
Teoria da Ciência da Informação \\
\hline Seção 2: gerenciamento da informação \\
\hline \hline O gerenciamento do total dos recursos de informação das organizações. \\
Planejamento Comunicações \\
Gerenciamento das Informações e \\
Sistemas de Controle Gerenciamento de recursos humanos \\
Gerenciamento financeiro Promoção, economia e marketing \\
Fatores políticos, éticos, sociais e legais \\
\hline Seção 3: tecnologia da informação \\
\hline \hline Tecnologia que pode ser usada na Ciência da Informação ou Gerenciamento da \\
Informação. \\
Sistemas de Computadores: hardware, software \\
Telecomunicações \\
Aplicações de tecnologia da informação \\
Ambiente
\end{tabular}

Fonte: Adaptado de Duque (2005).

Lyra (2012) apresenta o Quadro 2, comparando algumas abordagens que fundamentam os conceitos apresentados pelos autores para a definição do termo Ciência da Informação:

Os principais estudiosos da ciência da informação identificam algumas abordagens para o tratamento da informação. Essas abordagens são complementares, pois propõem diferentes perspectivas em relação ao universo de que trata a ciência da informação (LYRA, 2012. p. 26). 
Quadro 2: Abordagens para a Ciência da Informação

\begin{tabular}{|c|l|}
\hline \multicolumn{2}{|c|}{ Abordagens para a Ciência da Informação } \\
\hline Autor & Abordagem \\
\hline Saracevic (1995) & $\begin{array}{l}\text { (a) físico: trata dos sinais e sua representação; } \\
\text { (b) cognitivo: trata dos processos cognitivos, ou seja, a } \\
\text { informação é uma mudança de estado mental, provocado } \\
\text { pela interação da mente com um texto; } \\
\text { (c) contexto: a informação está relacionada à situação, } \\
\text { envolvendo motivação e intenção }\end{array}$ \\
\hline (2007) & $\begin{array}{l}\text { (a) físico: trata dos sinais e sua representação; } \\
\text { (b) cognitivo: trata dos processos cognitivos, ou seja, a } \\
\text { informação é uma mudança de estado mental, provocado } \\
\text { pela interação da mente com um texto; } \\
\text { (c) social: a informação está relacionada aos usuários e } \\
\text { seus contextos sociais. }\end{array}$ \\
\hline Bates (1999) & $\begin{array}{l}\text { (a) físico: "Quais são as características e as leis do } \\
\text { universo para informação gravada?" } \\
\text { (b) social: "Como as pessoas se relacionam, buscam e } \\
\text { usam informações?" } \\
\text { (c) desenho: "Como é possível o acesso às informações } \\
\text { gravadas ser mais rápido e eficaz?". }\end{array}$ \\
\hline
\end{tabular}

Fonte: Adaptado de Lyra (2012)

\subsubsection{Usos e necessidades da Informação}

Le Coadic (2004), afirma que um dos papéis da Ciência da Informação é a análise dos processos que se alimentam reciprocamente para conceber os sistemas, pela comunicação, uso e armazenamento da informação. Considera-se que a necessidade de informação surge como um problema a ser resolvido, um objetivo a ser atingido e percebe-se então, que ela pertence à categoria das necessidades humanas básicas, conforme a Figura 1.

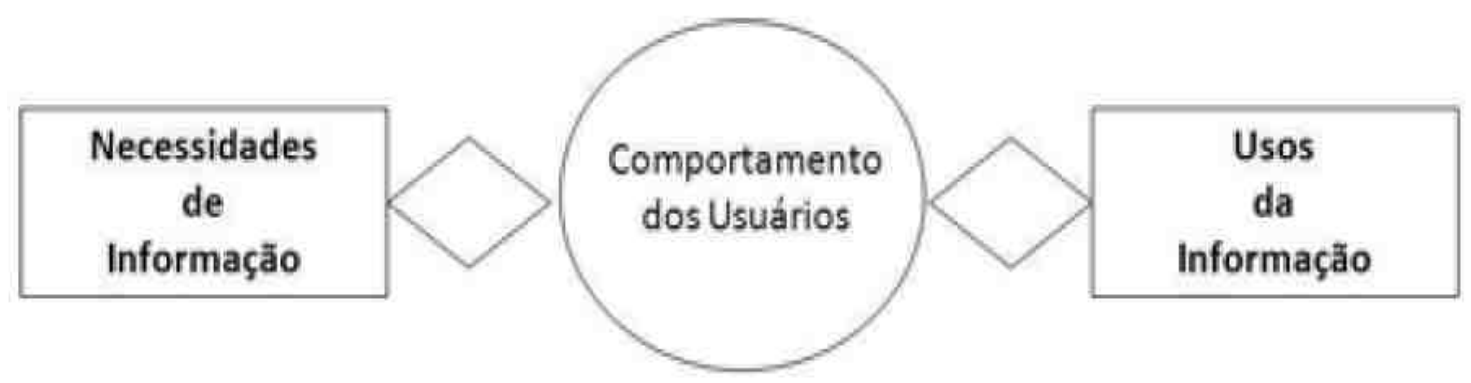

Figura 1: Usos e Necessidades da Informação (LE COADIC, 2004, p. 40). 
A informação, por ser objeto de estudo da Ciência da Informação, permeia os conceitos e definições da área. Porém, a informação não pode ser unicamente definida nem medida. O fenômeno mais amplo que esse campo do conhecimento pode tratar é a geração, transferência ou comunicação e uso da informação, aspectos contidos na definição de Ciência da Informação.

Segundo Lyra (2012) a Ciência da Informação trata de informação e, entre outros tópicos, como das questões relativas à sua estruturação. Nela encontram-se ferramentas necessárias ao estabelecimento de espaços informacionais compostos por grandes quantidades de informação, com elevado grau de descentralização e fragmentação.

\subsubsection{Os Sistemas de Informação e a Teoria Geral de Sistemas - TGS}

A sigla TGS é amplamente conhecida como a abreviatura para a Teoria Geral de Sistemas que surgiu com os trabalhos do biólogo Ludwig von Bertalanffy, publicados entre 1950 e 1968.

Segundo Bertalanffy (1973), ao propor a TGS ele buscou produzir teorias e formulações conceituais que pudessem criar condições de aplicação na realidade empírica, não buscando solucionar problemas ou tentar soluções práticas. Buscando atingir este objetivo, o autor sugere as seguintes premissas básicas:

- Existe uma nítida tendência para a integração nas várias ciências naturais e sociais;

- Essa integração parece orientar-se rumo a uma teoria dos sistemas;

- Essa teoria de sistemas pode ser uma maneira mais abrangente de estudar os campos não físicos do conhecimento científico, especialmente as ciências sociais;

- Essa teoria de sistemas, ao desenvolver princípios unificadores que atravessam verticalmente os universos particulares das diversas ciências envolvidas, aproxima-nos do objetivo da unidade da ciência;

- Isso pode levar a uma integração muito necessária da educação científica. 
Audy, Abreu e Cidral (2007) explicam que a TGS teve suas bases teóricas iniciais voltadas para a biologia, onde podemos perceber o estudo dos seres vivos classificados como sistemas abertos, ou seja, sistemas que interagem com 0 ambiente. Essa teoria de sistemas criada por Ludwig von Bertalanffy pode ser ainda considerada uma extensão da física, da química, da ciências naturais e da termodinâmica.

A TGS passou a ser aplicada em outras áreas do saber, como na administração em função da necessidade de uma síntese e uma maior integração das teorias anteriores (Científicas e Relações Humanas, Estruturalista e Comportamental oriundas das Ciências Sociais) e da intensificação do uso da cibernética e da tecnologia da informação nas empresas.

Bertalanffy (1973) explica que os sistemas passaram a ser identificados desde sistemas da química, das moléculas, dos seres vivos, ou da sociedade, entrando em áreas bem abrangentes como a administração e a tecnologia da Informação, provendo com isso uma visão mais geral dos sistemas e descobrir suas bases e núcleos. Atualmente, há uma grande variedade de sistemas e uma ampla gama de tipologias para classificá-los, de acordo com certas características básicas. Entre as mais utilizadas temos (Quadro 3):

Quadro 3: Tipologia dos Sistemas

\begin{tabular}{|c|l|}
\hline \multicolumn{2}{|c|}{ Tipologia dos sistemas } \\
\hline \multirow{2}{*}{$\begin{array}{c}\text { Quanto a sua } \\
\text { constituição: }\end{array}$} & $\begin{array}{l}\text { Físicos ou concretos: quando compostos de } \\
\text { equipamento, de maquinaria e de objetos e coisas reais } \\
\text { (equipamento, objetos, hardware); }\end{array}$ \\
\cline { 2 - 3 } & $\begin{array}{l}\text { Abstratos ou conceituais: quando compostos por } \\
\text { conceitos, planos, hipóteses e idéias que muitas vezes } \\
\text { só existem no pensamento das pessoas (conceitos, } \\
\text { planos, idéias, software). }\end{array}$ \\
\hline \multirow{5}{*}{ Quanto a sua natureza: } & $\begin{array}{l}\text { Fechados: não apresentam intercâmbio com o meio } \\
\text { ambiente que os circunda, sendo assim não recebem } \\
\text { nenhuma influencia do ambiente e por outro lado não } \\
\text { influenciam. Não recebem nenhum recurso externo e } \\
\text { nada produzem que seja enviado para fora. }\end{array}$ \\
\cline { 2 - 3 } & $\begin{array}{l}\text { Abertos: são os sistemas que apresentam relações de } \\
\text { intercâmbio com o ambiente, por meio de entradas e } \\
\text { saídas. }\end{array}$ \\
\hline
\end{tabular}




\begin{tabular}{|l|l|} 
Quanto a sua origem: & $\begin{array}{l}\text { Naturais: sistemas naturais são os sistemas que existem } \\
\text { na natureza. }\end{array}$ \\
\cline { 2 - 2 } & $\begin{array}{l}\text { Artificiais: sistemas artificiais são sistemas criados ou } \\
\text { inventados pelo Homem. }\end{array}$ \\
\hline
\end{tabular}

Fonte: Adaptado de Bertalanffy (1973).

Em relação ao quadro 3, Bertalanffy (1973) explica que há uma complementaridade entre sistemas físicos e abstratos, onde os sistemas físicos precisam de um sistema abstrato para funcionar, enquanto os sistemas abstratos só podem ser efetivados com a concepção de um sistema físico que o represente. Ainda, os sistemas abertos trocam matéria, energia e informação regularmente com o meio ambiente. São eminentemente adaptativos, que para sobreviver devem reajustar-se constantemente as condições do meio.

Audy, Abreu e Cidral (2007) e Rezende e Abreu (2013) explicam que a TGS auxiliou na criação de um pensamento sistêmico, que teve sua aplicação em diversas áreas do conhecimento humano, gerando crescentes avanços em várias áreas aplicadas. Entre elas, podemos citar os sistemas de informação que passaram a ter uma ordenação dos dados para se obter um objetivo. Com definição dessa teoria, hoje podemos fazer o uso em análises de sistemas onde sua base consiste em verificar os dados de entrada e transformá-los em informações úteis para a sociedade.

Audy, Abreu e Cidral (2007), em uma revisão conceitual de outros autores, apresentam uma definição para sistemas de informação (SI), como sistemas abertos composto por entradas, mecanismos de processamento, saídas, armazenamento de dados e realimentação (feedback), que interagem com um ambiente/contexto, conforme Figura 2. 


\section{AMBIENTE / CONTEXTO}

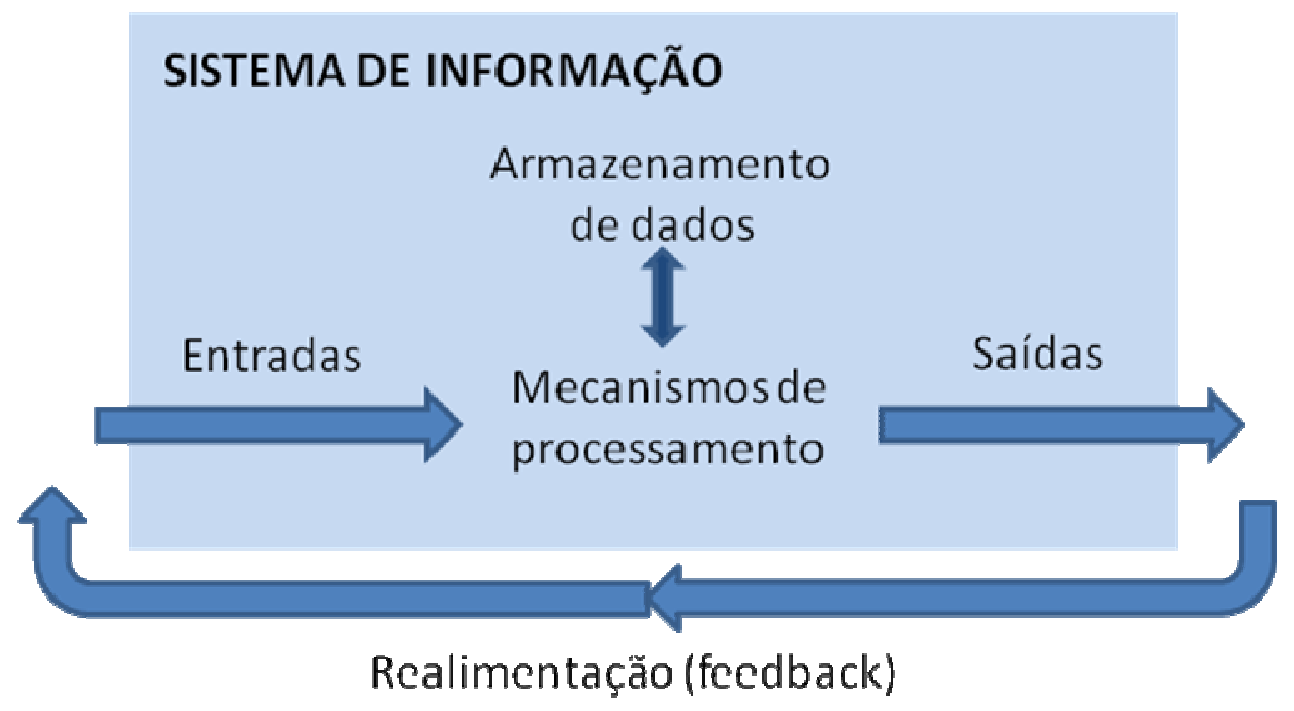

Figura 2: Sistema de Informação Aberto (AUDY, ABREU e CIDRAL, 2007).

Conforme a Figura 2, Audy, Abreu e Cidral (2007) explicam que um sistema de informação recebe dados (entradas) do ambiente, estes dados passam pelos mecanismos de processamento que os organizam de forma que se torne algo representativo, podendo neste processo armazenar e/ou recuperar dados previamente armazenados no sistema, gerando como resultado informações. As informações são disponibilizadas ao ambiente pela saída do sistema de informação, podendo estas saídas resultantes de um ciclo de processamento, serem insumos para novos ciclos de processamento, quando temos a realimentação (feedback).

\subsubsection{Dado, Informação e Conhecimento}

Um dos grandes desafios dos estudos sobre Ciência da Informação aborda a questão do real significado das palavras "dado", "informação" e "conhecimento", ou o que determinada comunidade científica entende como o conceito destes termos.

Lima-Marques (2011) apresenta uma pesquisa epistemológica acerca desses conceitos, estabelecendo uma revisão de literatura dos conceitos de dado, informação e conhecimento: 
- Dado - "dado é o estado das propriedades do objeto no instante imediatamente antes da sua apreensão pelo sujeito" (LIMA-MARQUES, 2011).

- Informação - "informação seria os dados persistentes no exato momento de sua apreensão pelo sujeito que reduzem a incerteza quando o sujeito recebe uma resposta a uma pergunta" (LIMA-MARQUES, 2011).

- Conhecimento - "o conhecimento é uma imagem, um conjunto de propriedades do objeto apreendido pelo sujeito. Conhecimento é diferente de sujeito e de objeto. Conhecimento aparece como um terceiro elemento que, por meio da correlação se conecta com estes dois elementos, formando uma trindade" (LIMA-MARQUES, 2011).

A T.G.S, no que se refere aos sistemas de informação, também apresenta definições para: dado, informação e conhecimento, agregando um novo conceito, a competência. Os autores Audy, Abreu e Cidral (2007) apresentam estas definições derivadas dos fundamentos da TGS Assim, temos:

Dado:

O dado consiste em um fato bruto (nome de um funcionário, número de matricula de um aluno, código de um produto, etc.) ou suas representações (imagens, sons, números, etc.) que podem ou não ser úteis ou pertinentes para um processo em particular. Diversos tipos de dados podem ser utilizados para representar esses fatos (AUDY, ABREU e CIDRAL, 2007, p. 94).

Informação:

A informação é uma coleção de fatos organizados de forma a possuir um valor adicional aos fatos em si. Em outras palavras, são dados concatenados, que passaram por um processo de transformação, cuja forma e conteúdo são apropriados para um uso específico (AUDY, ABREU e CIDRAL, 2007, p. 95).

Conhecimento:

O conhecimento implica estar ciente e ter entendimento de um conjunto de informações e como essas informações podem ser úteis para suportar determinado processo ou tarefa, envolvendo uma combinação de instintos, idéias, informações, regras e procedimentos que guiam ações e decisões. O Conhecimento é uma informação 
valiosa na mente humana, que inclui reflexão, síntese e contexto. É difícil de estruturar, difícil de capturar em computadores, normalmente é tácito (não explícito) e sua transferência é complexa (AUDY, ABREU e CIDRAL, 2007, p. 96).

Competência:

A competência é o processo contínuo e articulado de formação e desenvolvimento de conhecimentos, habilidades e atitudes de gestores a partir da interação com outras pessoas no ambiente de trabalho, tendo em vista o aprimoramento de sua capacidade. Assim, pode adicionar valor às atividades da organização (AUDY, ABREU e CIDRAL, 2007, p. 96).

\subsection{ARQUITETURA DA INFORMAÇÃO}

Wurman (1997) inicia a discussão propondo que a Arquitetura da Informação preocupa-se com o levantamento das necessidades de informação, a compreensão dos conteúdos e dos desafios de organizar informações. Seus conceitos foram inicialmente aplicados para auxiliar a busca de informações em publicações gráficas como mapas e guias e, com o passar do tempo, esses conceitos foram aproveitados em outras áreas.

Wurman (1997) apresentou uma definição para Arquitetura da Informação como a ciência e a arte de criar instruções para espaços organizados. Ele estabeleceu uma analogia entre a arquitetura de edifícios com a Arquitetura da Informação, onde um arquiteto predial desenvolve o projeto de um edifício para atender as necessidades dos seus futuros ocupantes. Neste sentido o autor explica que a Arquitetura da Informação busca entender os problemas de reunião, organização e apresentação da informação para sanar as necessidades informacionais dos usuários. Assim, as estruturas de informação influenciam interações no mundo da mesma forma que as estruturas dos edifícios estimulam ou limitam as interações sociais.

Peon Espantoso (2001) explica que a partir de 1990 os estudos acerca da Arquitetura da Informação são intensificados. Isso se dá devido à quantidade fenomenal de informação disponível gerada a todo instante. Assim, a Arquitetura da Informação possui a preocupação de desenvolver técnicas e estruturas que permitam com que a informação seja utilizada sob formas compreensíveis. 
No contexto histórico da Arquitetura da Informação descrito por Lima-Marques e Macedo (2006), o primeiro momento da preocupação com a sistematização e acesso ao conhecimento foi na explosão bibliográfica, em conseqüência da industrialização da imprensa comercial. Depois, o conceito se aperfeiçoou com a primeira obra sistemática da Ciência da Informação que apresentou um conceito de representação bibliográfica de documento em fichas padronizadas e a elaboração de repositórios cooperativos de dados.

Lima-Marques e Macedo (2006) explicam ainda que outra grande revolução foi a possibilidade de acesso às bases de dados a grandes distâncias por meio de uma linha telefônica para projetar remotamente em uma tela imagem em "fac-símile" como uma estação de trabalho ligada a centros de informações, representando um grande repositório de conhecimento humano. Desde o final do Século $X X$, as organizações do conhecimento publicam sobre o conhecimento, conectando os homens através do tempo e espaço, permitindo o aprendizado mais rápido e que atualmente se trata da Rede Mundial de Informações, a internet.

Lima-Marques e Macedo (2006), ao tratarem da definição de Arquitetura da Informação, afirmam o seguinte:

Sugere-se que a expressão Arquitetura da Informação, um pouco além dos objetivos propostos inicialmente por Saul Wurman (1997) e muito mais do que o seu uso corrente, sintetiza e expressa em uma fórmula (expressão) linguística simples, uma coleção de conceitos que dizem respeito e influenciam a própria percepção da realidade pelo ser. (Lima-Marques e Macedo, 2006)

Lyra (2012) estabelece uma revisão de literatura sobre Arquitetura da Informação. O autor explica que, em 1975, Richard Saul Wurman cunhou os termos Arquitetura da Informação e Arquiteto da Informação. Após isso, vários outros autores escreveram sobre estes termos.

Lyra (2012) explica com ainda que um dos objetivos da Arquitetura da Informação é organizar os espaços informacionais, que podem se definidos como:

Entende-se como espaço informacional um recorte de uma teia de informações organizacionais. Esse espaço precisa ter a capacidade de suprir as necessidades especificas de informações dos indivíduos, assim como de suas organizações. Ele deve gerar relações eficientes e eficazes entre os indivíduos e as informações, de maneira a 
proporcionar ao indivíduo o aprendizado necessário para que seja possível atingir as metas e os objetivos empresariais (LYRA, 2012, p. 26).

Ainda segundo os mesmos autores, “...em síntese, pelo exposto verifica-se que as correntes e as definições do conceito agrupam-se em torno de três tipos ou categorias principais." que segundo os autores são elas (Quadro 4):

Quadro 4: Classificação dos Conceitos de Arquitetura da Informação

\begin{tabular}{|l|l|}
\hline \multicolumn{2}{|c|}{ Classificação dos Conceitos de Arquitetura da Informação } \\
\hline \hline \multicolumn{1}{|l}{$\begin{array}{l}\text { Arquitetura da } \\
\text { Informação como } \\
\text { design }\end{array}$} & $\begin{array}{l}\text { Busca atender um ambiente específico. Como } \\
\text { representantes desta categoria pode-se citar a Arquitetura } \\
\text { da Informação voltada para a Web de Rosenfeld e Morville } \\
(2006), \text { no sentido que é usualmente aplicada na prática. - } \\
\text { Arquitetura da Informação voltada para organizações, de } \\
\text { Davenport (2001) ou de Mcgee e Prusak (1998); ou voltada } \\
\text { para sistemas de informação, nos termos de Bailey (2003) }\end{array}$ \\
\hline $\begin{array}{l}\text { Arquitetura da } \\
\text { Informação como } \\
\text { organização de } \\
\text { espaços de informação } \\
\text { de qualquer tipo }\end{array}$ & $\begin{array}{l}\text { Aqui, pode-se citar Rosenfeld e Morville (2006) adaptados } \\
\text { por Wyllys (2000) e a proposta original de Wurman (1997). } \\
\text { As propostas de Lima-Marques e Macedo (2006) e de } \\
\text { Macedo (2005) também poderiam ser enquadradas nesta } \\
\text { categoria. Não obstante, a preocupação desses autores } \\
\text { com aspectos filosóficos e epistemológicos sugere que eles } \\
\text { estejam em uma categoria intermediária para a seguinte. }\end{array}$ \\
\hline \hline $\begin{array}{l}\text { Arquitetura da } \\
\text { Informação como } \\
\text { percepção da realidade. }\end{array}$ & $\begin{array}{l}\text { Esta é a agenda da Grande Arquitetura da Informação } \\
\text { identificada por Dillon (2002). }\end{array}$ \\
\hline
\end{tabular}

Fonte: Adaptado de Lima-Marques e Macedo (2006)

Observando o Quadro 4, podemos perceber que a Arquitetura da Informação poderá influenciar e seqüenciar rotinas dos discentes em Instituições de Ensino, auxiliando os alunos para que não se sintam perdidos diante do volume e acúmulo de informações disponíveis, que se tem atualmente, em diversas fontes de informações.

Anteriormente a esses autores, Mooers (1951 apud Saracevic, 1995), afirma que um dos objetivos da $\mathrm{Cl}$ é facilitar o acesso rápido e eficaz para os usuários de Sistemas de Recuperação da Informação (SRI), às informações que tais sujeitos julguem ser relevantes. 
Segundo Le Coadic (2004), cabe à Arquitetura da Informação (Al) organizar e estruturar os processos de produção, comunicação e uso da informação, por meio do entendimento das necessidades de informação e do comportamento dos usuários. Assim, podemos perceber que é pertinente inferir que a Al busca prever todas as possíveis interpretações para um mesmo dado, provendo acesso a este dado por caminhos distintos, em diversas abordagens, para usuários imprevisíveis.

Lyra (2012) apresenta uma revisão de literatura sobre as várias definições acerca da Arquitetura da Informação. Com base nisso, entende que o objeto de estudo da Arquitetura da Informação é prover maneiras de projetar espaços informacionais, sendo também esta uma das linhas de pesquisa da ciência da informação. $O$ autor explica ainda que o estudo da Arquitetura da Informação vem ganhando importância e espaço nas últimas décadas dentro da Sociedade da Informação, bem como seus conceitos e definições têm evoluído de maneira significativa.

Lyra (2012) entende o espaço informacional como:

Um recorte de uma teia de informações organizacionais. Esse espaço precisa ter a capacidade de suprir as necessidades especificas de informações dos indivíduos, assim como de suas organizações. Ele deve gerar relações eficientes e eficazes entre os indivíduos e as informações, de maneira a proporcionar ao indivíduo o aprendizado necessário para que seja possível atingir as metas e os objetivos empresariais. Dito de outra forma, o desafio para os profissionais que lidam com espaços informacionais é projetá-los de forma estruturada, visando atender um objetivo específico: fazer um recorte adequado às necessidades do usuário, a partir de uma grande quantidade de informações, delimitando aquelas que são indispensáveis (LYRA, 2012, p. 26).

\subsubsection{Proposta de Modelo de Arquitetura da Informação}

Segundo Lima-Marques e Macedo (2006) a informação depende do comportamento dos usuários que farão uso dela e determinarão as suas necessidades. O uso da informação está no nível de aplicação que segundo o modelo de Arquitetura da Informação proposto por estes autores representa os processos básicos do ciclo da informação em três níveis, conforme podemos observar na Figura 3. 
- Nível de meta-modelagem - análise do contexto ou do ambiente informacional para realização do planejamento estratégico do sistema de informação;

- Nível de modelagem - definição do conteúdo que irá ser armazenado, organizado e representado, por meio da captura, armazenamento, organização, representação e comunicação;

- Nível de aplicação - aplicação das teorias e modelos construídos a partir dos níveis anteriores na implementação de sistemas de informação.

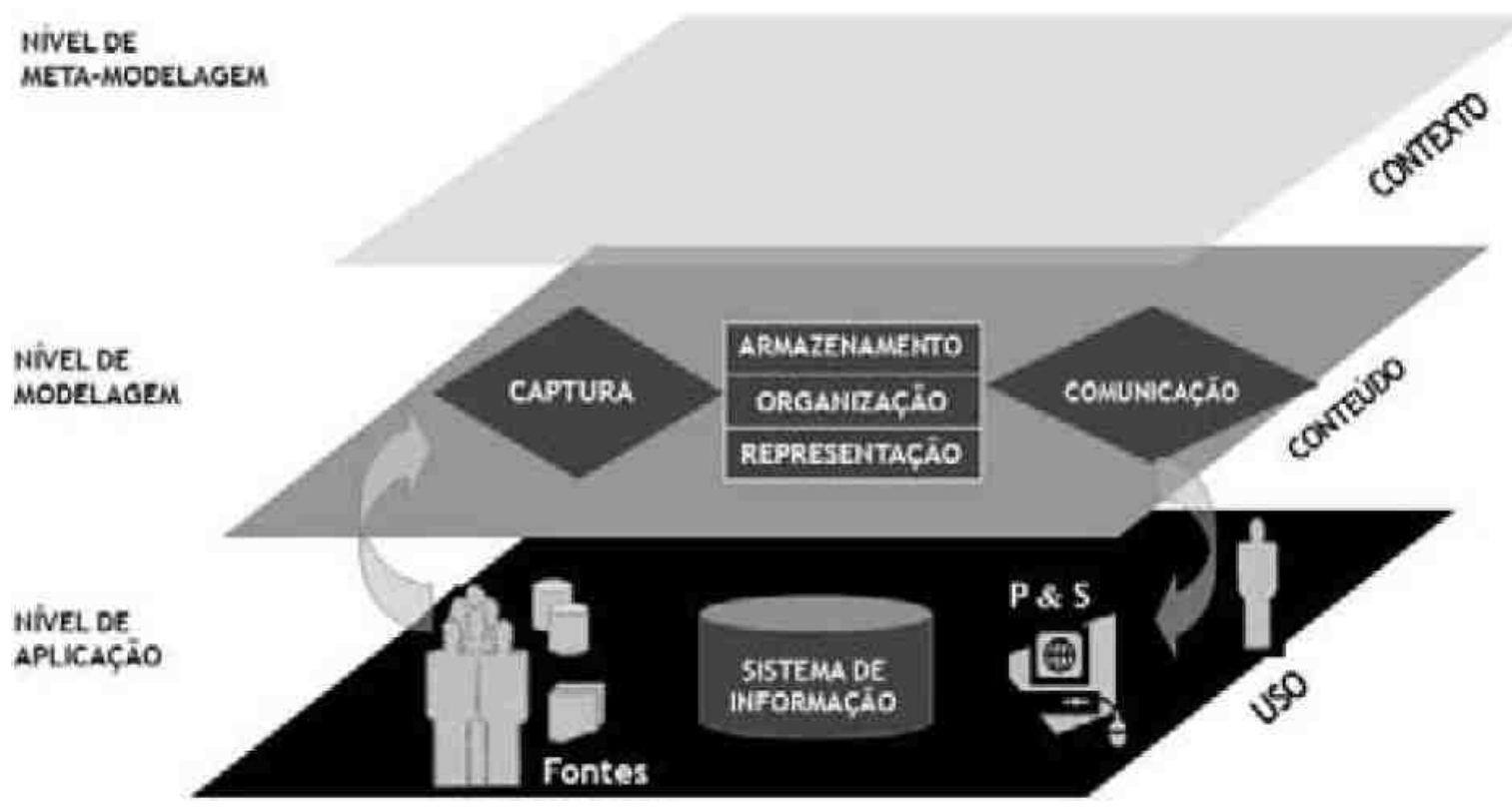

Figura 3: Proposta de Modelo de Arquitetura da Informação (LIMA-MARQUES; MACEDO, 2006, p. 253).

No âmbito da Arquitetura da Informação, desenhos de espaços de comunicação integrados a espaços de tecnologia da informação representam novas relações sociais que, por meio de processos centrados no usuário, são capazes de criar soluções adequadas ao ambiente humano. A Arquitetura da Informação deve reconhecer usuários como agentes do desenvolvimento tecnológico e garantir oportunidades de participação ativa no planejamento dos sistemas de informação, contrariando o determinismo tecnológico. (LIMAMARQUES; MACEDO, 2006, p. 253).

$\mathrm{Na}$ Arquitetura da Informação, para Wurman (1997), devem ser criadas estruturas ou realizado planejamento de informação que permitam o encontro de caminhos pessoais para o conhecimento. A tecnologia é somente um aspecto a ser 
considerado pela Arquitetura da Informação para permitir a agregação e disponibilização das informações necessárias em uma organização.

Lima-Marques (2011) apresenta e sugere uma proposta de explicação científica para um arcabouço geral da Arquitetura da Informação. O autor busca identificar os fundamentos teóricos para a Arquitetura de Informação com o desafio de propor uma Teoria Geral da Arquitetura de Informação (TGAI).

Nesse sentido é estabelecida uma revisão de literatura sobre os conceitos de dado, informação e conhecimento. Estas definições são influenciadas pela fenomenologia e pelos conceitos da física quântica, neste contexto o simples fenômeno da presença do observador (sujeito), implica na mudança do comportamento do objeto observado. Explica-se, assim, a diferença entre dado e informação, sendo o conceito de conhecimento resultado da abstração que deriva da experiência entre o observador e o objeto observado.

Após apresentar as definições básicas que fundamentam a TGAI, LimaMarques (2011) sugere os elementos da Arquitetura da Informação, espaço e estado. Onde o espaço é a definição dos limites entre os dados de forma que um ponto de um lado não pode alcançar o outro lado sem cruzar a fronteira que os separa. E o estado que consiste nas características dos dados em um intervalo de tempo, sendo que o decorrer do tempo pode implicar em mudanças no estado. Assim, segundo Lima-Marques (2011), o "espaço de informação" compreende um conjunto de informações, em um espaço distinto, num estado específico, compreendido num intervalo de tempo.

Sobre a Arquitetura da Informação, o autor explica que o conceito de Al pode ser aplicado em qualquer informação do espaço e que exemplos de espaços de informação podem ser genericamente caracterizados em qualquer conjunto de coisas. Lima-Marques (2011) cita Wurman (1997) para embasar o conceito de Al e explica que, atualmente, este autor trabalha com uma idéia de Arquitetura de Informação muito mais ampla, particularmente próxima a proposta de Lima-Marques (2011).

A definição primária de Al, proposta por Lima-Marques (2011) é: "Arquitetura de Informação é a configuração de estados dos elementos constitutivos da própria coisa e suas propriedades, caracterizadas pelo espaço-tempo da informação 
distinta". Com isso o autor explica que este conceito da Arquitetura de informação pode ser aplicado em qualquer espaço de informação. O termo Arquitetura de Informação é inerente a qualquer espaço de informação, em qualquer domínio. Como consequência das definições, pode-se dizer que não há espaço de informação sem Arquitetura de Informação.

Observa-se ainda que neste conceito o fator tempo implica na mudança de uma configuração de propriedades de seus elementos constitutivos, assim LimaMarques (2011) sugere uma definição completar: "Uma transformação é um conjunto de eventos, aplicados a um estado em particular, de modo a provocar alterações em estados futuros".

\subsection{AMBIENTES INFORMACIONAIS COLABORATIVOS DE ENSINO/APRENDIZAGEM}

Ambientes Informacionais colaborativos de ensino-aprendizagem têm sido estudados no âmbito da informática na educação. A proposta de trabalho em grupo tem sido estudada com o objetivo de prover suporte à aprendizagem colaborativa. Entre as formas de viabilizar o trabalho colaborativo, o groupware pode ser visto como uma tecnologia de apoio, definido pela WfMC (2004) como um exemplo de workflow com alto grau de colaboração e pouco estruturado.

Conforme podemos observar em Fuks et al. (2004a), Fuks et al. (2004b) e Raposo et al. (2004), o conceito de workflow, sob a forma de groupware tem sido explorado no sentido de modelagem da coordenação de grupos de trabalho em aprendizagem colaborativa, de forma transparente ao usuário. O conceito de groupware nos remete ainda a outros dois conceitos estudados por esses autores. São eles: o Trabalho Colaborativo Apoiado por Computador (Computer Supported Collaborative Work - CSCW) e por conseqüência, Aprendizagem Colaborativa Apoiada por Computador (Computer Supported Collaborative Learning - CSCL).

Steinmetz (2007) apresenta uma revisão de ambientes colaborativos de ensino/aprendizagem, destacando a utilização destes ambientes para o planejamento das atividades docentes e discentes. Neste contexto o autor apresenta e comenta diversas funcionalidades de vários ambientes colaborativos de ensino/aprendizagem informatizados, destacando pontos positivos e pontos 
negativos quanto à capacidade de prover o ensino/aprendizado colaborativo nos ambientes estudados.

Steinmetz (2007) apresenta ainda, uma breve explicação da diferença entre os ambientes CSCW - Computer Supported Cooperative Work e CSCL - Computer Supported Collaborative Learning. Onde o autor explica que:

O foco no trabalho colaborativo, desenvolvido nas pesquisas de CSCW, derivou o conceito de aprendizagem colaborativa apoiada por computador (CSCL), onde a aplicação de sistemas de workflow tem sido estudada. Os dois conceitos, apesar de semelhantes, apresentam algumas características distintas. O CSCW possui a finalidade de facilitar a comunicação e a produtividade do grupo de trabalho, com foco no produto das interações. A CSCL almeja sustentar uma aprendizagem eficaz em grupo e seu foco é no processo de interação (Steinmetz, 2007, p. 65)

Segundo Santoro et. al. (2004) a CSCL pode ser definida como uma estratégia educacional em que dois ou mais sujeitos constroem o seu conhecimento através da discussão, da reflexão e tomada de decisões, onde os recursos informacionais automatizados atuam como mediadores do processo de ensino-aprendizagem.

\subsubsection{Algumas aplicações de CSCL}

Existem várias aplicações de CSCL. Segundo Moreira (2012) estes ambientes virtuais são softwares desenvolvidos sobre metodologia pedagógica para auxiliar o professor na promoção de ensino-aprendizagem virtual ou semipresencial. Eles facilitam o gerenciamento de cursos educacionais para seus estudantes, ajudando professores e aprendizes com administração do curso.

Esses softwares acompanham e permitem o monitoramento por parte de professores e estudantes do processo de aprendizado. Eles atuam como ferramentas para a Educação a Distância (EaD) complementando o conteúdo dado em sala de aula e otimizando a assistência entre professor e aluno com fóruns e a disposição de conteúdo para download.

Moreira (2012) cita alguns exemplos de aplicações de CSCL:

- TelEduc: http://www.teleduc.org.br

- Moodle: http://www.moodle.org.br 
- AulaNet: http://aulanet.les.inf.puc-rio.br/aulanet/

Para este trabalho estaremos utilizando como exemplos de aplicações de CSCL estes três ambientes, considerando Moreira (2012) e outros fatores:

- São ambientes de groupware que estimulam a colaboração entre os seus membros.

- São ambientes desenvolvidos no Brasil, portanto estão voltados à realidade da educação nacional.

- São ambientes que estão em pleno uso e aperfeiçoamento, conforme podemos observar na revisão de literatura apresentada em Steinmetz (2007).

- São ambientes livres e gratuitos.

\section{TELEDUC}

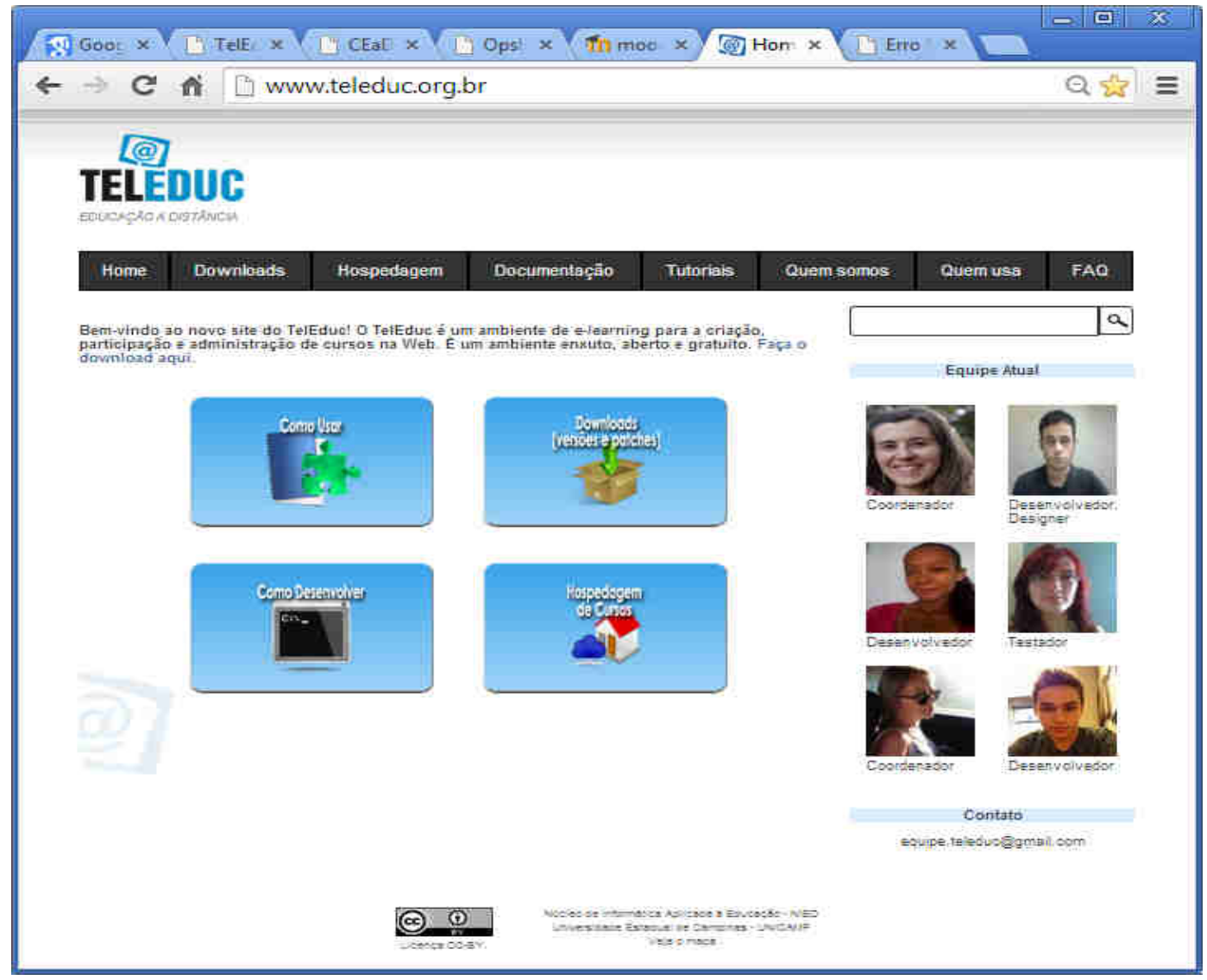

Figura 4: Página inicial do Projeto TelEduc ${ }^{1}$

Disponível em: http://www.teleduc.org.br 
O TelEduc (Figura 4) é um ambiente CSCL desenvolvido com foco no processo de formação de professores para informática educativa, baseado na metodologia de formação contextualizada desenvolvida por pesquisadores do Nied (Núcleo de Informática Aplicada à Educação) da UNICAMP e está na sua versão 4.x

O ambiente proporciona uma intensa comunicação entre os participantes do curso e ampla visibilidade dos trabalhos realizados. Ainda, possui um amplo conjunto de ferramentas de comunicação como o Correio Eletrônico, Grupos de Discussão, Mural, Portfólio, Diário de Bordo, Bate-Papo etc., além de ferramentas de consulta às informações geradas em um curso como a ferramenta Intermap, Acessos, etc.

Nas suas funcionalidades temos funções administrativas e de configuração, aviso automático por e-mail de mudanças no site, batepapo (chat), perfil dos participantes, perguntas freqüentes, avaliações, portfólio de participantes e grupos, estatísticas de acesso, dinâmica do curso, agenda, enquetes, atividades, mural, material de apoio, e-mail, diário de bordo, gestão de grupos, dentre outros.

\section{MOODLE}

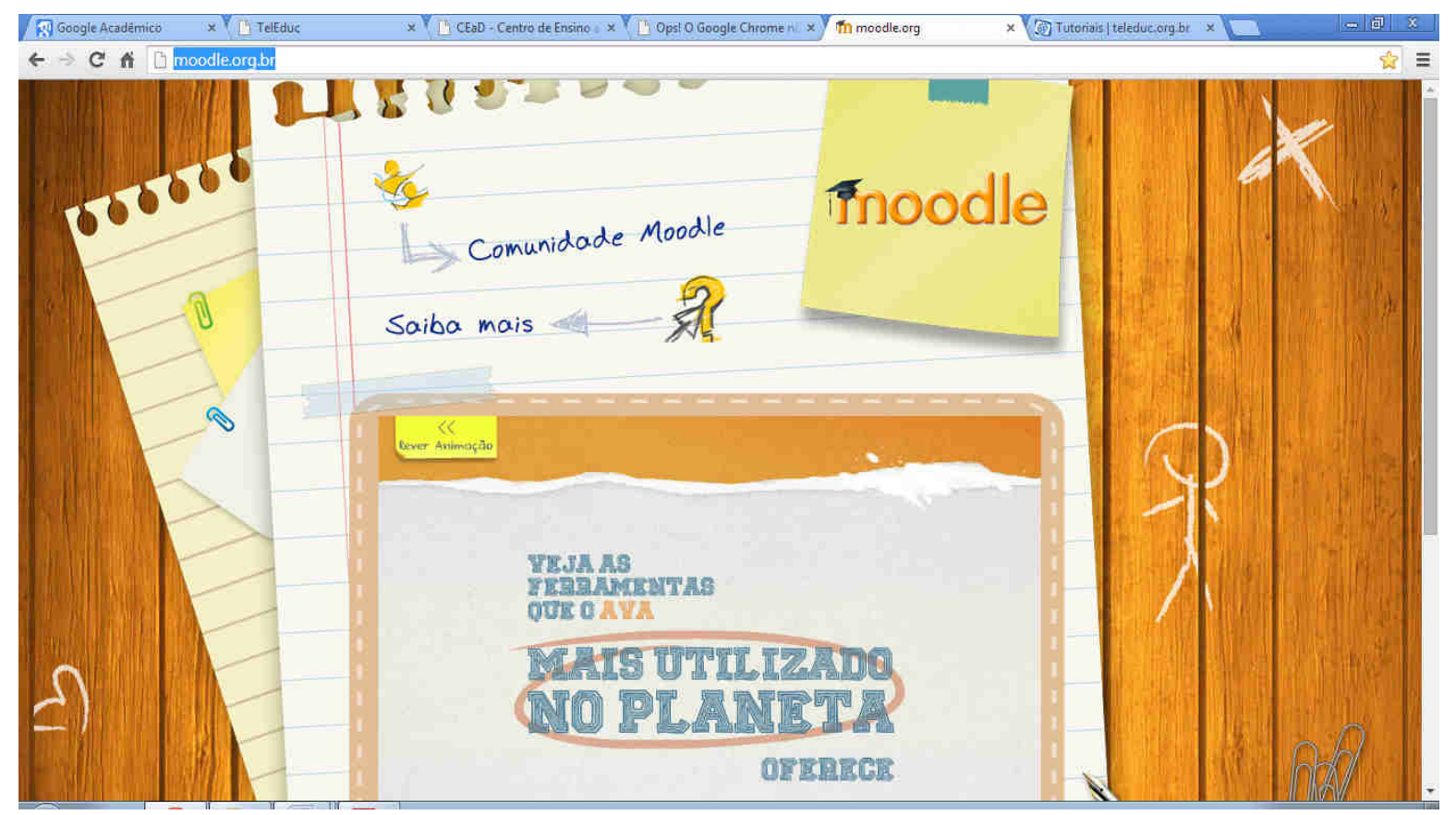

Figura 5: Página inicial do projeto Moodle ${ }^{2}$ 
O Moodle (Figura 5) é considerado um ambiente de CSCL mais utilizado no planeta, com uma proposta bastante diferenciada: "aprender em colaboração" no ambiente on-line, baseando-se na pedagogia sócio construtivista. Permite a administração de atividades educacionais em comunidades on-line, em ambientes virtuais voltados para a aprendizagem.

O Moodle é por natureza um groupware, pois tem por objetivo permitir que processos de ensino-aprendizagem ocorram por meio não apenas da interatividade, mas, principalmente, pela interação, ou seja, privilegiando a construção/reconstrução do conhecimento, a autoria, a produção de conhecimento em colaboração com os pares e a aprendizagem significativa do aluno. Esta filosofia é também aplicada na própria concepção do projeto, pois o desenvolvimento e evolução do ambiente ocorrem com base nos conceitos do CSCL.

O Moodle permite a administração total de cursos a distância ou semipresenciais e entre as suas principais funcionalidades podemos observar:

- Avaliação do curso;

- Pesquisa de opinião;

- Atividades didáticas colaborativas (WIKIs, fóruns, chats, diálogos);

- Atividades didáticas individuais (questionários, tarefas,diários, glossário, lição e trabalho com revisão);

- Partilha de conteúdos entre instituições;

- Gestão total do ambiente virtual de aprendizagem;

- Realização de avaliações de alunos;

- Suporte tecnológico para a disponibilização de conteúdos de acordo com um modelo pedagógico e design institucional;

- Controle de acessos;

- Atribuição de notas.

Entre as vantagens indicadas pelo uso do Moodle, os autores do projeto destacam o aumento da motivação dos alunos e a facilidade na produção e distribuição de conteúdos. 


\section{AULANET}

Fuks et al. (2004a), Fuks et al. (2004b), Raposo et al. (2004) e Lucena et al. (2006) apresentam o modelo de colaboração $3 \mathrm{C}$ que norteou e foi refinado a partir do desenvolvimento do ambiente AulaNet. Este modelo baseia-se em três conceitos principais: comunicação, coordenação e cooperação, que são explorados a partir dos serviços disponíveis no ambiente.

O modelo de colaboração $3 \mathrm{C}$, adotado no ambiente AulaNet, é baseado na idéia de que para colaborar, um grupo tem que exercer três atividades principais: comunicar-se, coordenar-se e cooperar, conforme pode ser observado no diagrama da Figura 6.

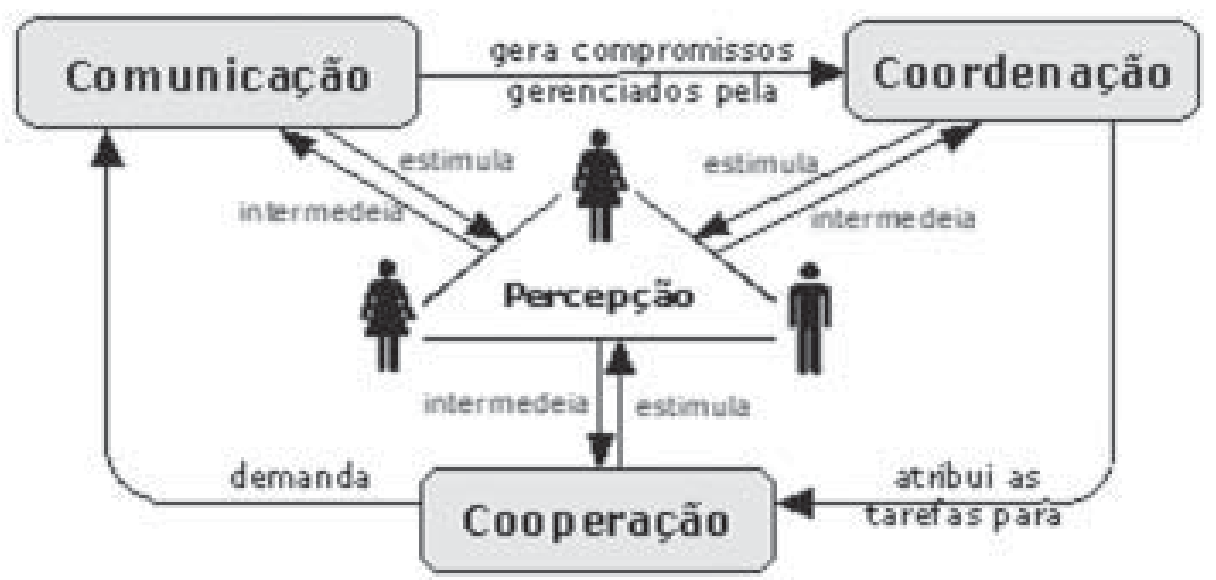

Figura 6: Diagrama do Modelo de Colaboração 3C (FUKS et al., 2004b)

O AulaNet ${ }^{3}$ é um ambiente baseado numa abordagem de groupware para o ensino-aprendizagem na Web. Os serviços de colaboração do ambiente AulaNet são organizados em serviços de comunicação, de coordenação e de cooperação e são colocados à disposição do docente durante a criação e atualização do curso, possibilitando a ele selecionar e configurar quais ficarão disponíveis aos aprendizes.

O AulaNet oferece serviços integrados que podem ser acrescentados ao curso, inclusive no seu decorrer, de forma a complementá-lo. Os serviços escolhidos pelo docente ficam acessíveis aos participantes por meio de um menu representado graficamente como um controle remoto. Estes serviços são organizados em comunicação, coordenação e cooperação, conforme Quadro 5:

Quadro 5: Serviços de comunicação, coordenação e cooperação do AulaNet.

${ }^{3}$ Disponível em: http://groupware.les.inf.puc-rio.br e http://www.eduweb.com.br 


\begin{tabular}{|c|c|}
\hline \multicolumn{2}{|c|}{ Serviços de comunicação, coordenação e cooperação do AulaNet } \\
\hline $\begin{array}{l}\text { SERVIÇOS DE } \\
\text { COMUNICAÇÃOO }\end{array}$ & $\begin{array}{l}\text { Contato com o professor: possibilita o envio de mensagens } \\
\text { eletrônicas (e-mail) para o autor do curso; Grupo de interesse: } \\
\text { Newsgroup dividido por temas normalmente escolhidos por } \\
\text { professores e alunos, tendo como base o assunto abordado no } \\
\text { curso; Grupo de discussão: Lista de discussão relativa ao } \\
\text { curso; Debate: possibilita a discussão em tempo real entre os } \\
\text { integrantes do curso. }\end{array}$ \\
\hline $\begin{array}{l}\text { SERVIÇOS DE } \\
\text { COORDENAÇÃO }\end{array}$ & \begin{tabular}{|l} 
Aglutinam os recursos de avaliação e informação presentes em \\
um curso, como: Agenda: possibilita informar os dias em que \\
haverá Chats, videoconferências, etc.; Notícias dos Cursos: é \\
um tipo de "quadro de avisos", aonde são colocados informes \\
pertinentes ao curso; Provas: um dos recursos de avaliação \\
dos alunos que participam dos cursos; Trabalhos: possibilita ao \\
autor informar quais os trabalhos a Ihe serem enviados e as \\
datas limite para o envio; Exercícios: publicação de exercícios \\
a serem utilizados pelos alunos.
\end{tabular} \\
\hline $\begin{array}{l}\text { SERVIÇOS DE } \\
\text { COOPERAÇÃO }\end{array}$ & $\begin{array}{l}\text { Conjunto de ferramentas de mecanismos que permite a ação } \\
\text { cooperativa dos integrantes dos cursos. Esses mecanismos } \\
\text { são: Demonstração: permite a utilização de demonstrações } \\
\text { através de animações como material de referência para o } \\
\text { curso; Co-autoria de professor: permite que o autor indique } \\
\text { outros professores para serem co-autores de um curso; } \\
\text { Co-autoria de aluno: possibilita aos alunos fornecerem material } \\
\text { a ser inserido no curso; Download: através deste recurso os } \\
\text { participantes de um curso poderão descarregar para seus } \\
\text { computadores os materiais utilizados no mesmo; Tutorial: } \\
\text { tutorial de utilização do ambiente AulaNet para criação e } \\
\text { participação em cursos. }\end{array}$ \\
\hline
\end{tabular}

Fonte: Elaborado pelo autor

Moreira (2012) explica que em Ambientes CSCL o foco não é a tecnologia e sim a interação humana em diálogo com o pensamento expresso. Essa relação 
propicia a construção social de significados e a produção individual de conhecimento, as quais não se esgotam na experiência comunicativa, evidenciando um complexo sistema de inter-relações que faz da interação o centro organizador da atividade.

Entretanto, Oliveira e Tedesco (2010) observam que:

Apesar da grande oferta de ambientes virtuais de ensino e aprendizagem no mercado, estes ainda continuam a tratar todos os seus usuários de maneira semelhante. Consequentemente, muitas vezes não há incentivo para uma construção e compartilhamento efetivos do conhecimento, o que gera problemas de desmotivação e baixos rendimentos (OLIVEIRA; TEDESCO, 2012).

\subsection{MULTIMODALIDADE}

Tal como explica Guo (2004), os avanços tecnológicos na comunicação e os diferentes estágios culturais e tecnológicos, têm alterado o processo comunicativo que envolve texto, imagem, som, gestos etc., independente do modo utilizado para se comunicar, onde o objetivo normalmente é a compreensão da mensagem. Assim, Guo (2004) explica que a Multimodalidade está associada ao estudo dos meios utilizados que levam à compreensão do contexto multimodal que se refere a modos múltiplos, como o falado, escrito, impresso, digital etc.

Duque e Carvalhêdo (2008) partilham de uma visão semelhante ao explicarem que a evolução dos meios de comunicação ocorrida tem permitido que o acesso à informação seja cada vez mais facilitado, sobretudo, pelo advento de novas tecnologias da informação. Isso se deve em muito ao surgimento da Web, que proporcionou um maior acesso a informação por parte das pessoas, que com isso, tornaram-se leitores/escritores. A informação disponibilizada nesse serviço é atemporal, pois ao mesmo tempo em que é contemporânea, é coetânea (temos acesso à informação histórica, inclusive disponibilizada em material multimídia reformatado, temos acesso à informação de culturas que apesar de terem a mesma idade que a nossa são impares em vários aspectos).

Monte Mór (2010) e Steinmetz e Duque (2011), apresentam breves revisões de literatura na área da multimodalidade e entendem que a multimodalidade se refere à utilização de vários modos comunicativos durante uma interação entre sujeitos ou entre sujeitos e documentos. Sendo o modo uma forma de estabelecer a 
comunicação e a multimodalidade se refere ao uso de mais de um modo de representação durante a comunicação. Um exemplo disso pode ser observado em paginas Web que utilizam o modo descritivo, imagens e em alguns casos som, para estabelecer a representação de um gênero discursivo.

Os estudos sobre multimodalidade são realizados e analisados sob diferentes abordagens. Algumas das perspectivas estudadas por autores da área são: Análise semiótica social Multimodal, Análise do discurso Multimodal e Análise Multimodal Interacional, conforme segue:

- Análise Sociossemiótica Multimodal: está associada à significação, produção e recepção de mensagens tanto o autor quanto o leitor de uma determinada comunidade interpretativa. Os trabalhos de Kress, Garcia e Van Leeuwen (2000) Kress, e Van Leeuwen (2001) e Kress (2010), tratam da interpretação do significado do contexto e essa abordagem foca a análise de significados na interação entre os indivíduos, envolvendo também o produtor e o observador. Esses autores desenvolveram metodologias que permitem a análise de imagens ( $A$ gramática do designer visual). Essa pesquisa se deu devido a novas tecnologias e ao uso de diversos recursos semióticos. O foco é o "Signo", o significado e a maneira como cada grupo os interpreta em diferentes situações e contextos.

- Análise Multimodal Interacional: aborda questões associadas à interação face a face entre indivíduos no dia a dia, em tempo real, ou seja, são modos para representar a realidade. Por exemplo: gestos, olhar, movimento do corpo e layout e outros modos. Segundo Norris (2004): "O objetivo principal da abordagem multimodal interacional é a análise, descrição e compreensão do que acontece entre um evento comunicativo, com ênfase nas expressões e reações realizadas pelos indivíduos em situações específicas, na qual uma interação em andamento é sempre co-construída"

- Análise do Discurso Multimodal: que para O'Toole (2011) seria a análise da compreensão e organização da linguagem em uso. Ou seja, analisar o significado de coisas diferentes. 
Dessa forma, os autores que descrevem a Análise Sociossemiótica Multimodal, a Análise Multimodal Interacional e a Análise do Discurso Multimodal, exploram os modos e os recursos semióticos articulados entre essas diferentes perspectivas e também qual questão cada perspectiva pode resolver. Essas abordagens permitem explicar questões diversas sobre a multimodalidade, dentre elas, a compreensão e interação com textos, produção e interpretação de significado e o entendimento que os estudos oferecem ao indivíduo que tem a capacidade de produzir, interpretar e reelaborar o significado produzido. Segundo Kress (2010), o indivíduo deve ser agente na produção de significado criticando, reelaborando, produzindo o novo.

Os autores Kress, Garcia e Van Leeuwen (2000, p. 6) afirmam que "os significados são expressos através de um modo semiótico, que torna disponível a mais plausível subjetividade, a forma mais apta" e que o sistema semiótico tem o signo como noção central, mas a semiótica é mais que esse signo. Kress, Garcia e Van Leeuwen, (2000) explicam, ainda, que o modo semiótico deve servir a vários requisitos de comunicação e de representação a fim de funcionarem como um sistema completo de comunicação.

O termo Multimodalidade foi desenvolvido pelo autor Gunter Kress (1998), e está associado aos múltiplos modos existentes que podem ser utilizados como auxílio no processo de ensino e aprendizagem. Para compreender sobre o que é Multimodalidade é preciso entender alguns pontos relevantes que auxiliam no contexto de maneira geral como, por exemplo, os Gêneros Discursivos (GD) que produzem significados e estabelecem relações através dos textos ou discursos neles veiculados.

Considerando o significado de GD, juntamente com a reflexão de Bakhtin (1992), podemos perceber que a noção de gênero discursivo se reporta ao funcionamento da língua em práticas comunicativas, reais e concretas, construídas por sujeitos que interagem nas esferas das relações humanas e da comunicação. Assim, ocorre a materialização do GD através da linguagem.

Neste contexto, podemos entender a relação entre gênero e gênero discursivo, onde o Gênero consiste na forma de funcionamento da língua dos sujeitos enquanto o gênero discursivo está relacionado à designação que diz respeito a manifestações concretas do discurso produzidas pelos sujeitos. 
Ainda, podemos perceber a relação o gênero e a Multimodalidade, que conforme a revisão de literatura apresentada pode ser entendida como todo o arranjo visual existente no gênero, como exemplo, em textos escritos ela está presente na diagramação, saliência, cores, figuras e tipo de papel utilizado.

No caso de textos orais ela se apresenta na maneira como as pessoas se comportam nesses textos utilizando gesto, entonação de voz, expressão facial, etc. Isso ocorre porque os gêneros textuais e discursivos produzem significados e estabelecem relações através dos textos ou discursos neles veiculados. Esses gêneros se materializam através da linguagem verbal ou não-verbal.

Uma mensagem impressa em um texto, por exemplo, é composta de um arranjo visual que envolve recursos multimodais visualmente percebidos. Esses recursos na escrita fazem com que o texto estabeleça uma ordem de leitura, o que possibilita maior compreensão do contexto da mensagem. Esses recursos multimodais em textos podem fazer toda a diferença por ressaltar aquele detalhe que atrai maior atenção do leitor.

Kress e Van Leewen (2006) explicam que um exemplo de texto multimodal pode ser uma página que há letras em negrito, fontes com diferentes cores ou, por exemplo, algum detalhe na escrita que promove um maior destaque para partes específicas do texto ou em determinadas palavras chaves no meio do texto, mesmo o fato de se privilegiar uma determinada informação numa seqüência de textos sucessivos já implica num modo distinto.

Segundo Descardesi (2002), uma página possui, além do código escrito, outras formas de representação como a diagramação da página (layout), a cor e a qualidade do papel, o formato e a cor (ou cores) das letras, a formatação do parágrafo, etc. interferem na mensagem a ser comunicada e que todo esse arranjo visual existente no gênero do texto escrito possibilita o seu entendimento porque "complementam a composição da mensagem".

\subsubsection{A Gramática Visual em Documentos Multimodais}

Considerando que a sociedade está cada vez mais baseada em padrões visuais, a multimodalidade possibilita através dos estudos sobre a Gramática Visual de Kress e Van Leeuwen (1998, 2006), compreender a relação e as maneiras como as imagens representam as relações entre as pessoas, os lugares e os objetos que 
nelas estão retratados em análise de textos multimodais com a noção teórica "Hallidayana ${ }^{4}$ " de metafunções (ideacional, interpessoal e textual), sendo que:

- Ideacional: Realizada visualmente uma idéia ou atividade (em concreto ou abstrato) dos participantes (pessoas / objetos) representados na imagem.

- Interpessoal: É a expressão das interações sociais que são fabricadas a partir do tipo de interação que os participantes representaram os produtores da imagem e os espectadores.

- Textual: Realiza a "coerência" e a "coesão" entre significados ideacionais e interpessoais por meio de recursos de quadros (conectores ou seccionadores) e saliências (tamanho, cor, brilho, contraste, expressão da estrutura e formato do texto que se realiza no sistema da informação ou tema).

Segundo Halliday et al. (2004, p. 31), "toda a arquitetura da linguagem se organiza em linhas funcionais. A linguagem é como é, por causa das funções em que se desenvolveu na espécie humana. O termo 'metafunção' foi adotado para sugerir que função é uma componente nuclear na totalidade da teoria".

Kress e Van Leeuwen (1998), ainda tratando da gramática visual, afirmam que existem três princípios de composição das imagens que são visualizados pelo espectador:

- Valor de informação: o local dos elementos (participantes e sintagmas que relatam uns aos outros e ao Espectador) tem valores informacionais específicos anexados às várias zonas da imagem: direita e esquerda, parte superior e parte inferior, centro e margem.

- Saliência: é ela que pode estabelecer uma hierarquia de importância entre os elementos, que são feitos para atrair a atenção do espectador em diferentes graus:plano de fundo ou primeiro plano, tamanho, contrastes de tons e cores, diferença de nitidez, etc.

4 Linguística Sistêmica Funcional desenvolvida por Michael Halliday em 1994 e revisada em 2004. 
- Estruturação: a presença ou ausência de planos de estruturação (realizado por elementos que criam linhas divisórias, ou por linhas de estruturação reais) desconecta ou conecta elementos da imagem, significando que eles pertencem ou não ao mesmo sentido.

Para Kress e Van Leeuwen $(1998,2006)$, não há texto monomodal, ou seja, todo texto é multimodal. Concordando com esse contexto, Descardeci (2002, p.20), afirma que "qualquer que seja o texto escrito, ele é multimodal, isto é, composto por mais de um modo de representação". Segundo esse autor, em uma página, além do código escrito, outras formas de representação como a diagramação da página (layout), a cor e a qualidade do papel, o formato e a cor (ou cores) das letras, a formatação do parágrafo, etc. interferem na mensagem a ser comunicada e que todo esse arranjo visual existente no gênero do texto escrito possibilita o entendimento porque complementam na composição da mensagem.

Para Bateman (2008) documentos multimodais envolvem combinações de informações que empregam diferentes meios de apresentação ou diferentes modos. Este mesmo autor explica ainda que um documento multimodal é composto por alguns elementos que podem ser identificados e descritos de uma maneira reprodutível. Para isso, o autor explica que uma página de um documento pode ser analisada por diferentes perspectivas: como um objeto de interpretação; como um objeto de percepção; como um sinal a ser processado e como objeto de produção. A Figura 7 apresenta um modelo que explica estas perspectivas quanto à produção $e$ a recepção de um documento e suas paginas.

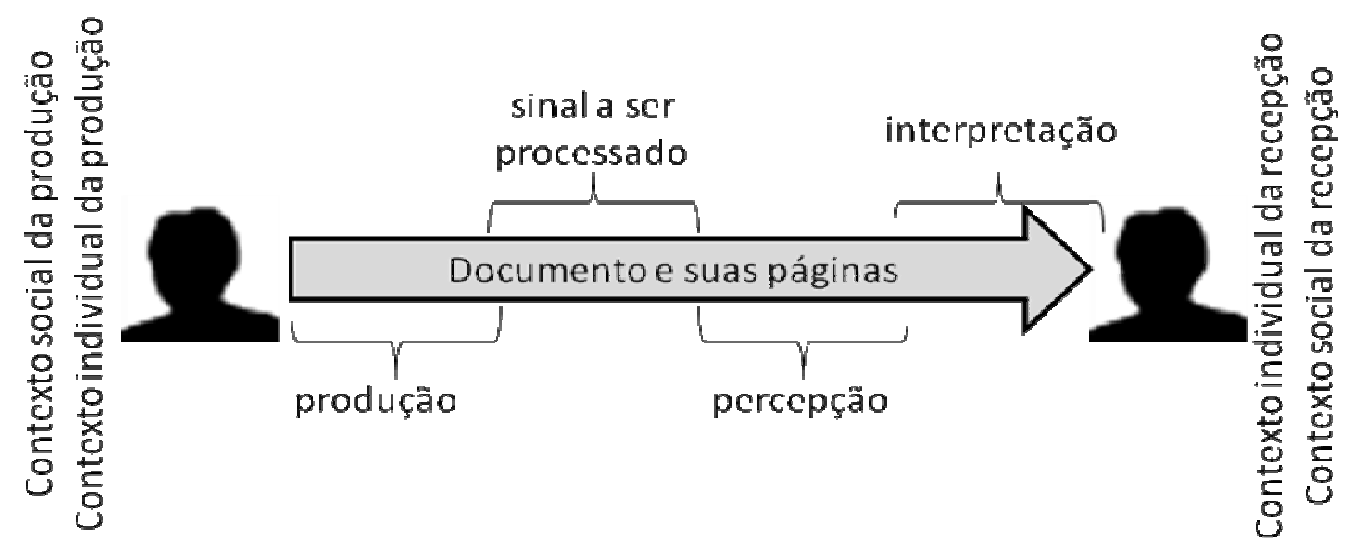

Figura 7: Espectro de abordagens para um documento e suas páginas (BATEMAN, 2008, p 25). 
Nestas perspectivas o autor busca identificar o que acontece dentro uma página multimodal e, para isso, considera o design gráfico como "macro-pontuação", similar ao texto-base de tipografia ou formatação e considera páginas como entidades visuais onde o design do documento constitui um processo de decomposição visual.

Entre as técnicas utilizadas para efetivar a decomposição visual de uma página de um documento multimodal, Bateman (2008) utiliza a Gramática Visual de Kress e Van Leewen (1998) que define nove possíveis composições de layout de acordo com o valor da informação no documento. A Figura 8 apresenta uma dessas composições de layout propostas, onde a informação é distribuída na pagina em setores e cada um dos quais atribui valores específicos para os elementos colocados dentro dele.

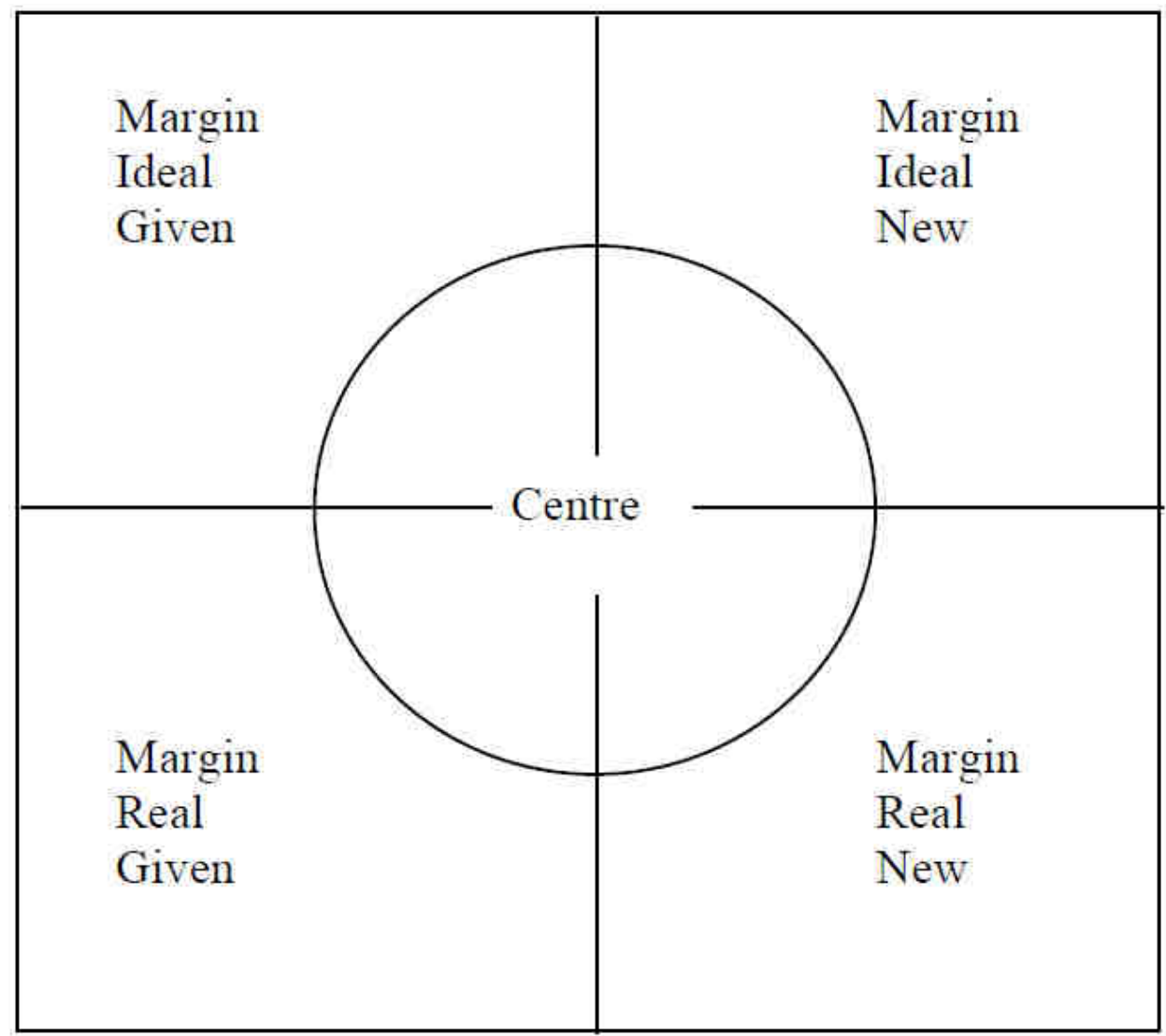

Figura 8: Proposta de Composição de Layout (KRESS e VAN LEEWEN, 1998, p 223). 
Neste exemplo, o layout sugerido consiste em uma área central e quatro áreas marginais equivalentes aos quatro cantos da página, a informação que estiver no centro recebe um valor de importância maior, em relação ao resto nas margens.

\subsection{TEORIA DA RELEVÂNCIA}

A Teoria da Relevância, proposta por Dan Sperber e Deirdre Wilson (1986, 2002), explica como ocorre o processamento de informações durante a comunicação humana. Os autores explicam que a comunicação humana se realiza por meio de dois mecanismos: o primeiro é baseado na codificação e decodificação de enunciados, e o segundo, baseado na ostensão por parte do falante e na inferência feita pelo ouvinte. Assim, a Teoria da Relevância pode ser vista como uma teoria fundamentada na Cognição e na Comunicação, sendo desenvolvida na interface entre a Comunicação e a Cognição.

$\mathrm{Na}$ inferência, o ouvinte utiliza um processo de raciocínio dedutivo que the permite gerar suposições e conclusões que estejam coerentes com a situação comunicativa. Na ostensão o falante assume uma atitude que parte do seu comportamento quando este deixa explícita a intenção de manifestar algo, ou seja, é a atitude de fazer com que o ouvinte perceba sua intenção e chegue a uma interpretação relevante da mesma. Todo esse processo interpretativo é guiado pela busca da relevância.

Assim, podemos entender que a Teoria da Relevância é um modelo de comunicação e cognição humana que se propõe a explicar como a informação é representada mentalmente e processada de maneira inferencial em situações comunicativas intencionais da vida real. Essa abordagem é baseada nos princípios lógico e o cognitivo.

O princípio cognitivo é fundamentado nos preceitos da psicologia cognitiva, que vê o processo do raciocínio humano não como uma estrutura, mas o considera algo dinâmico e ligado a fatores como atenção, memória e representação conceitual, o que será fundamental para o processamento de deduções. E o princípio lógico baseia-se nos moldes da lógica formal para a construção das hipóteses interpretativas (formulando e confirmando essas hipóteses), quer dizer, a partir de 
formas lógicas (enunciados) constroem premissas e conclusões à semelhança do modelo formal. Entretanto, essas premissas e conclusões não têm caráter de verdade absoluta, são possibilidades para uma interpretação plausível realizada com base no modelo dedutivo de inferências que seguem um cálculo não-trivial (não podem ser provadas, mas deduzidas), que envolvem fatores como a experiências prévias, contexto social, etc.

Sperber e Wilson $(1986,2002)$ defendem que a cognição humana tem uma tendência para a relevância. Assim, eles propõem o 'princípio de relevância', que explica a predisposição de um indivíduo para determinado ato comunicativo em precedência a outro.

De acordo com o 'princípio de relevância' o cérebro/mente vão sempre na direção daquilo que para determinado indivíduo é mais relevante. Isso é descrito como o princípio abdutivo que melhor explica o processamento inferencial extremamente rápido da mente direcionado à comunicação humana para aquilo que é mais relevante em determinado momento.

\subsection{CIÊNCIA DA INFORMAÇÃO, ARQUITETURA DA INFORMAÇÃO E MULTIMODALIDADE NO PROCESSO DE ENSINO/APRENDIZAGEM}

Sobre o processo de ensino-aprendizagem, existem estudos de Steinmetz et al.(2012), Duque et al. (2012), Steinmetz e Duque (2013) e Steinmetz e Duque (2014) que demonstram preocupação com a qualidade do ensino/aprendizagem e sugerem que há uma necessidade do uso da Multimodalidade como fator facilitador no processo de comunicação eficiente e eficaz. Esses autores desenvolveram pesquisas exploratórias que buscam estabelecer um arcabouço teórico que fundamentam as relações entre a Arquitetura da Informação e a Multimodalidade aplicadas no processo ensino/aprendizagem.

Ainda, considerando que a Multimodalidade está associada ao contexto e que se refere a múltiplos modos comunicativos, existem algumas discussões sobre seus possíveis reflexos da multimodalidade em iniciativas de inclusão dos discentes em programas de iniciação científica. Nesse sentido, Steinmetz et al.(2012) apresentam 
os resultados do Projeto Papic ${ }^{5}$ que têm como objetivo principal promover e estimular a iniciação científica em alunos de Instituições de ensino privadas do DF. Os autores observam o possível impacto do uso de diversos recursos multimodais utilizados no Blog do projeto, que podem levar os alunos a contextualizarem melhor as informações aumentando a sua competência informacional sobre os assuntos abordados no Blog e, através da Iniciação Científica, participarem de eventos com publicações científicas.

Farias, Obilinovic e Orrego (2011) fazem uma leitura ilustrada com textos multimodais usados para ensinar Inglês no Chile onde a multimodalidade pode ser produtiva se estiver envolvida no diálogo. Neste mesmo sentido, Mayer e Moreno, (2002, p. 5) afirmam que: "o diálogo pode ser construído quando há uma via de mão dupla entre a ciência cognitiva e a instrução que permite uma interação rápida entre a teoria e a prática".

Farias, Obilinovic e Orrego (2011) ao falarem de multimídia (o uso de som, voz humana, efeitos especiais, fotos, vídeo, animação, gráficos e textos) como auxilio ao processo de ensino aprendizagem, afirmam que a agilidade com que se dão as mudanças de impressão, baseadas em meios orientados visualmente e digitalizados, reapresentações de informações, envolve também uma resposta rápida de educadores para tirar proveito da multimodalidade envolvendo os alunos no sentido cognitivo, para que esses alunos tenham capacidade crítica e compreendam a sociedade. Eles ressaltam sobre alfabetização visual e sobre formas mais eficientes de representação da informação.

Uma mensagem comunicada deverá ser compreendida, caso contrário o processo de comunicação não obteve sucesso. A Multimodalidade estuda diversos modos que podem ser utilizados para que essa mensagem seja construída de modo que o leitor ou o público receptor a compreenda, pois o uso de recursos multimodais na mensagem se preocupa com a realidade cultural do contexto social onde ela é produzida e consumida, portanto, consumada enquanto mensagem. Ou seja, ela não está desvinculada dos avanços tecnológicos na comunicação da informação nem dos diferentes estágios culturais e tecnológicos para análise do processo comunicativo que envolve texto, imagem, som, gestos, etc.

5 Projeto Papic, disponível em: http://projetopapic.blogspot.com.br/ 
Rocha e Duarte (2013) apresentam uma reflexão sobre a usabilidade no contexto dos estudos de usuários da informação, com base na evolução da Interação Humano-Computador e suas apropriações no campo da Ciência da Informação. Os autores relacionam os paradigmas orientadores dos estudos da $\mathrm{Cl}-$ físico, cognitivo e social - aos estudos realizados no campo da interação humanocomputador. Concluiram de que os estudos de usabilidade na $\mathrm{Cl}$, no geral, têm orientação cognitivista, alinhada ao paradigma físico, e não contemplam a complexidade do comportamento informacional dos usuários. Dentre os temas abordados podemos observar estudos que procuram entender o Trabalho Colaborativo Apoiado por Computador (CSCW).

Duque et al. (2012), Steinmetz e Steinmetz (2013) e Steinmetz e Duque (2013) apresentam o resultado da utilização de recursos multimodais como forma de incentivar a inclusão de alunos de graduação em um projeto de iniciação cientifica utilizando-se um blog. Entre as observações dos autores, podemos destacar o aumento do engajamento dos alunos de graduação em atividades de iniciação cientifica e um dos motivos disto, são as características multimodais aplicadas à Arquitetura da Informação no blog utilizado como forma de comunicação e divulgação das ações do projeto. Os autores percebem que a utilização da multimodalidade na Arquitetura da Informação pode ter gerado o aumento da relevância das informações do blog para o publico alvo, os alunos.

Steinmetz, Steinmetz e Duque (2012) explicam que a Multimodalidade é analisada por diferentes abordagens. Dessa forma, os autores exploram os modos e os recursos semióticos articulados entre essas diferentes perspectivas e também a qual questão cada perspectiva pode resolver. Essas abordagens explicam questões diversas sobre a multimodalidade, dentre elas, a compreensão e interação de textos, produção e interpretação de significado e o empoderamento que os estudos oferecem ao indivíduo que tem a capacidade de produzir, interpretar e de reelaborar o significado produzido.

Steinmetz, Steinmetz e Duque (2012) e Steinmetz e Duque (2013) buscam encontrar elementos teóricos e que fundamentam a integração dos conceitos de Ciência da Informação, Arquitetura da Informação e Multimodalidade. Observam em suas conclusões que a Ciência da Informação tem como principal objetivo buscar 
meios e formas para atender as necessidades de informação dos indivíduos, impostas pela evolução da sociedade. A informação, sendo o objeto de estudo da Ciência da Informação, depende da definição de um contexto para que possa ter um significado válido, mas pode ser vista como o fenômeno mais amplo que este campo do conhecimento pode tratar, através da sua geração, transferência ou comunicação e do seu uso.

Steinmetz, Steinmetz e Duque (2012) observam ainda que em modo não presencial e atemporal, a comunicação depende de um registro físico da informação para que ocorra a transferência da informação. Assim, podemos entender que um documento, sendo visto com um registro de informação, pode ser o canal de transferência da informação, seja ele um documento físico ou virtual, podendo ser a Gramática Visual uma forma de definir um design da Arquitetura da Informação do espaço informacional em questão. 


\section{METODOLOGIA}

\subsection{CLASSIFICAÇÃO DA PESQUISA}

Segundo Gil $(1991,1999)$ uma pesquisa cientifica pode ser classificada de várias maneiras, quanto a sua natureza, quanto aos seus objetivos, quanto à forma, quanto à abordagem do problema, entre outros tipos de classificação. Sendo a classificação da pesquisa fundamental para determinar as técnicas e metodologias a serem aplicadas para que os resultados obtidos sejam aderentes aos resultados pretendidos.

Quanto à natureza da pesquisa, esta pesquisa pode ser classificada como uma pesquisa aplicada (GIL, 1991). Neste caso, buscou-se gerar conhecimento na área específica do estudo da Arquitetura da Informação para aplicação prática dirigida a solução de problemas específicos na concepção e utilização de ambientes informacionais de apoio ao processo de ensino e aprendizagem.

Quanto aos objetivos, a pesquisa pode ser classificada como uma investigação exploratória (GIL, 1991), pois não existe conhecimento acumulado e sistematizado sobre modelos de interação em ambientes acadêmicos informacionais colaborativos. Também pode ser vista como uma pesquisa metodológica, porque apresentar-se uma proposta de modelo de Arquitetura da Informação Multimodal para atender os objetivos da pesquisa.

Gil (1999) explica que as pesquisas exploratórias buscam fornecer uma visão geral de um determinado fato. Uma investigação exploratória envolve pesquisa bibliográfica, coleta de dados e experiências com profissionais que tem, ou tiveram, experiência prática com o problema pesquisado.

Assim, a pesquisa exploratória é realizada quando geralmente não se possui muito, ou nenhum conhecimento sobre a questão que está sob investigação. Neste tipo de estudo pretende-se identificar elementos que diminuam a incerteza acerca do problema investigado, identificando possíveis padrões, idéias ou hipóteses. Para tanto, uma pesquisa exploratória não tem como finalidade testar ou confirmar uma 
determinada hipótese, mas estabelecer um arcabouço teórico e metodologias potenciais que podem ser aplicados para solucionar o problema investigado.

Quanto à forma e a abordagem do problema, ainda segundo Gil (1991), a pesquisa pode ser classificada como qualitativa, pois não requer o uso de métodos e técnicas estatísticas. A proposição do modelo é o foco principal da abordagem. 0 procedimento técnico do estudo consiste em uma pesquisa bibliográfica, principalmente em livros, artigos de periódicos científicos, textos e pesquisas disponibilizadas na Internet, a fim de estabelecer um conjunto de contribuições teóricas relacionadas ao problema.

\subsection{PERCURSO METODOLÓGICO}

Esta pesquisa tem como ponto de partida uma das propostas de trabalhos futuros apresentada por Steinmetz (2007), onde o autor apresenta um ambiente colaborativo de ensino-aprendizado baseado em sistemas de workflow e sugere o estudo e melhoria das interfaces desse ambiente, a fim de melhorar a sua usabilidade. Assim, a delimitação do escopo inicial desta pesquisa levou em consideração ambientes de ensino-aprendizagem, apoiados em sistemas de informação. Bem como a Ciência da Informação e Arquitetura da Informação podem contribuir para melhorar a usabilidade destes ambientes, considerando os conceitos da Multimodalidade e da Teoria da Relevância.

Com o escopo definido, iniciou-se uma pesquisa bibliográfica com a seleção e leitura de textos e artigos científicos que fornecessem a fundamentação teórica suficiente para subsidiar a estruturação do procedimento metodológico a ser utilizado. Com base nesta revisão busca-se a construção de uma proposta preliminar de uma Arquitetura da Informação que possa contribuir na melhoria das interfaces de ambientes CSCL aumentando a relevância destes ambientes para seus usuários, ou seja, para os estudantes.

Com a elaboração da proposta preliminar, foi elaborado um grupo focal que teve por objetivo obter impressões, críticas e sugestões de um grupo préselecionado. Este grupo foi formado por diversos profissionais especializados em educação, ciência da informação e Arquitetura da Informação, que discutirão e 
avaliarão as propostas apresentadas pelo pesquisador, pronunciando-se sobre cada uma delas, validando-as ou não. As características qualitativas e exploratórias da pesquisa justificam a escolha do grupo focal como técnica de coleta de dados, pois permitiram ao pesquisador explorar habilidades, conhecimentos e experiências dos sujeitos envolvidos com o objeto do estudo, em busca da compreensão do tema pesquisado.

Segundo Powell e Single (1996), um grupo focal é "um conjunto de pessoas selecionadas e reunidas por pesquisadores para discutir e comentar um tema, que é o objeto da pesquisa, a partir de sua experiência pessoal". Ainda, Vergara (2007, 2009) explica que grupos focais são entrevistas coletivas conduzidas por um pesquisador, que tem o papel de estimular a comunicação e a interação entre os entrevistados, mas não deve emitir opiniões pessoais nem tentar influenciar os entrevistados. Neste mesmo sentido Veiga e Gondim (2001) entendem que o grupo focal é um recurso metodológico para compreender o processo de construção das percepções, atitudes e representações sociais de grupos de pessoas.

Trad (2009) explica que a técnica de Grupo Focal - GF tem origem anglosaxônica no final da década de 1940. Desde então, tem sido utilizada como metodologia de pesquisas sociais. Essa técnica possui um custo relativamente baixo, o seu emprego possibilita a obtenção de dados válidos e confiáveis em um tempo abreviado. Esse fato contribuiu para o incremento na utilização dos grupos focais nos últimos anos. A autora observa que:

A técnica de GF experimenta uma espécie de renascimento. No campo das ciências sociais, sua penetração se inicia pelo campo da política, mas se espraia progressivamente pelos diversos segmentos da pesquisa social (TRAD, 2009, p. 2).

Lyra (2012) utilizou grupo focal em sua pesquisa e apresentou uma breve revisão de literatura sobre este método, ressaltando um conjunto de requisitos e características comuns aos grupos focais segundo os autores estudados, conforme o Quadro 6: 
Quadro 6: Requisitos e Características Comuns aos Grupos Focais.

\begin{tabular}{|c|c|}
\hline AUTOR & Requisitos/Características \\
\hline $\begin{array}{l}(\text { VERGARA, 2007) } \\
\text { (VERGARA, 2009) }\end{array}$ & $\begin{array}{l}\text { As sessões do grupo focal devem ter duração variando } \\
\text { entre uma e duas horas. }\end{array}$ \\
\hline $\begin{array}{l}(\text { DE ANTONI et al., 2001) } \\
\text { (THIOLLENT, 1997) } \\
\text { (GATTI, 2005) } \\
\text { (KIPNIS, 2005) }\end{array}$ & $\begin{array}{l}\text { Com base na afinidade que o grupo focal tenha com o } \\
\text { tema, uma sessão é suficiente para coletar as } \\
\text { impressões dos participantes e validar o tema } \\
\text { discutido. }\end{array}$ \\
\hline $\begin{array}{l}(\text { IERVOLINO e PELICIONI, } \\
\text { 2001) }\end{array}$ & $\begin{array}{l}\text { Deve ser formado por membros com algumas } \\
\text { características homogêneas, mas que permitam uma } \\
\text { adequada heterogeneidade de visões sobre o tópico } \\
\text { discutido. }\end{array}$ \\
\hline (LUDWIG, 2009) & $\begin{array}{l}\text { A discussão deve ser iniciada por tópicos mais simples } \\
\text { e generalistas, culminando em itens mais específicos e } \\
\text { profundos. }\end{array}$ \\
\hline $\begin{array}{l}\text { (MARCZAK e SEWELL, } \\
\text { 2012) }\end{array}$ & $\begin{array}{l}\text { Normalmente, discutem-se até cinco questões/tópicos } \\
\text { por sessão. }\end{array}$ \\
\hline
\end{tabular}

Fonte: Lyra (2012)

Lyra (2012) ainda aponta algumas limitações que merecem destaque na utilização de grupos focais. Em contraponto, o autor explica ser plenamente possível a utilização deste método, indicando medidas corretivas a serem adotadas pelo pesquisador, a fim de mitigar essas limitações, conforme o Quadro 7.

Quadro 7: Limitações de Grupos Focais e Medidas Mitigadoras

\begin{tabular}{|l|l|}
\hline \multicolumn{1}{|c|}{ Limitação/desvantagem } & \multicolumn{1}{c|}{ Ação mitigadora / justificativa } \\
\hline $\begin{array}{l}\text { Possível dificuldade de expressar ou } \\
\text { articular opiniões e idéias } \\
\text { (pesquisador e/ou participante). }\end{array}$ & \begin{tabular}{l} 
Elevou-se o nível de qualificação exigido para \\
\hline $\begin{array}{l}\text { Grupo focal pode ter experiências ou } \\
\text { níveis de qualificação muito } \\
\text { desnivelados. }\end{array}$
\end{tabular} \\
\hline
\end{tabular}




\begin{tabular}{|l|l|}
\hline $\begin{array}{l}\text { Grupo focal pode não se preparar } \\
\text { adequadamente para contribuir com } \\
\text { o tema. }\end{array}$ & $\begin{array}{l}\text { Um material com o contexto da pesquisa foi } \\
\text { enviado aos participantes do grupo focal com } \\
\text { seis dias de antecedência. Além disso, minutos } \\
\text { iniciais do encontro foram utilizados para que o } \\
\text { pesquisador explicasse os procedimentos do } \\
\text { trabalho e esclarecesse eventuais dúvidas. }\end{array}$ \\
\hline $\begin{array}{l}\text { Pesquisador influenciar } \\
\text { deliberadamente a entrevista e } \\
\text { direcionar as opiniões emitidas. }\end{array}$ & $\begin{array}{l}\text { Além de haver uma proibição sobre a } \\
\text { participação de parentes e de pessoas } \\
\text { subordinadas hierarquicamente, o pesquisador } \\
\text { deixou claro, desde que fez o primeiro contato } \\
\text { com os participantes do grupo focal, de que } \\
\text { sua participação seria meramente instigadora e } \\
\text { não persuasiva. }\end{array}$ \\
\hline Participante pode se sentir inibido. & $\begin{array}{l}\text { Discussão inicial envolveu temas mais simples } \\
\text { e generalistas, de forma a criar um ambiente } \\
\text { propício para discussão. }\end{array}$ \\
\hline $\begin{array}{l}\text { Dificuldade em registrar os } \\
\text { comentários e manter a atenção nos } \\
\text { participantes. }\end{array}$ & $\begin{array}{l}\text { Alocação de um profissional da área } \\
\text { exclusivamente para registrar, e gravar a } \\
\text { reunião. }\end{array}$ \\
\hline
\end{tabular}

Fonte: Lyra (2012)

Observando os requisitos e características comuns aos grupos focais expostos no Quadro 6, juntamente com as limitações e medidas mitigadoras no Quadro 7, podemos perceber que este método permite o levantamento de dados de validação da pesquisa em questão.

Para tanto, um grupo focal foi montado após a elaboração da proposta preliminar do modelo de Arquitetura da Informação Multimodal para Ambientes Informacionais Colaborativos de Ensino Aprendizagem apoiados em computador. Este grupo focal avaliou, discutiu a proposta preliminar do modelo proposto e contribuiu na pesquisa em questão, sugerindo melhorias ao modelo de Arquitetura da Informação Multimodal para Ambientes Informacionais Colaborativos de Ensino Aprendizagem apoiados em computador. 


\section{DESCRIÇÃO E ANÁLISE DO MODELO DE ARQUITETURA DA INFORMAÇÃO MULTIMODAL}

Steinmetz e Duque (2013) apresentam algumas contribuições teóricas que agregam conceitos de Ciência da Informação, Arquitetura da Informação e Multimodalidade que podem servir como embrião para uma Arquitetura da Informação multimodal. Neste contexto, os autores observam que a Arquitetura da Informação busca atender à necessidade de informação dos usuários, utilizando diversas técnicas e ferramentas para prover espaços informacionais que supram esta necessidade. Estes espaços podem ser sistemas de informação que permitem a navegação e organização da informação por parte usuários na busca e gerenciamento de suas necessidades de informação.

No tocante ao modo e a multimodalidade, Steinmetz e Duque (2013) explicam que ela pode ser entendida, ainda, como todo o arranjo visual que define em textos escritos, a diagramação, a saliência, as cores, as figuras e o tipo de mídia utilizada, etc. A Análise Sociossemiótica Multimodal está associada à significação, produção e recepção de mensagens tanto do proponente quanto do leitor em um determinado contexto. Assim, a interpretação do significado do contexto está vinculada a análise de significados na interação entre os indivíduos, envolvendo também o produtor e o observador.

Steinmetz, Steinmetz, Costa e Duque (2013) realizam um estudo para compreender os pontos convergentes entre Arquitetura da Informação, Teoria da Relevância e Multimodalidade, bem como, uma proposta para investigar se seria possível construir as relações entre essas áreas, conforme descrito a seguir.

\subsection{ARQUITETURA DA INFORMAÇÃO, TEORIA DA RELEVÂNCIA e MULTIMODALIDADE APLICADAS EM SITEMAS DE INFORMAÇÃO}

Steinmetz et al. (2013) apresentam uma fundamentação teórica dos assuntos abordados enfatizando que, ao estudar os conceitos da Teoria da relevância, é necessário compreender que ela está centrada no sujeito. Ou seja, é relevante pra 
quem? E se algo é relevante, é assim porque alguém que está inserido em determinado contexto acha determinada coisa, objeto, assunto etc., relevante. Nesse aspecto, entende-se que a relevância está no olhar do sujeito, o que precisa é estudar e identificar o que é ou não relevante para pessoas de determinados contextos em determinadas situações.

Ao analisarmos a seguinte expressão: "Ele deu uma de João sem braço". Significa que alguém, com conhecimento sobre determinado fato, finge que não estar entendendo o ocorrido para tirar vantagem disso. O significado e a relevância dessa frase para brasileiros são diferentes do significado e da relevância dessa frase para um estrangeiro que não sofre influência da cultura brasileira. O significado e o grau de relevância dependem do indivíduo, já que vários aspectos podem estar envolvidos no seu contexto atual, que influenciam o seu grau de relevância.

Steinmetz et al. (2013) abordam ainda, do ponto de vista da Ciência da Informação, a recuperação de informações em documentos que tenham sido armazenados, com a finalidade de permitir o acesso dos usuários aos itens de informação, objetos de uma consulta. Os autores observam ainda que hoje enfrentamos um problema para selecionar a informação relevante diante de tantas fontes e formas de acesso a informação devido à grande quantidade de informações são produzidas e disponibilizadas diariamente.

Para atender a esta demanda os autores explicam que o uso de sistemas de recuperação de informações pode auxiliar o usuário a encontrar informações relevantes desde que atendam aos conceitos de Eficácia, Revocação e Precisão. SHI et al. (2005) explicam que a eficácia de um Sistema de Recuperação da Informação está diretamente ligada a dois índices, Precisão e Revocação:

- Precisão: que é a habilidade de recuperar documentos mais bem classificados quanto à relevância da pesquisa.

- Revocação: que é a habilidade de pesquisa para encontrar todos os itens relevantes de uma coleção.

Os autores entendem que é muito importante, para não haver prejuízo na recuperação de informações relevantes, buscar medidas de eficácia que 
equacionem a relação da Precisão com a Revocação de forma a resultarem em consultas com maior número de documentos relevantes conforme a Figura 9.

\section{Relação entre Revocação e Precisão}

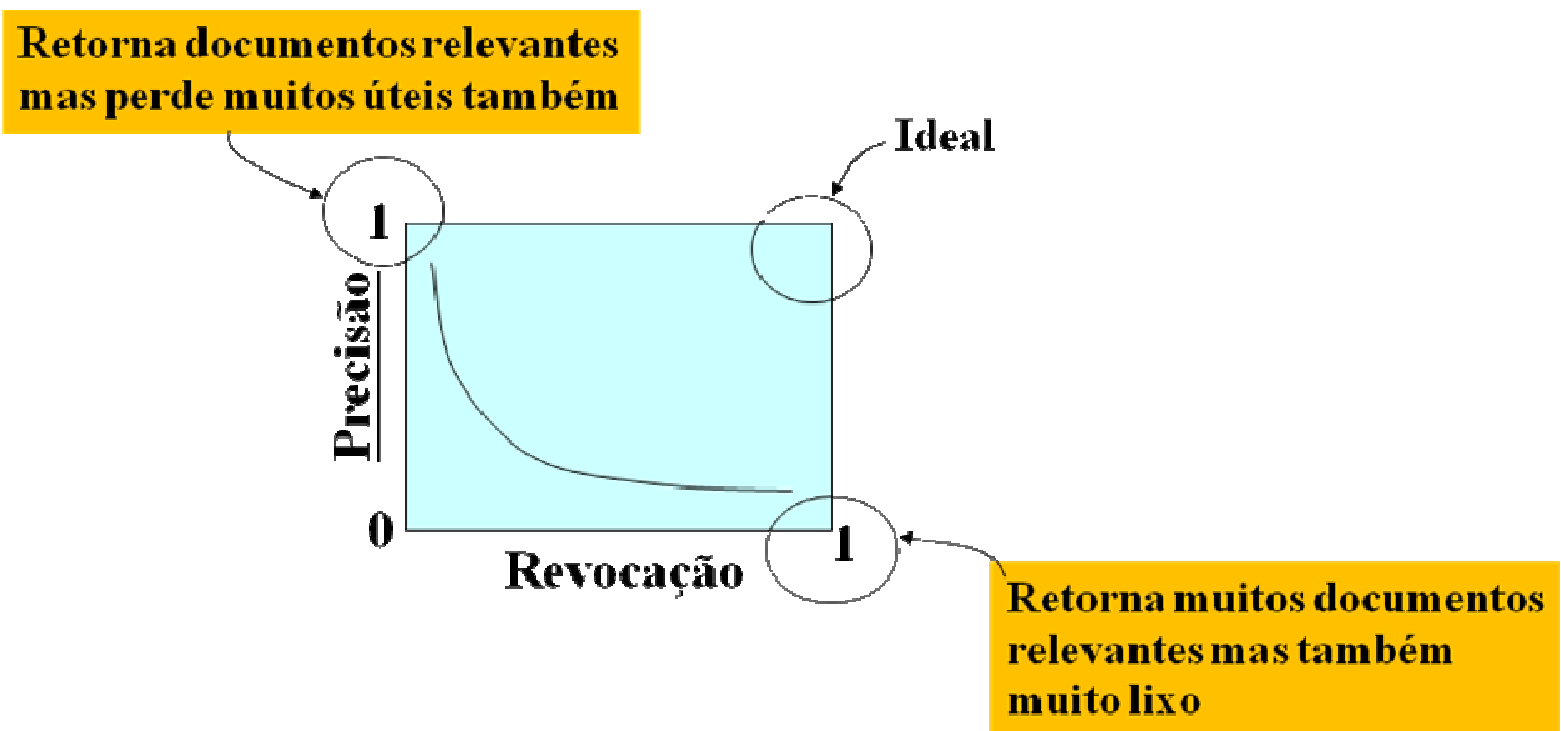

Figura 9: Relação da Precisão X Revocação em SRls (Steinmetz et al. 2013, p. 13).

Entre os pontos convergentes encontrados pelos autores, podemos destacar:

Tanto a Ciência da Informação, a Teoria da Relevância, a Arquitetura da Informação e também a Multimodalidade, possibilitam que o indivíduo, comum e também estudantes em ambientes de ensino aprendizagem, não caiam em uma zona de inibição cognitiva. Ou seja, permite que esse indivíduo obtenha uma interface interativa/multimodal de comunicação e cognição possibilitando uma aprendizagem significativa que resulta em competência informacional. Considerando que a competência Informacional possibilita que a pessoa deve ser capaz de reconhecer quando precisa de informação e possuir habilidade para localizar a informação relevante para a mesma, ter a capacidade de avaliar se essa informação é de fato relevante e assim tomar a decisão e/ou usar efetivamente a informação (Steinmetz et al. 2013, p. 14).

Steinmetz et al. (2013) apresentam uma base conceitual para uma Arquitetura da Informação Multimodal. Para isso, os autores identificam o estado da arte sobre os assuntos abordados no artigo e colocam algumas premissas que permitem estabelecer esta base conceitual relacionando à Arquitetura da Informação, a Multimodalidade, a Teoria da Relevância e as formas de representação e 
recuperação de informações. Nesse mesmo sentido, Steinmetz e Duque (2014) apresentam algumas contribuições da Arquitetura da Informação para ambientes colaborativos de ensino/aprendizagem, conforme o Quadro 8 apresentado a seguir:

Quadro 8: Resumo da Relação entre Arquitetura da Informação, a Multimodalidade, a Teoria da Relevância.

\begin{tabular}{|c|c|}
\hline Base conceitual & Pressuposto/Inferência \\
\hline $\begin{array}{l}\text { A Arquitetura da Informação tem } \\
\text { como objetivo gerar espaços } \\
\text { informacionais para atender as } \\
\text { necessidades de informação dos } \\
\text { usuários, enquanto a } \\
\text { Multimodalidade está associada ao } \\
\text { estudo dos meios utilizados que } \\
\text { levam a compreensão de uma } \\
\text { mensagem em um determinado } \\
\text { contexto. }\end{array}$ & $\begin{array}{l}\text { Partindo do pressuposto que um espaço de } \\
\text { informação pode ser multimodal, podemos } \\
\text { perceber que a Arquitetura da Informação e a } \\
\text { Multimodalidade são complementares no } \\
\text { objetivo de atender as necessidades } \\
\text { informacionais das pessoas. Onde, para a } \\
\text { Arquitetura da Informação este objetivo está } \\
\text { explicito e para a Multimodalidade isso acaba } \\
\text { sendo uma consequência da interação } \\
\text { multimodal entre o espaço de informação e o } \\
\text { usuário. Ainda, podemos inferir que a } \\
\text { multimodalidade pode influenciar no 'principio } \\
\text { da relevância melhorando o processo de } \\
\text { transmissão da informação. }\end{array}$ \\
\hline $\begin{array}{l}\text { A Arquitetura da Informação é } \\
\text { considerada interdisciplinar } \\
\text { agregando áreas como a usabilidade } \\
\text { e ergonomia. A multimodalidade } \\
\text { estuda os vários modos de } \\
\text { comunicação e/ou interação entre os } \\
\text { sujeitos e objetos. }\end{array}$ & $\begin{array}{l}\text { Considerando que a usabilidade e a ergonomia } \\
\text { podem influenciar a interação dos usuários } \\
\text { com os objetos informacionais, podemos inferir } \\
\text { que a Multimodalidade e a Arquitetura da } \\
\text { Informação tem objetivos de estudo } \\
\text { semelhantes. }\end{array}$ \\
\hline $\begin{array}{l}\text { A Multimodalidade e a Gramática } \\
\text { Visual buscam compreender e } \\
\text { prover múltiplas formas de } \\
\text { comunicação com o uso e a } \\
\text { organização de padrões visuais. A } \\
\text { Arquitetura da Informação busca }\end{array}$ & $\begin{array}{l}\text { Ao assumirmos que um padrão visual pode ser } \\
\text { um design, pode ser uma forma de } \\
\text { organização e representação de informações } \\
\text { utilizadas para estabelecer uma comunicação, } \\
\text { temos uma relação direta entre a } \\
\text { Multimodalidade/Gramática Visual com a }\end{array}$ \\
\hline
\end{tabular}




\begin{tabular}{|c|c|}
\hline $\begin{array}{l}\text { prover a organização, representação } \\
\text { e comunicação das informações. }\end{array}$ & $\begin{array}{l}\text { Arquitetura da Informação, pois nos dois casos } \\
\text { a organização do espaço informacional na } \\
\text { forma de uma representação que apóie a } \\
\text { comunicação é o principal objetivo. }\end{array}$ \\
\hline $\begin{array}{l}\text { A Arquitetura da Informação pode } \\
\text { ser vista como a integração entre } \\
\text { contexto, conteúdo e usuários, } \\
\text { enquanto a Multimodalidade busca } \\
\text { tratar da interpretação do significado } \\
\text { do contexto pelo sujeito. }\end{array}$ & $\begin{array}{l}\text { É possível deduzir que o estudo do contexto } \\
\text { em que o sujeito e a informação estão } \\
\text { inseridos são preocupações comuns tanto para } \\
\text { Multimodalidade quanto para Arquitetura da } \\
\text { Informação. }\end{array}$ \\
\hline $\begin{array}{l}\text { A Multimodalidade foca na análise } \\
\text { de significados, na interação entre } \\
\text { os indivíduos, envolvendo o produtor } \\
\text { e o observador da informação. Na } \\
\text { proposta da Teoria Geral da } \\
\text { Arquitetura da Informação, o } \\
\text { fenômeno da presença do } \\
\text { observador implica na mudança do } \\
\text { comportamento do objeto observado } \\
\text { determinando a diferença entre dado } \\
\text { e informação, sendo o conceito de } \\
\text { conhecimento resultado da } \\
\text { abstração que deriva da interação } \\
\text { entre o observador e o objeto } \\
\text { observado. }\end{array}$ & $\begin{array}{l}\text { Neste ponto, se considerarmos a interação } \\
\text { como um fenômeno, temos uma sobreposição } \\
\text { de conceitos aplicados no desenvolvimento } \\
\text { tanto da Multimodalidade como da Arquitetura } \\
\text { da Informação, que apontam para definições } \\
\text { semelhantes sob pontos de vista diferentes. } \\
\text { Pois, podemos perceber uma relação entre a } \\
\text { análise de significados na interação e a } \\
\text { definição de conhecimento proposta na TGAI. }\end{array}$ \\
\hline $\begin{array}{l}\text { Sendo um documento visto como o } \\
\text { registro da informação. } \\
\text { Considerando que todo texto é } \\
\text { multimodal e documentos } \\
\text { multimodais envolvem combinações } \\
\text { de informações que empregam } \\
\text { diferentes meios de apresentação. }\end{array}$ & $\begin{array}{l}\text { Podemos inferir que documentos textuais são } \\
\text { documentos multimodais e ainda, podemos } \\
\text { perceber que a organização visual destas } \\
\text { informações no documento pode ser } \\
\text { considerada uma Arquitetura da Informação e, } \\
\text { ainda, que esta organização pode influenciar } \\
\text { na relevância das informações para o usuário. }\end{array}$ \\
\hline
\end{tabular}




\begin{tabular}{|c|c|}
\hline $\begin{array}{l}\text { Considerando que a Teoria da } \\
\text { Relevância implica predisposição de } \\
\text { um indivíduo para determinado ato } \\
\text { comunicativo em precedência a } \\
\text { outro e que a Arquitetura da } \\
\text { Informação busca organizar os } \\
\text { espaços informacionais para atender } \\
\text { as necessidades dos usuários, } \\
\text { juntamente com a definição de } \\
\text { multimodalidade como o estudo os } \\
\text { vários modos de comunicação. }\end{array}$ & $\begin{array}{l}\text { Podemos inferir que um espaço informacional, } \\
\text { definido pela Arquitetura da Informação, pode } \\
\text { ser multimodal, bem como podemos utilizar a } \\
\text { multimodalidade para aumentar a relevância } \\
\text { das informações contidas neste espaço } \\
\text { informacional, melhorando o ato comunicativo } \\
\text { em questão e atendendo a necessidade de } \\
\text { informação do usuário de maneira mais } \\
\text { eficiente. }\end{array}$ \\
\hline
\end{tabular}

Fonte: Steinmetz e Duque (2014)

Steinmetz et al. (2013a) concluem identificando que é possível estabelecer um modelo para elaboração de uma Arquitetura de Informação Multimodal para Ambientes Informacionais Colaborativos de Ensino/Aprendizagem. Considerando que tanto a Ciência da Informação, a Arquitetura da Informação e a Multimodalidade podem contribuir na relevância do ambiente CSCL utilizado no processo de ensino/aprendizagem, melhorando assim o resultado deste processo.

Steinmetz e Duque (2014) explicam que o significado que a informação assume para cada individuo pode ser singular, ou seja, a abstração que cada indivíduo faz do ambiente CSCL pode ser singular, devido ao contexto onde este indivíduo está inserido. Por conseqüência a colaboração destes indivíduos nos ambiente CSCL depende desta abstração, pois é com base na definição de conhecimento de Lima-Marques, (2011) a abstração será um dos requisitos para formação do conhecimento. A Figura 10 explicita esta situação, conforme o fluxo da informação na comunicação de uma estudante com um Ambiente CSCL.

Ainda, analisando a Figura 10, podemos perceber que existe uma relação entre o fluxo da informação em um ambiente CSCL e a Teoria da Relevância, pois a segundo o princípio da relevância, existe uma predisposição de um indivíduo para determinado ato comunicativo em precedência a outro. Assim, um Ambiente CSCL pode influenciar o ato comunicativo positivamente se for suficientemente relevante aos seus usuários. 


\section{Fluxo da Informação em um Ambiente CSCL}

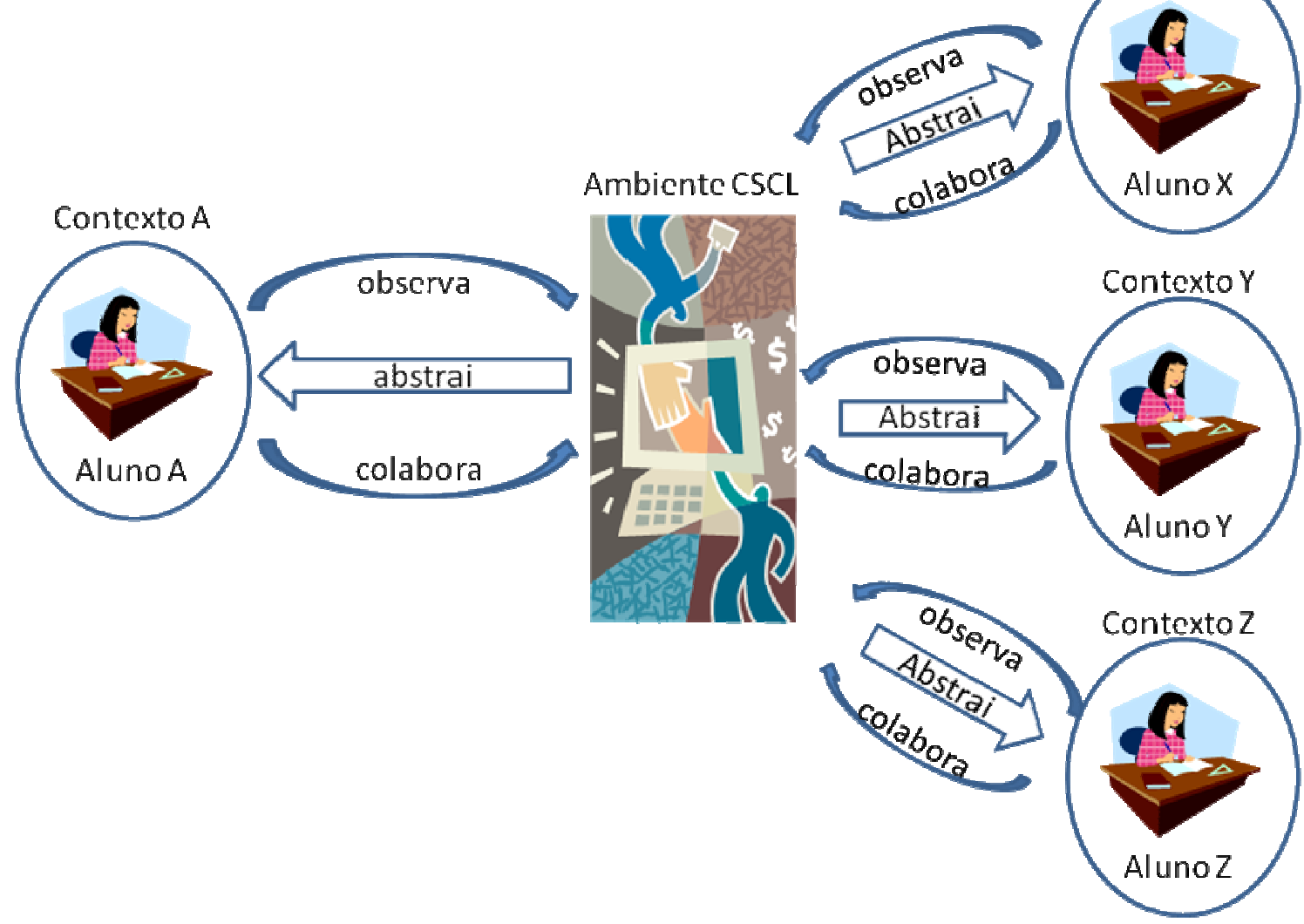

Figura 10: Fluxo da Informação em um Ambiente CSCL (STENMETZ e DUQUE, 2014).

Com o entendimento do Fluxo de Informações em um Ambiente CSLS podemos então partir para o estudo de um modelo para elaboração de uma Arquitetura de Informação Multimodal para Ambientes Informacionais Colaborativos de Ensino/Aprendizagem.

Neste sentido Rocha e Duarte (2013) explicam que a boa usabilidade de um sistema de informação está diretamente ligada a como este ambiente é concebido, sendo que esta concepção deve partir de uma perspectiva centrada no usuário (Design Centrado no Usuário), de forma a reconhecer e atender às suas necessidades, a partir de processos que nem sempre são os mesmos da engenharia de software. Para isso os autores sugerem a norma ISO/IEC 13407/1999, que busca definir o design centrado em humanos através de ciclos iterativos, conforme a Figura 11. 


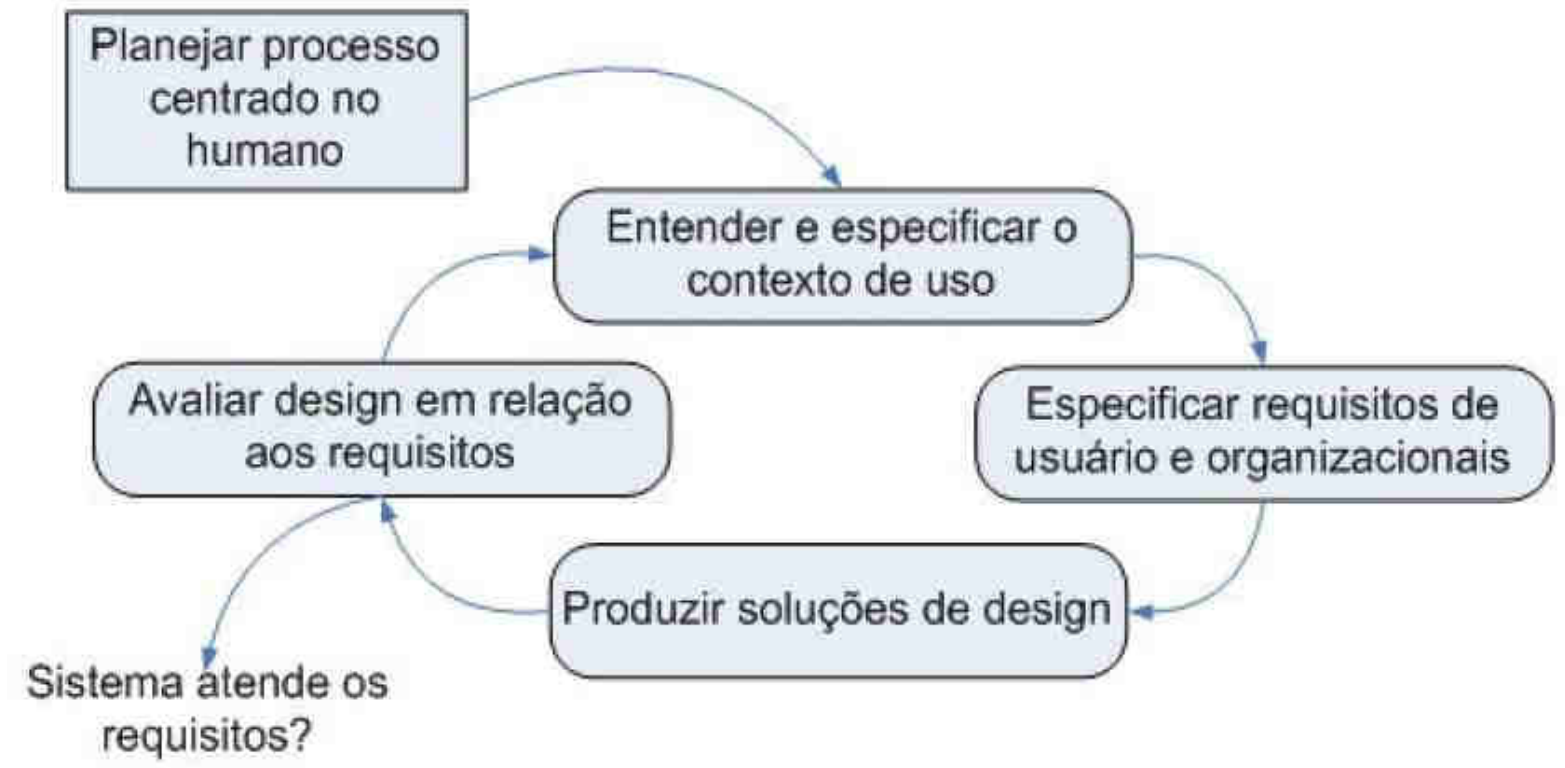

Figura 11: Design centrado no humano - (ISO/IEC 13407, 1999).

Ao observarmos a Figura 11 podemos perceber que o design centrado no humano é recursivo. Após o planejamento do processo, entende-se e especifica-se o contexto de uso, com isso os requisitos de usuário e organizacionais são especificados, produzindo-se uma solução de design que é avaliada com base nos requisitos. Se a solução de design atender aos requisitos, o processo é encerrado, mas se houver requisitos não atendidos, o ciclo é reiniciado.

\subsection{A BASE EPISTEMIOLÓGICA DA PROPOSTA}

Observando o exposto no tópico anterior, podemos perceber que:

1. Sob a ótica da Multimodalidade e da Teoria da Relevância, o contexto em que o sujeito está inserido influencia diretamente no seu interesse e na sua percepção do ambiente informacional que está sendo utilizado.

2. A qualidade da informação recuperada de um SRI está diretamente condicionada à relação entre Precisão e Revocação de um SRI conforme demonstrado na Figura 9 (p.57).

3. Existe uma clara relação teórica entre a Arquitetura da Informação, a Multimodalidade e a Teoria da Relevância conforme apresentado no Quadro 8 (p.58). 
4. A abstração que cada indivíduo faz do ambiente CSCL pode ser singular, devido ao contexto onde este indivíduo está inserido. Bem como a sua colaboração no ambiente CSCL depende desta abstração. Sendo este fluxo de informações requisito para formação do conhecimento e conseqüente sucesso do processo de ensino/aprendizagem, conforme Figura 10 (p. 61).

5. Atender às necessidades de informação do usuário depende da qualidade de usabilidade de um sistema de informação, que deve partir de uma perspectiva centrada no usuário (Design Centrado no Usuário), conforme podemos constatar na Figura 11 (p.62).

Com estas observações, começamos a responder o questionamento que norteia esta tese, descrito no item 1.1. Inicialmente, é fundamental entendermos que um ambiente CSCL é um sistema de informação computacional, pois sua definição o classifica de tal forma: "um ambiente de Aprendizagem Colaborativa Apoiada por Computador", conforme explicam Santoro et. al.(2004), Raposo et. al.(2004) e Steinmetz (2007). Assim, podemos buscar algumas respostas preliminares nos conceitos de Sistemas de Informação e na Engenharia de Software, observando a ressalva citada por Rocha e Duarte (2013) sobre a importância da usabilidade de um sistema de informação, que nem sempre são contemplados nos processos da engenharia de software.

No âmbito da Ciência da Informação e da Arquitetura da Informação, considerando as definições já apresentadas nos itens 2.1 e 2.2, para estes termos, podemos perceber que não existe uma clara definição única para os termos dado, informação e conhecimento na literatura. Ainda, ao observarmos os conceitos para estes termos apresentados pela TGS, teremos um novo conceito a ser agregado nesta discussão, a sabedoria.

Para tanto, podemos entender que a definição destes conceitos depende da área do conhecimento em que eles estão sendo aplicados. Por exemplo, qual seria a definição de informação no âmbito das Ciências Exatas e da Terra ${ }^{6}$ e nas suas subáreas (matemática, estatística, física, etc.)? Em contraponto, nas Ciências 
Biológicas $^{7}$ e suas subáreas (Biologia Geral, Genética, Botânica, etc.), como podemos definir esses conceitos?

Considerando que um ambiente $C S C L$ é um sistema de informação computacional, optamos em adotar as definições da TGS acerca de dado, informação, conhecimento e competência, onde temos o dado como um fato bruto; a informação consiste em dados organizados que possuem valor ao usuário desta informação; o conhecimento implica em estar ciente e ter o entendimento de um conjunto de informações para alcançar um determinado objetivo; a competência consiste no processo contínuo e articulado de formulação de novos conhecimentos, habilidades e atitudes a partir da interação com outras pessoas no ambiente colaborativo de ensino aprendizagem.

Assim, podemos inferir que a competência informacional dos estudantes é diretamente influenciada pelo resultado das interações e trocas de informações mediadas pelo ambiente CSCL. Sendo a Arquitetura da Informação, aplicada neste ambiente, de fundamental importância para permitir o fluxo eficiente das informações conforme vimos na Figura 10.

A Arquitetura da Informação deve permitir que o ambiente contemple os conceitos aplicados aos SRIs, como a precisão: que consiste em retornar documentos com alto grau de relevância para os parâmetros consultados. E a revocação: que consiste em retornar a maior quantidade de documentos referentes os parâmetros consultados. Atendendo às necessidades informacionais dos estudantes tanto no momento da recuperação da informação quando no momento de compartilhar suas opiniões e conhecimentos derivados das interações inerentes ao processo de ensino aprendizado.

Com isso podemos identificar um conjunto inicial de características básicas que devem ser contempladas em uma ambiente CSCL, que contemple uma Arquitetura da Informação multimodal segundo os preceitos da multimodalidade e da teoria da relevância:

7 Disponível em: http://www.memoria.cnpq.br/areasconhecimento/2.htm 
1. O ambiente deve ser concebido/adaptado ao contexto dos estudantes/usuários.

2. O ambiente deve oferecer vários modos comunicacionais, conforme prevê a definição do termo multimodalidade.

3. O ambiente deve considerar a usabilidade e a ergonomia a fim de influenciar positivamente a interação dos usuários.

4. O ambiente deve apresentar uma Arquitetura da Informação que permita a inclusão, organização e recuperação das informações de forma simples e eficiente.

5. Em complemento aos itens 3 e 4 o ambiente deve oferecer um Design centrado no humano.

\subsection{PROPOSTA PRELIMINAR DO MODELO DE ARQUITETURA DA INFORMAÇÃO MULTIMODAL PARA AMBIENTES CSCL}

Como ponto de partida, para definição da proposta preliminar de uma Arquitetura da Informação Multimodal para Ambientes CSCL, utilizaremos o Modelo de Arquitetura da Informação proposto por Lima-Marques e Macedo (2006) onde a informação depende do comportamento dos usuários que farão uso dela e determinarão as suas necessidades, apresentado no item 2.2.1 desta pesquisa.

Juntamente com as características iniciais definidas no item anterior, surge 0 desafio de sistematizar tais elementos em um sistema, conforme propõe a TGS, para isso é preciso observar, ainda, que um determinado curso pode ser executado uma ou várias vezes e que seu planejamento pedagógico prévio deve contemplar um plano de curso com seus componentes e conteúdos.

A execução de um curso em um ambiente CSCL implica na utilização de um sistema de informação. Assim, busca-se na Engenharia de Software o conceito de Ciclo de Vida do Desenvolvimento de Sistemas (SDLC - Systems Development Life Cycle). Sommerville (2003) e Pressman (2006) observam que o SDLC também é conhecido como o "modelo de processo de software" refere-se aos estágios de concepção, projeto, criação, implementação e manutenção de um Sistema de Informação. 
Pressman (2006) explica que não existe um único modelo de processo de software universalmente aceito, mas 0 autor indica três grandes fases deste processo conforme Figura 12:

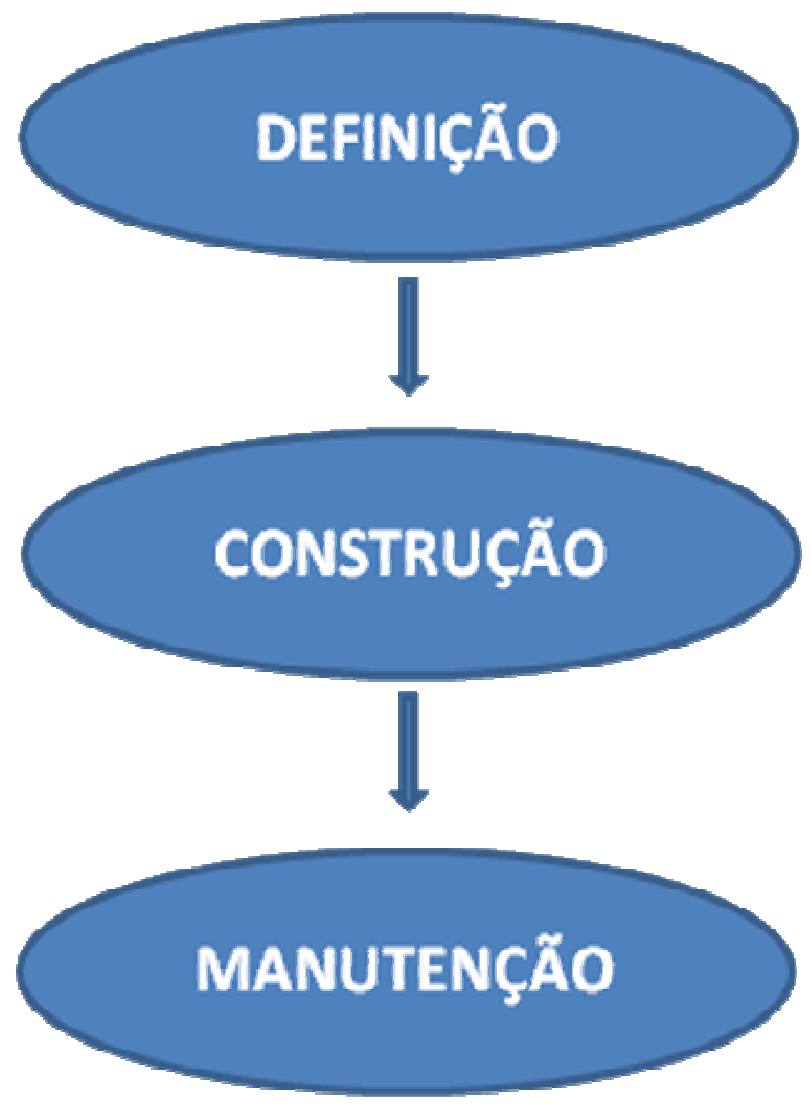

Figura 12: Principais fases dos modelos de processo de software - (Pressman, 2011).

Sendo a Definição a fase onde as necessidades dos usuários são identificadas e uma solução lógica do sistema é elaborada, na Construção esta solução lógica é implementada e testada criando-se uma sistema de informação pronto para ser utilizado, ficando a fase da manutenção como a etapa onde ocorrem ajustes e alterações do software para corrigir algum defeito ou atender alguma nova necessidade dos usuários. Pressman (2006) explica ainda que o software pode se tornar obsoleto e ser descontinuado, ou seja, "morto".

Nesta mesma linha, Gordon e Gordon (2006) explicam que não há modelo de $S D L C$ uniformemente aceito e apresentam um modelo mais detalhado (Figura 13), aplicando esses conceitos da engenharia de software sob a ótica da gerencia dos sistemas de informação. 


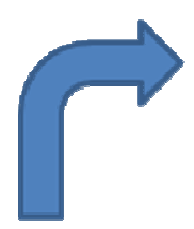

MANUTENÇÃOO
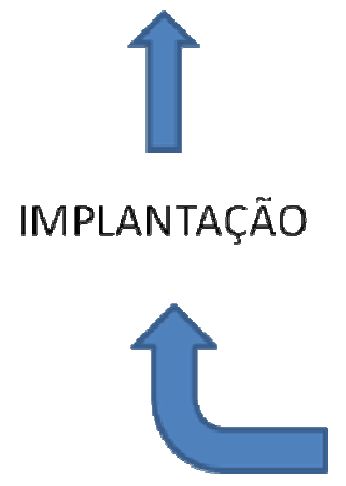

LEVANTAMENTO

DAS NECESSIDADES

\section{DESENVOLVIMENTO}

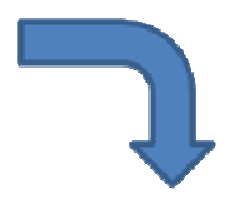

ANÁLISE DE

ALTERNATIVAS

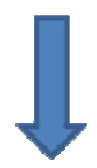

PROJETO

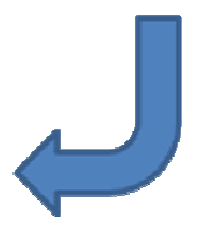

Figura 13: Modelo de Ciclo de Vida do Desenvolvimento de Sistemas (GORDON e GORDON , 2006)

Na Figura 13, o levantamento das necessidades também chamado de análise de requisitos, identifica as necessidades de informações. A análise de alternativas consiste na identificação e avaliação de sistemas alternativos. O projeto trata da construção das especificações detalhadas para o projeto selecionado.

Essas especificações incluem o projeto das interfaces, banco de dados, características físicas do sistema, tais como número, tipos e localizações das estações de trabalho, hardware de processamento, o cabeamento e os dispositivos de rede. Deve especificar os procedimentos para testar o sistema completo antes da instalação.

No Desenvolvimento ocorre a codificação ou aquisição do software, a aquisição do hardware e o teste do novo sistema. A implantação ocorre após o sistema ter passado satisfatoriamente por testes de aceitação. O sistema é transferido do ambiente de desenvolvimento para o ambiente real de uso. A manutenção refere-se a todas as atividades relacionadas a um sistema depois que ele é implementado. Deve incluir atividades tais como a correção de software que não funcione 
corretamente, a adição de novos recursos aos sistemas em resposta às novas demandas dos usuários.

Percebe-se na proposta de Gordon e Gordon (2006) um modelo de processo cíclico com retro alimentação onde, após a etapa de manutenção, inicia-se uma nova etapa de levantamento das necessidades dando início a uma nova execução do processo, aderente com a Teoria Geral de Sistemas - TGS.

Considerando o Modelo de Ciclo de Vida do Desenvolvimento de Sistemas proposto por Gordon e Gordon (2006), podemos propor um diagrama (Figura 14) que apresenta um conjunto de fases a serem executadas para acomodar o conjunto de características básicas de uma Arquitetura da Informação multimodal para ambientes CSCL, apresentado no item 2.2.1.

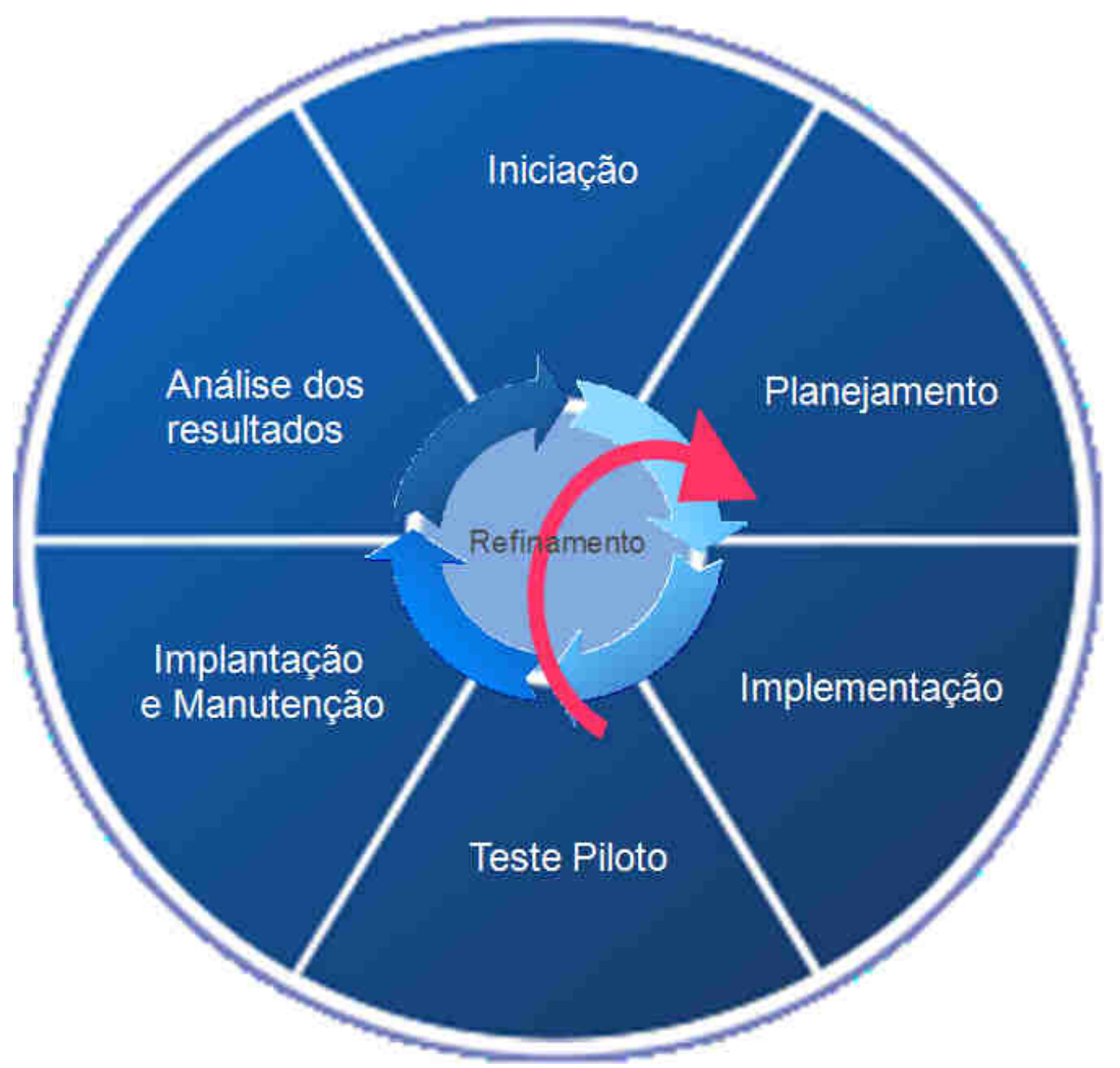

Figura 14: Diagrama de fases para concepção de uma Arquitetura da Informação Multimodal para ambientes CSCL - DAIM:CSCL 
Na Figura 14 que apresenta o DAIM:CSCL, temos as seguintes fases:

- Iniciação: corresponde à fase da identificação da demanda, identificação do público alvo, identificação do contexto do público alvo, definição da equipe responsável pelo processo, levantamento inicial das necessidades, definição dos objetivos gerais a serem alcançados.

- Planejamento: trata da construção das especificações detalhadas para que os objetivos sejam alcançados. Tais como: projeto das interfaces que deve considerar recursos multimodais identificados segundo o contexto dos usuários; o projeto de banco de dados que devem atender os conceitos de precisão e revocação dos SRIs; o projeto transacional que deve comportar as solicitações postadas na interface retornando os resultados do banco de dados; e as características físicas do sistema. Sendo o conjunto das interfaces, banco de dados e transações os elementos que definem a Arquitetura da Informação Multimodal. Ainda, podemos considerar a possibilidade de aquisição de hardware e softwares necessários para viabilizar a execução do processo. Finalmente, devem ser preparados os testes do sistema.

- Implementação: consiste no desenvolvimento do ambiente segundo as especificações definidas na fase de planejamento, ocorre a codificação ou aquisição do software, a aquisição do hardware e o teste do novo sistema.

- Teste Piloto: esta fase ajuda a aprimorar o novo ambiente considerando que o trabalho já foi conceituado e planejado nas fases anteriores. Consiste em submeter o ambiente a um teste real com variáveis controladas, buscando o refinamento da Arquitetura da Informação Multimodal, já desenvolvida, com base nos preceitos do Design Centrado no Humano conforme apresentado na Figura 11. Neste momento o ambiente CSCL deve ser alimentado com as informações referentes ao curso a ser ministrado, sendo importante que estes conteúdos estejam adequados ao contexto dos usuários e aos modos comunicativos definidos nas etapas de iniciação e planejamento. 
- Implantação e Manutenção: Consiste na utilização do ambiente em larga escala, sendo efetuadas as manutenções corretivas e adaptativas pertinentes, bem como do registro histórico destas manutenções, dos índices de satisfação dos usuários e sugestões de melhorias.

- Analise dos Resultados: esta fase completa o ciclo de aprimoramento do processo buscando revisar os relatórios do que foi executado, se o esforço alcançou os objetivos pretendidos inicialmente e como podemos implementar futuras mudanças de forma a melhorar a qualidade, eficiência e eficácia, aprimorando a execução e corrigindo eventuais falhas. Esta fase pode ser vista também como uma fase de aprendizado para a equipe que executa o processo, sendo importante que os registros sejam mantidos através de todo o ciclo do processo.

Fazendo uma interseção entre o Diagrama de fases para concepção de uma Arquitetura da Informação Multimodal para ambientes CSCL - DAIM:CSCL (Figura 14), com o modelo de Modelo de Arquitetura da Informação (Figura 3) proposto por Lima-Marques e Macedo (2006).

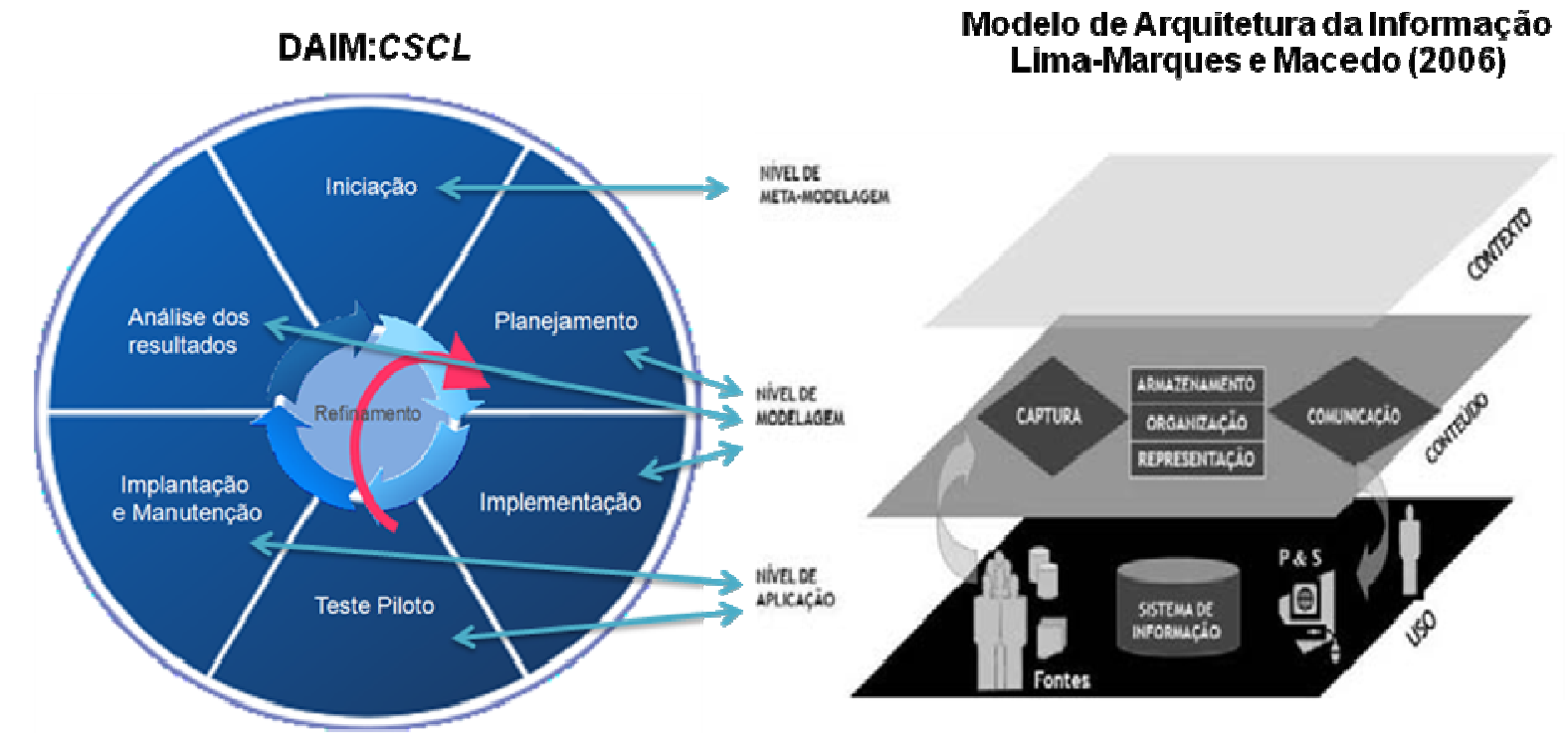

Modelo de Arquitetura da Informação Lima-Marques e Macedo (2006)

Figura 15: Interseção entre o DAIM:CSCL e o Modelo de Arquitetura da Informação

Observando a interseção entre DAIM:CSCL e o Modelo de Arquitetura da Informação, conforme Figura 15, podemos perceber que na fase de iniciação temos uma relação direta com o nível de Meta-modelagem, quando são identificadas, as necessidades, a demanda, o contexto e o público alvo. As fases de planejamento e 
implementação se relacionam com o nível de Modelagem, onde o ambiente é planejado e construído considerando os elementos que definem a Arquitetura da Informação Multimodal. As fases de Teste Piloto, de Implantação e Manutenção correspondem ao nível de Aplicação, que consiste na utilização do ambiente e todas as atividades relacionadas ao registro do histórico dessa utilização. A fase de Análise dos resultados remete novamente a fase ao nível de Modelagem, pois com base nos registros históricos de utilização do ambiente, poderá serem gerados propostas de melhoria para o ambiente a serem aplicadas nos novos ciclos do DAIM:CSCL.

\subsection{DEFINIÇÃO DO GRUPO FOCAL}

A Definição do grupo focal partiu do Quadro 7: Limitações de Grupos Focais e Medidas Mitigadoras proposto por Lyra (2012), apresentado na página 53. Onde o pesquisador indica ações para serem tomadas a fim de mitigar as limitações do uso do grupo focal como forma de validação da Arquitetura da Informação multimodais proposta no item anterior.

Kitzinger (2000) explica que o número de participantes nos grupos focais, encontrados na literatura, apresenta uma variação entre seis a quinze membros. $O$ tamanho ótimo para um grupo focal é aquele que permita a participação efetiva dos participantes e a discussão adequada dos temas. O mesmo autor, explica ainda que, observada a quantidade de participantes, o perfil e a qualificação dos membros do grupo focal é o principal elemento de qualidade dos dados derivados da utilização dessa prática.

Silva (2001) explica que o universo de uma pesquisa é composto por todos os elementos que compartilham um conjunto de particularidades de interesse para a investigação. Nesse contexto a composição do grupo focal levou em consideração dois perfis ideais aos seus membros, são eles:

- Ser profissional ou pesquisador da área de educação com experiência na utilização de ambientes CSCL.

- Ser profissional ou pesquisador da área de Arquitetura da Informação. 
Com estes dois perfis básicos definidos, a composição do grupo focal levou em consideração a localização geográfica do pesquisador e o potencial da cidade de Brasília/DF quanto aos possíveis candidatos a membro do grupo focal. A cidade conta com vários profissionais atuando em instituições privadas e públicas de ensino, distrital ou federal. Bem como, pesquisadores da área de educação e Arquitetura da Informação, vinculados principalmente, a grupos de pesquisa nos departamentos de Letras e Ciência da Informação da Universidade de Brasília UnB.

O convite aos possíveis membros do grupo focal foi enviado por e-mail, conforme descrito no Apêndice A desta tese, três semanas antes da data prevista para a realização da reunião contendo a data, local e horário da reunião e um breve roteiro das atividades a serem desenvolvidas, segundo sugere Lyra (2012):

Roteiro da reunião do Grupo Focal: O grupo será formado por até 10 especialistas, um mediador e um redator. Primeiramente o mediador solicitará que cada participante se apresente. Após, esclarecerá o objetivo da pesquisa. O mediador, então, apresentará uma questão para os participantes sobre o tema da pesquisa. Os participantes discutirão livremente a questão e cada um colocará seu ponto de vista. Essas observações serão todas registradas pelo mediador e farão parte da sua pesquisa. O processo é repetido para cada questão e, no final, o mediador fará o encerramento da sessão, toda a reunião será gravada para posterior análise por parte do pesquisador (LYRA, 2012, p.131).

Dos possíveis membros convidados, dez responderam confirmando a presença. Considerando os perfis definidos para o grupo focal, o pesquisador solicitou previamente aos participantes uma breve descrição das suas atuações como profissionais ou pesquisadores da área de educação, com experiência na utilização de ambientes CSLC e/ou das atuações como profissionais ou pesquisadores da área de Arquitetura da Informação. Esta estratégia de seleção dos especialistas possibilitou qualidade na coleta das impressões, pois o pesquisador pode avaliar se os candidatos correspondiam aos perfis exigidos para o grupo focal. As qualificações dos participantes estão descritas conforme segue: 
- Participante 1: Bacharel em Administração com habilitação em Sistema de Informação pela União Educacional de Brasília/UNEB. PósGraduação em Especialização em Tecnologia de Redes de Computadores com certificação CISCO pela União Educacional de Brasília/UNEB, Especialização Gestão em EaD - IFPR (em andamento). Técnica em Arquivo na função de Técnica em Arquivo. Graduanda em Arquivologia na UNB. Possui experiência em docência e coordenação de cursos no Ensino Superior. Professora conteudista em AVA nos cursos tecnólogos de Administração de Empresa e Gestão de Serviços Públicos. Atua como tutora em EaD em cursos do eixo superior e técnico profissionalizante. É professora conteudista no Programa Profuncionário vinculada ao sistema Rede e-Tec Brasil visando a oferta de educação profissional e tecnológica a distância. É pesquisadora no Programa de Iniciação Científica da Faculdade de Ciência da Informação (ProlC/FCl/UNB) no Projeto de Pesquisa "Documentos Audiovisuais, Informação e Memória: identificação de acervos fotográficos e fílmicos no Distrito Federal" financiado pelo CNPq.

- Participante 2: Doutorando em Ciência da Informação (UnB); Mestrado em Administração pela Universidade de Brasília, possui graduação em Administração pela Centro Universitário do Distrito Federal e em Direito pela Universidade Paulista. É especialista em Administração de Recursos Humanos pela Escola Brasileira de Administração Pública/Fundação Getúlio Vargas e Metodologia do Ensino Superior, pela União Educacional de Brasília, em Planejamento e Administração de Recursos de Defesa pela National Defense University em Washington; em Gestão Estratégica da Informação pela Funiversa/Universidade Católica de Brasília; em Direito Penal e Processual Penal pela Faculdade Processus e Direito Público pela Universidade Castelo Branco; Gestão do Conhecimento pelo Turkish General Staff Partnership for Peace Training Center em Ankara Turquia. Tem experiência acadêmica presencial e no Ensino à Distância (EaD) nas áreas de Administração e Direito com ênfase em Gestão de Projetos, Gestão de Processos, Planejamento, Comportamento 
Organizacional. Membro do Grupo de Pesquisa em Arquitetura da Informação, Linguística Computacional e Multimodalidade, Mídias e Interatividade (PPGCInf/FCI/UnB) - CNPq.

- Participante 3: Mestre em Ciência da Informação, pela Faculdade de Ciência da Informação da Universidade de Brasília (UnB); Mestrando em Ciência da Educação, pela Universidad Americana, de Assuncion, Paraguay (em fase de Defesa de Dissertação); Professor dos Cursos de Bacharel em Administração, nas disciplinas de Tecnologia da Informação e Planejamento Estratégico; do Curso de Gestão Pública, lecionando na disciplina de Ciências Políticas e Teoria Geral do Estado e no curso de Tecnologia da Informação, lecionando via EaD a disciplina Informática e Sociedade, na Faculdade Fortium, Brasília - DF. Possui experiência em Tecnologia da Informação, em Ciência da Informação. Membro do Grupo de Pesquisa em Arquitetura da Informação, Linguística Computacional e Multimodalidade, Mídias e Interatividade (PPGCInf/FCI/UnB) - CNPq.

- Participante 4: Doutorando em Ciência da Informação (UnB); Mestre em Gestão do Conhecimento e da Tecnologia da Informação pela UCB, Especialista em Governança de TI pela UNB, Especialista em Engenharia de Software pela UCB e graduação em Tecnólogo em Processamento de Dados pela UCB. Professor de graduação nas áreas de análise de sistemas e modelagem de dados. Professor de pósgraduação nas áreas de Gerenciamento de Projetos, BSC voltado para $\mathrm{TI}$ e Engenharia de Software com experiência em EaD. Membro do Grupo de Pesquisa em Arquitetura da Informação, Linguística Computacional e Multimodalidade, Mídias e Interatividade (PPGCInf/FCI/UnB) - CNPq.

- Participante 5: Possui graduação em Engenharia Elétrica pela Universidade de Brasília, Especialização em Tecnologia de Redes de Computadores pela União Educacional de Brasília e mestrado em Engenharia Elétrica pela Universidade de Brasília. Atualmente é professor do Instituto Federal de Brasília (IFB), onde atua nos cursos Técnicos em Informática ministrando componentes de ensino na 
modalidade presencial e também à distância. Possui experiência como professor e coordenador do pólo de EaD do Campus Brasília.

- Participante 6: Graduado em Engenharia de Redes de Comunicação pela UnB e mestre em Engenharia Elétrica também pela UnB. Tem experiência nas áreas de Redes de Comunicação, Desenvolvimento de Sistemas e Docência nas áreas de Informática, Redes e Engenharia Elétrica. Atuou como professor substituto na Universidade de Brasília. Atualmente é professor de Ensino Básico, Técnico e Tecnológico do Instituto Federal de Brasília. Tem experiência no uso de ambiente virtual de aprendizagem como suporte para o ensino presencial desde 2006. A partir de 2010, gerenciou a plataforma moodle disponível para os professores do ensino presencial do Instituto Federal de Brasília. Foi parte da equipe de tecnologia do Núcleo de Ensino a Distância do IFB onde foi coordenador adjunto de TI responsável pela configuração e gerenciamento do ambiente CSCL utilizado na instituição. Participou da elaboração de planos de curso na área de informática para a modalidade EaD.

- Participante 7: Possui graduação em Tecnologia em Sistemas de Informação pelo Centro Federal de Educação Tecnológica de Goiás, Especialização Gestão em EaD - IFPR (em andamento) e Mestrado em Engenharia Elétrica pela Universidade Federal de Uberlândia. Atualmente é docente em informática: análise e desenvolvimento de sistemas do Instituto Federal de Brasília, onde atua nas modalidades de ensino presencial e em EaD. Foi parte da equipe que criou e estruturou o Núcleo de Ensino a Distância do Instituto Federal de Brasília.

- Participante 8: Bacharel em Sistemas de Informação pelo Centro Universitário Luterano de Palmas. Especialista em Educação - Técnica de Nível Médio Integrado a Modalidade de Educação de Jovens e Adultos pelo CEFETPA. Mestre em Educação pela UnB na Área de Concentração: Políticas Públicas e Gestão da Educação com foco na Formação de Professores da Educação Profissional e Tecnológica. É docente no Instituto Federal de Brasília onde possui experiência em diversos cargos de gestão na Área de Ensino e atua nas modalidades 
de ensino presencial e em EaD. É professora conteudísta de material de Informática para cursos Técnicos da rede E-Tec Brasil.

- Participante 9: Graduada em pedagogia pela Universidade de Brasilia, Especialista em Educação pela UnB e está cursando Especialização Gestão em EaD - IFPR (em andamento). Possui experiência em docência na Área de Ensino Instituto Federal de Brasília, onde atua nas modalidades de ensino presencial e em EaD. Participou, como pedagoga, da elaboração de planos de curso para a modalidade EaD em várias áreas do conhecimento é membro do Núcleo de Ensino a Distância do Instituto Federal de Brasília, desde a sua criação. Atualmente é coordenadora adjunta de tutoria.

- Participante 10: Doutorando em Ciência da Informação na Universidade de Brasília; Mestre em Ciência da Informação pela Universidade de Brasília; Especialização em Análise e Projeto de Sistemas de Informação pela Universidade Federal de Goiás e graduação em Tecnologia de Processamento de Dados pela Sociedade Objetivo de Ensino Superior. Tem experiência como professor em Instituições Privadas de Ensino Superior atuando nas modalidades presencial e EaD. Tem experiência na área de Ciência da Computação, com ênfase em Sistemas de Informação, atuando principalmente nos seguintes temas: engenharia de software, sistema de informação, ontologias e Web Semântica. Membro do Grupo de Pesquisa em Arquitetura da Informação, Linguística Computacional e Multimodalidade, Mídias e Interatividade (PPGCInf/FCl/UnB) - CNPq.

Como resultado da análise das qualificações e experiências dos possíveis membros do grupo focal, foi sintetizado no Quadro 9 conforme segue: 
Quadro 9: Relação dos especialistas candidatos com os perfis definidos para participação no grupo focal.

\begin{tabular}{|l|c|c|}
\hline & $\begin{array}{l}\text { Perfil 1: Ser profissional ou } \\
\text { pesquisador da área de de } \\
\text { educação com experiência na } \\
\text { utilização de ambientes CSLC }\end{array}$ & $\begin{array}{l}\text { Perfil 2: Ser profissional ou } \\
\text { pesquisador da área de } \\
\text { Arquitetura da Informação }\end{array}$ \\
\hline Participante 1 & $\mathrm{X}$ & $\mathrm{X}$ \\
\hline Participante 2 & $\mathrm{X}$ & $\mathrm{X}$ \\
\hline Participante 3 & $\mathrm{X}$ & $\mathrm{X}$ \\
\hline Participante 4 & $\mathrm{X}$ & \\
\hline Participante 5 & $\mathrm{X}$ & \\
\hline Participante 6 & $\mathrm{X}$ & \\
\hline Participante 7 & $\mathrm{X}$ & $\mathrm{X}$ \\
\hline Participante 8 & $\mathrm{X}$ & \\
\hline Participante 9 & $\mathrm{X}$ & \\
\hline Participante 10 & $\mathrm{X}$ & \\
\hline
\end{tabular}

Fonte: o autor

Considerando que a regra para participação no grupo focal era que o especialista estivesse enquadrado em pelo menos um dos perfis, o Quadro 9 demonstra que todos os candidatos correspondem ao perfil $1 \mathrm{e}$, ainda em complemento, cinco membros atendem ao perfil 2 . Isso demonstra a homogeneidade do grupo em relação ao perfil 1 , em contra ponto a heterogeneidade em relação ao perfil 2 .

Outro ponto importante a ser observado nos especialistas é a formação acadêmica. O Quadro 10 demonstra que o grupo possui titulação compatível com as necessidades da pesquisa.

Quadro 10: Formação Acadêmica dos membros dos especialistas do grupo focal.

\begin{tabular}{|l|c|c|}
\hline & Titulação & $\begin{array}{c}\text { Área do Conhecimento } \\
\text { Tecnologia da Informação e } \\
\text { Ciência da Informação }\end{array}$ \\
\hline Participante 1 & Especialista & Ciência da Informação \\
\hline Participante 2 & Doutorando & $\begin{array}{c}\text { Ciência da Informação e } \\
\text { Educação }\end{array}$ \\
\hline Participante 3 & Mestre & Ciência da Informação \\
\hline Participante 4 & Doutorando & \\
\hline
\end{tabular}




\begin{tabular}{|l|c|c|}
\hline Participante 5 & Mestre & Tecnologia da Informação \\
\hline Participante 6 & Mestre & Tecnologia da Informação \\
\hline Participante 7 & Mestre & $\begin{array}{c}\text { Tecnologia da Informação e } \\
\text { Educação }\end{array}$ \\
\hline Participante 8 & Mestre & $\begin{array}{c}\text { Tecnologia da Informação e } \\
\text { Educação }\end{array}$ \\
\hline Participante 9 & Especialista & Educação \\
\hline Participante 10 & Doutorando & Ciência da Informação \\
\hline
\end{tabular}

Fonte: o autor

\subsubsection{Procedimentos metodológicos de aplicação do grupo focal}

Trad (2009), explica que o sucesso da utilização de grupo focal, aplicado nas ciências sociais, tem como um dos seus pontos importantes o seu planejamento e execução considerando o perfil dos seus integrantes. Nesse tópico são descritos os procedimentos metodológicos utilizados na preparação, na aplicação e na coleta de dados.

Dos possíveis membros convidados para compor o grupo focal, dez responderam confirmando a presença e todos compareceram a reunião do grupo focal que foi realizada no Instituto Federal de Brasília, sala 110, bloco A. SGAN 610, Módulos D, E, F e G, Brasília/DF, CEP 70830-450 - Asa Norte Brasília DF, no dia 19/10/2015, segunda-feira das $19 \mathrm{~h}$ às 20h30. Aos participantes que responderam confirmando a participação no grupo focal foi enviado um texto introdutório explicando os objetivos da pesquisa e a metodologia do grupo focal conforme Apêndice B desta tese.

Lyra (2012) utiliza um percurso metodológico para realização de grupos focais no âmbito da Arquitetura da Informação. O autor executou as seguintes etapas:

1. Elaboração do roteiro para orientação do pesquisador na condução do grupo focal.

2. Elaboração das questões de discussão do grupo focal, considerando os objetivos gerais da pesquisa. 
3. Definição do local da pesquisa da realização do grupo focal.

4. Formação do grupo focal e aplicação da técnica, descrevendo os passos da realização do encontro.

5. Processamento e avaliação dos resultados.

\section{Elaboração do roteiro}

O roteiro da pesquisa têm como objetivo servir como linha mestre para a condução das discussões do grupo focal. Assim, após a definição dos membros do grupo focal foi encaminhado um e-mail com um texto resumo sobre a pesquisa e foi elaborado um questionário para incentivar e orientar a discussão dos membros do grupo focal, utilizado como norte na condução da técnica, orientando a discussão a partir do tema principal até a abordagem de assuntos mais específicos, possibilitando o encadeamento de idéias do todo ao particular.

\section{Princípios gerais considerados na elaboração do roteiro e das questões}

A sequência das questões foi realizada para identificar a percepção dos membros do grupo focal sobre o Diagrama de fases para concepção de uma Arquitetura da Informação Multimodal para ambientes CSCL - DAIM:CSCL e suas fases. Para determinar a quantidade de questões a serem abordadas, levou-se em consideração o tempo estimado do grupo focal (em torno de 1h30).

\section{Local da pesquisa}

Instituto Federal de Brasília, sala 110, bloco A. SGAN 610, Módulos D, E, F e G, Brasília/DF, CEP 70830-450 - Asa Norte Brasília DF, no dia 19/10/2015, segundafeira das $19 \mathrm{~h}$ às $20 \mathrm{~h} 30$.

\section{Formação e aplicação do grupo focal e aplicação da técnica}

Os seguintes passos foram seguidos para a realização da pesquisa:

$\checkmark$ Passo 1: Definição dos membros e do local do grupo focal. 
$\checkmark$ Passo 2: Envio do e-mail com orientações sobre a execução do grupo focal, texto resumo sobre a pesquisa e do questionário para incentivar e orientar a discussão (APÊNDICE A, B e C)

$\checkmark$ Passo 3: Recepção dos participantes ao local indicado para a reunião;

$\checkmark$ Passo 4: Breve fala introdutória do pesquisador explicando os objetivos gerais da pesquisa, as condições de gravação da reunião e os aspectos éticos envolvidos nas discussões. (10 minutos);

$\checkmark$ Passo 5: Apresentação e esclarecimento aos participantes sobre o objeto de pesquisa, sobre o objetivo do grupo focal e sobre como as informações serão analisadas após a coleta;

$\checkmark$ Passo 6: Apresentação da proposta preliminar (APÊNDICE D).

$\checkmark$ Passo 7: Início do debate pelo pesquisador, conforme as questões propostas no roteiro.

$\checkmark$ Passo 8: Após 1h30, a discussão foi encerrada, o mediador agradeceu a todos pela participação e enfatizou o valor das opiniões geradas na reunião, acrescentando ainda que os resultados da pesquisa seriam enviados para posterior validação. Além disso, todos seriam informados sobre o resultado final da pesquisa.

\section{Processamento e avaliação dos resultados}

Nesta etapa foi realizada a organização documental da pesquisa, transcrição dos principais pontos abordados no grupo focal, seleção e processamento das informações mais relevantes. Com essas informações e contribuições coletadas durante a aplicação do grupo focal, foi elaborada a proposta final. 


\section{RESULTADOS E DISCUSSÕES}

Neste tópico são apresentados os resultados da reunião do grupo focal, bem como o detalhamento da sua condução por parte do pesquisador. Com base nesses resultados foi elaborada uma nova proposta para o DAIM:CSCL, contemplando algumas das contribuições dos participantes do grupo focal.

\subsection{REALIZAÇÃO DA REUNIÃO DO GRUPO FOCAL}

Conforme o roteiro definido e os passos da aplicação da técnica do grupo focal, a reunião começou no horário previsto com a presença de nove dos membros que haviam confirmado participação no grupo focal. Quando o pesquisador iniciou a recepção dos participantes ao local indicado para a reunião com um conversa informal solicitando que todos se acomodassem na sala, de forma que ficassem confortáveis. Após alguns minutos, chegou o décimo participante que também tomou seu lugar.

A reunião foi realizada na sala 110 do bloco $A$ do Campus Brasília-IFB, uma sala de aula/vídeo que contava com uma mesa um projetor multimídia ligado a um computador, quadro branco, pincel e apagador. No fundo da sala foi posicionada uma filmadora digital para registrar a reunião e posterior análise das contribuições. As cadeiras foram dispostas em formato de " $U$ " para facilitar a interação entre os participantes do grupo focal, conforme pode ser visto na Figura 16. 


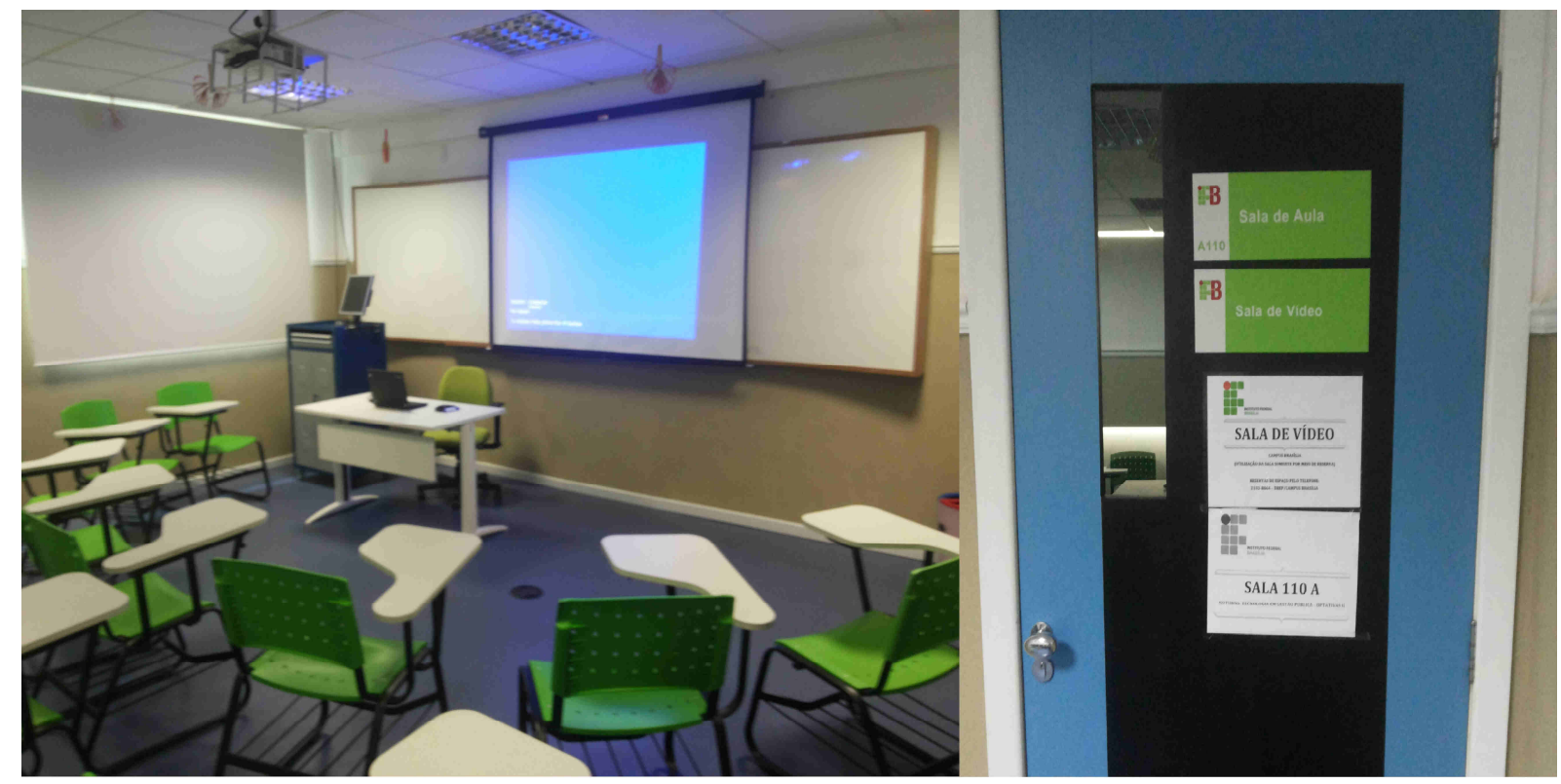

Figura 16: Organização e recursos da sala para a reunião do grupo focal.

Com todos os participantes devidamente acomodados o pesquisador fez uma breve explanação explicando os objetivos gerais da pesquisa, as condições de gravação da reunião e os aspectos éticos envolvidos nas discussões. Foram feitos os esclarecimentos aos participantes sobre o objeto de pesquisa, sobre o objetivo do grupo focal e sobre como as informações seriam analisadas após a reunião. Todos concordaram com os termos apresentados e iniciou-se a gravação por volta das $19 \mathrm{~h} 10$.

Após o inicio do registro das atividades do grupo focal o pesquisador distribuiu uma cópia impressa da apresentação da proposta preliminar (APÊNDICE D) e do questionário (APÊNDICE B) previamente enviado por e-mail aos membros do grupo focal. A apresentação da proposta preliminar e os questionamentos ocuparam aproximadamente 15 minutos da reunião. Assim, se iniciou o debate entre os membros do grupo focal, tendo como roteiro o questionário.

A primeira pergunta do questionário: 1 - Observando o desenho do DAIM:CSCL, quais seriam as sugestões de alteração da figura proposta? Foi a que demandou maior discussão e contribuições à proposta apresentada, consumindo aproximadamente 30 minutos do total da reunião. Foram analisadas as fases e o desenho que representam o modelo, considerando a descrição de cada uma das fases explicada na apresentação da proposta. 
Dentre as contribuições podemos destacar o detalhamento da figura que representa o DAIM conforme indicado pelos participantes 1, 2, 4, 7 e 8, onde temos os participantes 1 e 2 com a seguinte sugestão: "Complementar o DAIM com algum mecanismo (cor, percentual, etc), que demonstre quais itens de uma Arquitetura da Informação (conteúdo, contexto, usuário) contemplam as etapas. Assim, se sugere que cada etapa (fatia) do diagrama seja desenvolvida por vários atores contemplando a proposta de arquitetura de informação de Lima-Marques/Macedo." Nesse caso os participantes se referem ao Modelo de Arquitetura da Informação (Figura 3) proposto por Lima-Marques e Macedo (2006).

Os participantes 4, 7 e 8 sugerem uma alteração na estrutura da figura que representa o DAIM discutidas durante o grupo focal e esboçadas nas folhas do questionário entregues ao pesquisador ao final da reunião, conforme podemos verificar na Figura 17. 


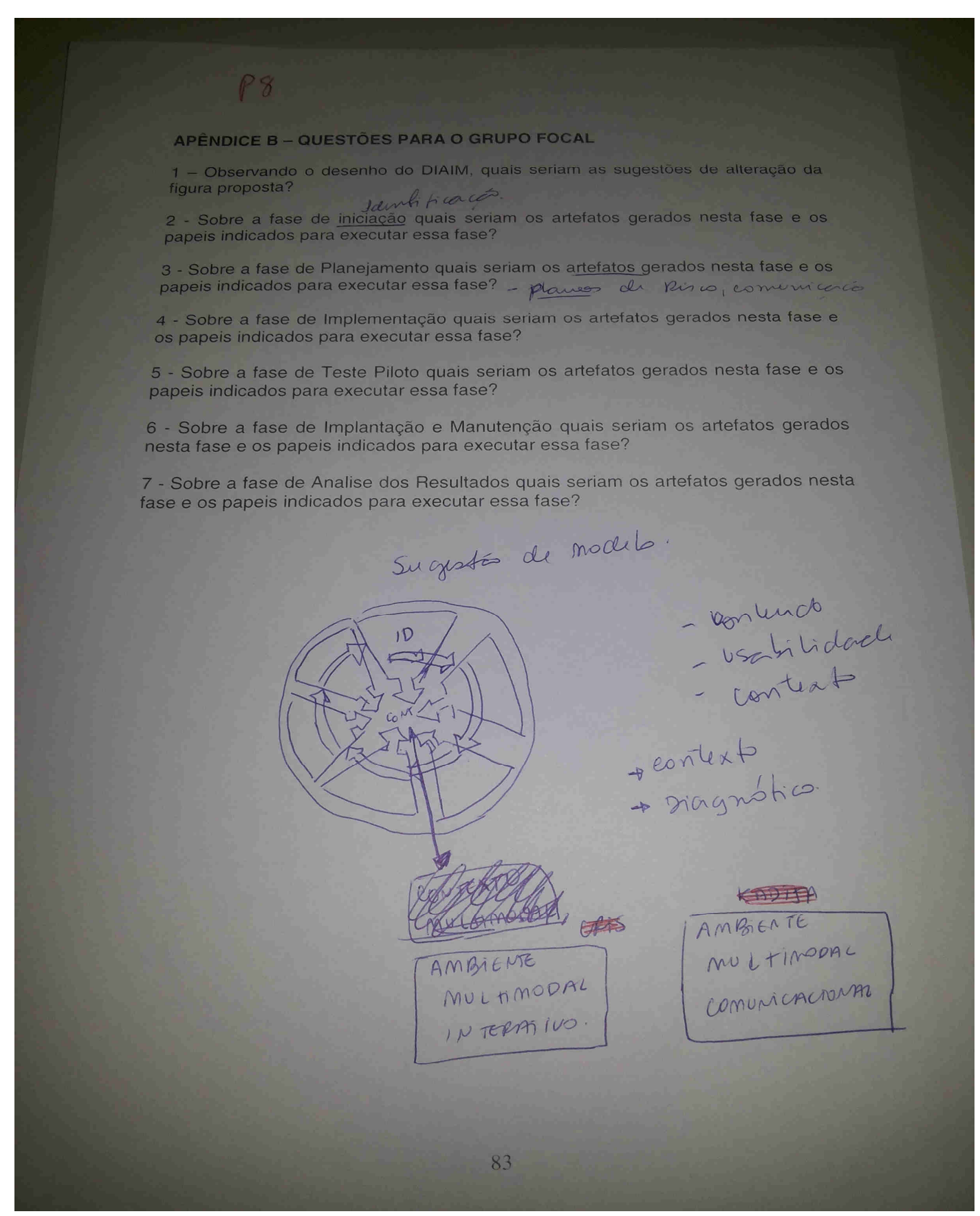

Figura 17: Proposta de alteração da figura do DAIM:CSCL do participante 8.

Os participantes 4 e 7 apresentam uma proposta de alteração da figura do DAIM:CSCL semelhante a sugestão apresentada pelo participante 8 conforme podemos verificar na Figura 18. Em resumo, as propostas consistem em expandir a figura separando as fases, colocando setas entre elas que indiquem o fluxo promovendo mais destaque ao refinamento. 


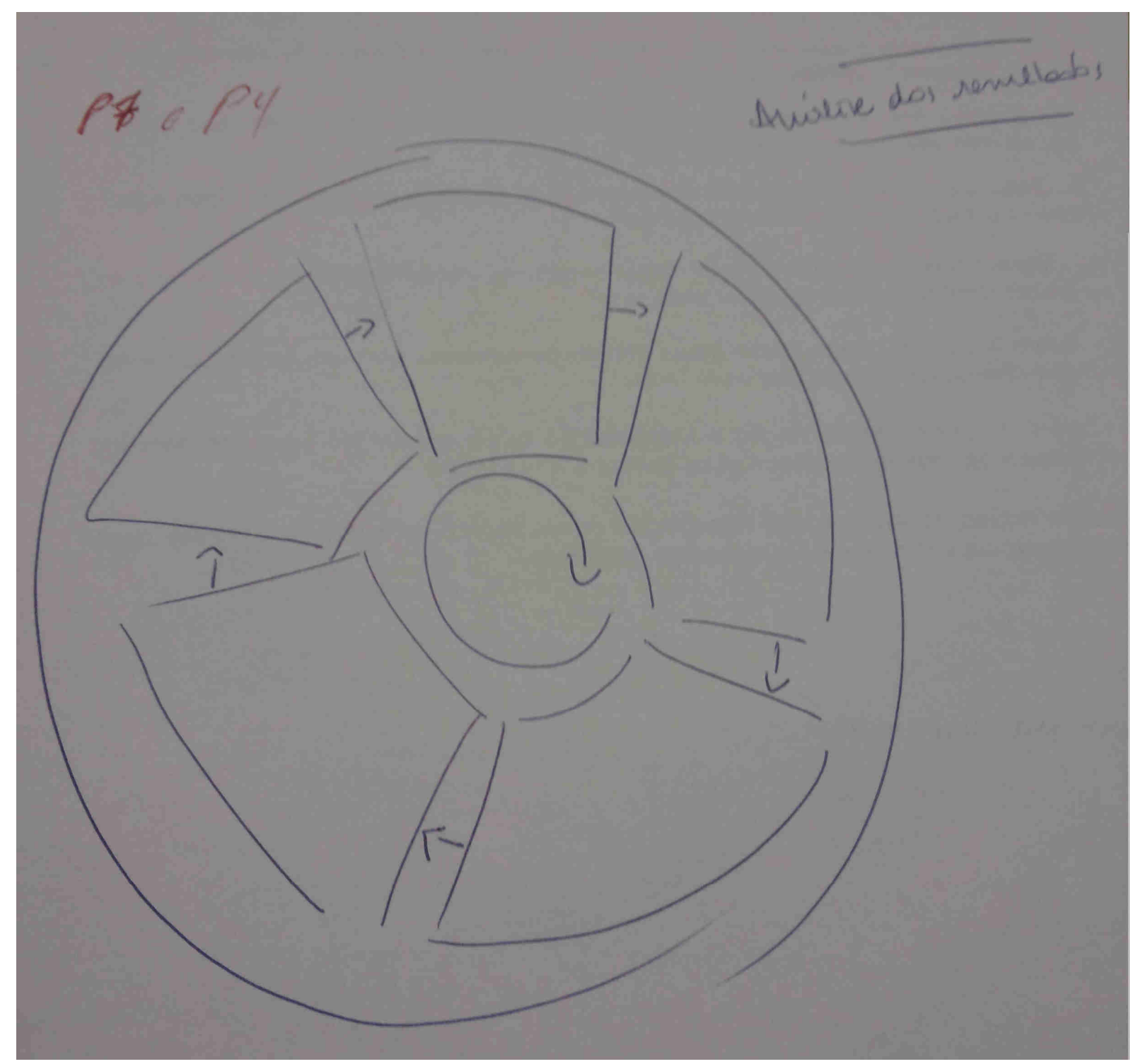

Figura 18: Proposta de alteração da figura do DAIM:CSCL do participantes 4 e 7.

Os participantes 3, 4, 6 e 8 sugeriram que o nome da fase "Iniciação" fosse alterado para "Identificação", devido às atividades propostas na descrição dessa fase, o participante 6 justificou essa mudança de nomenclatura citando que na descrição da fase encontramos os termos: identificação da demanda e identificação do público alvo.

Após a discussão inicial referente à pergunta 1 do questionário, o pesquisador abriu a discussão das questões 2 até 7, considerando que essas se referem a sugestões de atores e artefatos para cada uma das fases do DAIM:CSCL. Nesse momento o pesquisador efetuou a leitura de cada uma das perguntas e da definição apresentada para a fase em questão. 
O participante 2 solicitou a palavra e sugeriu que o modelo seja executado em forma de projeto abrangendo os documentos básicos para a execução de um projeto conforme o guia Project Management Body of Knowledge(PMBOK $\left.{ }^{8}\right)$. Essa colocação foi corroborada pelo participante 10, com a seguinte ressalva: "A Idéia de usar o PMBOK é perfeita, mas é importante se ter cuidado para não burocratizar o processo. Pois, o PMBOK é bastante extenso e muito completo. Seria interessante filtrar os artefatos a serem utilizados para não deixar o processo inchado." Essa colocação foi endossada por todos os outros participantes ficando a cargo do pesquisador uma análise dos principais documentos do PMBOK a serem incorporados ao modelo proposto.

O participante 10 sugeriu que uma equipe base para a execução do modelo em formato de processos. Sendo esta equipe composta por um gerente de projetos, um analista de requisitos e um arquiteto da informação. O participante 9 acrescentou que, por se tratar de um processo de ensino aprendizagem, é importante a participação de um pedagogo e de um especialista na área de conhecimento em que será oferecido o curso. O participante 5 observou que: "Concordo com tudo isso, mas as vezes uma pessoa pode assumir mais de um papel dentro do projeto." O participante 10 concordou com essa afirmação.

O participante 6 fez a seguinte observação: "É muito importante identificar os fluxos dos processos dentro da fase.... vou mais longe.... isso poderia ser feito em todas as fases. Identificar os workflows das fases para organizar o que deve ser feito primeiro."

Sobre a fase de iniciação/identificação, o participante 1 sugeriu a elaboração de um Mapa Mental como forma de identificar os elementos subjetivos referentes à multimodalidade e à teoria da relevância nessa fase. Os participantes 3 e 4 salientaram a importância da participação dos futuros usuários do ambiente nessa etapa. O pesquisador observou que a identificação do público alvo é uma das atividades da fase de iniciação/identificação.

8

O guia Project Management Body of Knowledge (PMBOK) é um conjunto de práticas na gestão de projetos organizado pelo Project Management Institute (PMI), é considerado a base do conhecimento sobre gestão de projetos por profissionais da área. 
O participante 5 sugeriu a utilização de um documento de visão como artefato de saída desta fase, questionado sobre o que seria esse documento de visão? Explicou: "O documento de visão é um documento típico da engenharia de software. Ele mostra uma visão geral do projeto e do ambiente do cliente, identifica o problema, traz um esboço da solução, define os objetivos do projeto, etc... se encaixa muito bem na primeira fase."

O participante 2 observou que entre os documentos do PMBOK na primeira fase o termo de abertura do projeto e o plano de projeto são fundamentais. Os participantes 6 e 10 concordaram com esses artefatos na fase inicial.

Para a fase de Planejamento o participante 9 sugeriu que fosse incluída uma atividade de diagnóstico e um documento que contemplasse essa atividade. $O$ participante 5 ponderou que o documento de visão poderia ser utilizado como artefato inicial desse diagnostico e, ao final da segunda fase, o documento de visão atualizado poderia conter os elementos do diagnostico sugerido pela participante 9.

O participante 3 ressaltou a importância do projeto de interfaces e fez a seguinte fala: "A atual hostilidade dos ambientes de EaD é a receita para o fracasso, é o que estamos vendo nas nossas escolas". O pesquisador destacou que mitigar esse impacto negativo dos ambientes CSCL é um dos objetivos da pesquisa.

Quanto aos elementos que definem a Arquitetura da Informação multimodal na fase de planejamento, ou seja, os múltiplos modos comunicativos envolvidos, 0 participante 7 exemplifica que a utilização de redes sociais integradas ao ambiente de ensino aprendizagem podem ser vistas como elementos multimodais que estimulam a ostensividade do emissor: “... quando o meu celular toca que chegou uma mensagem do whatsap, eu logo vou ver o que é?"

Ainda sobre elementos multimodais o participante 6 cita que existem algumas aplicações em vídeo aula com elementos de interação que permitem ao aluno criar seu próprio processo de aprendizagem com base nessa interação com o ambiente de aprendizagem e com os colegas. O participante fala: "Já existem formas que, durante a vídeo-aula, você pode clicar em um determinado lugar e ele te leva para determinado tópico da aula. Por exemplo: ao responder um questionário errado 
durante a aula, o aluno é levado a rever o conteúdo. Você tem ícones no vídeo que permitem ao aluno avançar ou retroceder os conteúdos."

O participante 9 observou que na fase de planejamento devem ser elaborados os planos de curso, se for o caso, e uma lista de objetos de aprendizagem como as próprias vídeo aulas, apostilas, etc.

O participante 5 comentou que na fase de Implementação, não seriam necessários outros artefatos além dos que já são utilizados por equipes de desenvolvimento de software atualmente. Os participantes 1 e 2 acrescentaram que o mapa mental elaborado na primeira fase seria um documento de requisito importante para que a implementação contemplasse os elementos multimodais na Arquitetura da Informação, conforme descrição da fase de planejamento.

O participante 7 falou sobre a fase de Teste Piloto salientando a importância do refinamento e da participação de usuários reais na prototipação do ambiente CSCL. O Participante 4 comentou que o protótipo do sistema deve destacar os elementos multimodais identificados nas fases iniciais e sugeriu que um documento que permita verificar se esses elementos estão contemplados no protótipo, utilizando um modelo de documento com chek-list.

O Participante 4 sugeriu, ainda, a criação de um repositório de objetos educacionais na fase de Implementação que seria utilizado ao longo da vida útil do sistema, citando a fase de Implantação e Manutenção.

Foi comentado pelos participantes 5 e 6 que durante a fase de Implantação e Manutenção é importante que seja feito o registro das alterações aplicadas ao ambiente CSCL para servir como insumo para fase de analise dos resultados. $O$ Participante 4 sugeriu a utilização de um repositório na fase de análise de resultados para criar um histórico de relatos.

O Participante 2 falou que na análise de resultados poderia ser criada uma matriz de ponderação de resultados, relacionando os itens multimodais agregados na interface e os resultados obtidos. O participante faz a seguinte observação: "Essa matriz de ponderação de resultados poderia ter como ponto de partida 0 planejamento das interfaces e os elementos multimodais que foram incluídos. Por 
exemplo: verificar se uma determinada musica ou vídeo alcançou o objetivo para que foi concebido. Não sei bem como seria isso, é uma idéia que me ocorreu agora."

Após 1 h30 de reunião, o pesquisador encerrou o grupo focal agradecendo pela presença de todos e foi questionado sobre a possibilidade de mais encontros para o prosseguimento das discussões acerca do tema. Os membros do grupo focal se mostraram bastante motivados e interessados pelos assuntos abordados na pesquisa, bem como nos resultados que seriam gerados a partir dela.

\subsection{NOVA PROPOSTA DE ARQUITETURA MULTIMODAL PARA AMBIENTES CSCL, CONFORME RESULTADOS DO GRUPO FOCAL}

Considerando as sugestões dos participantes do grupo focal, identificas no item anterior, podemos propor uma nova figura de representação para o DAIM:CSCL, conforme Figura 19.

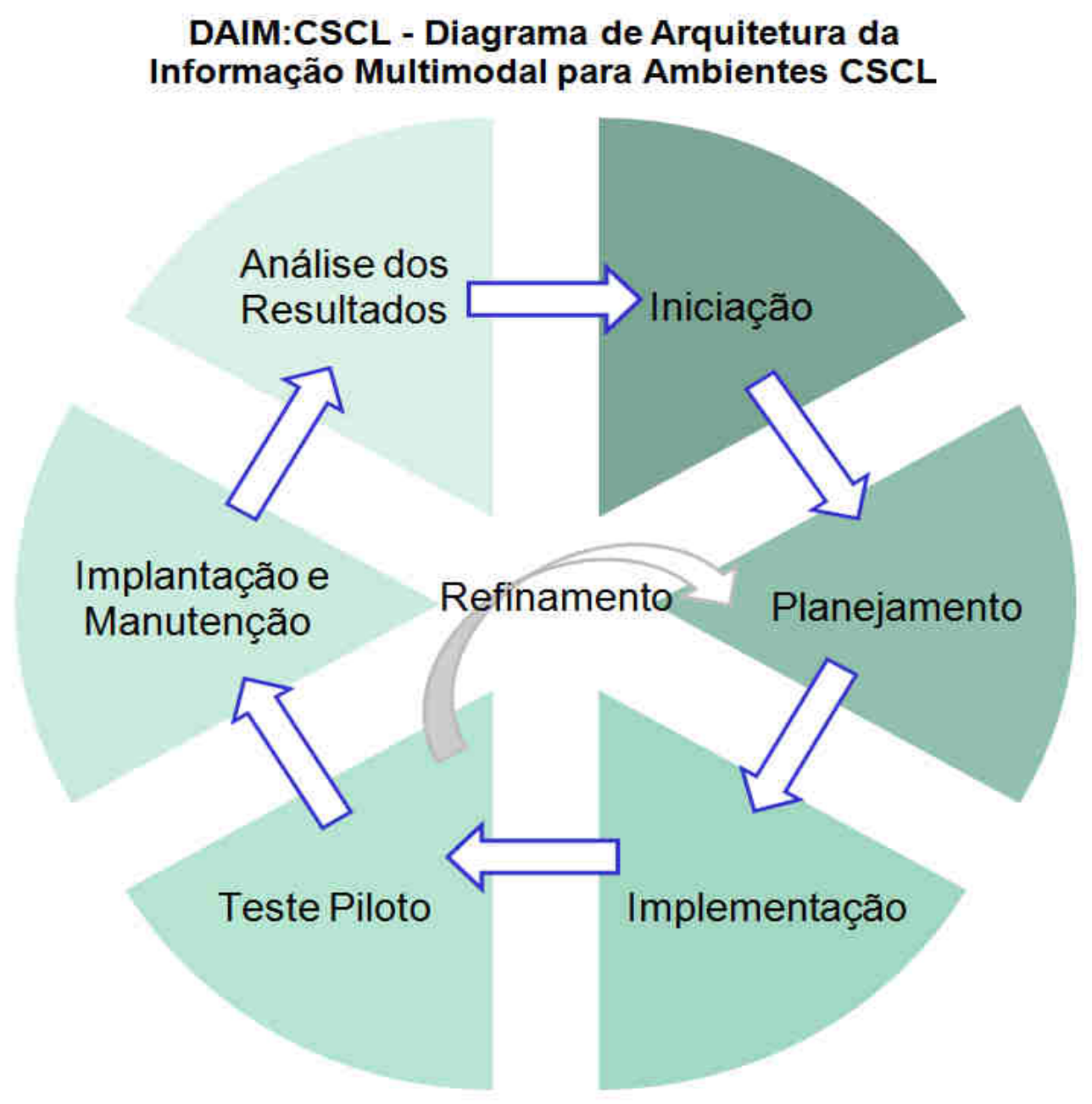

Figura 19: Novo DAIM:CSCL - Diagrama de Arquitetura de Informação Multimodal para Ambientes CSCL. 
Observando a Figura 19 podemos identificar que a sugestão dos membros do grupo focal em expandir a figura, colocando setas para indicação do fluxo aumentando o destaque da fase de refinamento foi contemplada. Entretanto a interação da nova figura com o Modelo de Arquitetura da Informação (Figura 3), proposto por Lima-Marques e Macedo (2006), continua implícita, mantendo a mesma dinâmica proposta na Figura 15.

No que se refere as questões 2 até 7 propostas pelo pesquisador para identificar os atores e artefatos em cada uma das fases do DAIM:CSCL, os membros do grupo focal sugeriram que a distribuição dos atores ao longo das fases não fosse estanque, agregando flexibilidade e pluralidade de diversas áreas do conhecimento ao longo do projeto. Foram sugeridos os seguintes papeis:

- Um gerente de projetos - responsável pelo planejamento, pela condução e coordenação das atividades em cada uma das fases. Deve participar a análise dos resultados;

- Um analista de requisitos - responsável por identificar os requisitos do sistema de informação a ser gerado. Deve integrar a equipe que irá desenvolver ou adaptar o ambiente CSCL;

- Um arquiteto da informação - responsável por auxiliar o analista de requisitos e elaborar os artefatos que contemplam os elementos multimodais da arquitetura de informação do ambiente. Deve integrar a equipe que irá desenvolver ou adaptar o ambiente CSCL. Deve participar a análise dos resultados;

- Um pedagogo - responsável por auxiliar o arquiteto da informação e produzir os objetos de aprendizagem (vídeo aulas, apostilas, etc) que serão utilizados no ambiente CSCL observando os elementos multimodais da arquitetura de informação. Deve participar a análise dos resultados;

- Um especialista na área de conhecimento do curso - responsável por auxiliar o pedagogo na construção dos conteúdos dos objetos de aprendizagem.

- Uma equipe de desenvolvimento de sistemas - responsável pela fase de implementação e manutenção do ambiente CSCL. 
Quanto aos artefatos propostos pelos membros do grupo focal, temos o resumo desses artefatos distribuídos pelas fases, conforme o Quadro 11:

Quadro 11: Artefatos de entrada e saída das fases do DAIM:CSCL

\begin{tabular}{|c|c|c|}
\hline Fase & Artefatos de Entrada & Artefatos de saída \\
\hline Iniciação & - Demanda/necessidade & $\begin{array}{l}\text { - Descrição do público alvo; } \\
\text { - Descrição do contexto do } \\
\text { público alvo; } \\
\text { - Relação dos membros da } \\
\text { equipe responsável pelo } \\
\text { projeto; } \\
\text { - Levantamento inicial das } \\
\text { necessidades; } \\
\text { - Objetivos gerais a serem } \\
\text { alcançados; } \\
\text { - Mapa Mental dos elementos } \\
\text { subjetivos (multimodalidade); } \\
\text { - Documento de visão }\end{array}$ \\
\hline Planejamento & $\begin{array}{l}\text { - Descrição do público alvo; } \\
\text { - Descrição do contexto do } \\
\text { público alvo; } \\
\text { - Relação dos membros da } \\
\text { equipe responsável pelo } \\
\text { projeto; } \\
\text { - Levantamento inicial das } \\
\text { necessidades; } \\
\text { - Objetivos gerais a serem } \\
\text { alcançados; } \\
\text { - Mapa Mental dos elementos } \\
\text { subjetivos (multimodalidade); } \\
\text { - Documento de visão; }\end{array}$ & $\begin{array}{l}\text { - Projeto das interfaces; } \\
\text { - Recursos multimodais } \\
\text { identificados segundo o } \\
\text { contexto dos usuários; } \\
\text { - Projeto de banco de dados; } \\
\text { - Projeto transacional que deve } \\
\text { considerar os multimodais } \\
\text { identificados; } \\
\text { - Relatório de aquisição de } \\
\text { hardware e softwares; } \\
\text { - Documentos de testes do } \\
\text { sistema; } \\
\text { - Documento de visão com o } \\
\text { diagnóstico da situação atual; } \\
\text { - Interação com redes sociais; } \\
\text { - Plano de curso; } \\
\text { - Lista de objetos de } \\
\text { aprendizagem; }\end{array}$ \\
\hline Implementação & $\begin{array}{l}\text { - Projeto das interfaces; } \\
\text { - Recursos multimodais } \\
\text { identificados segundo o }\end{array}$ & $\begin{array}{l}\text { - Objetos de aprendizagem que } \\
\text { contemplem os recursos } \\
\text { multimodais identificados; }\end{array}$ \\
\hline
\end{tabular}




\begin{tabular}{|c|c|c|}
\hline & $\begin{array}{l}\text { contexto dos usuários; } \\
\text { - Projeto de banco de dados; } \\
\text { - Projeto transacional que } \\
\text { deve considerar os } \\
\text { multimodais identificados; } \\
\text { - Relatório de aquisição de } \\
\text { hardware e softwares; } \\
\text { - Documentos de testes do } \\
\text { sistema; } \\
\text { - Documento de visão com o } \\
\text { diagnóstico da situação } \\
\text { atual; } \\
\text { - Interação com redes sociais; } \\
\text { - Plano de curso; } \\
\text { - Lista de objetos de } \\
\text { aprendizagem; } \\
\text { - Mapa Mental dos elementos } \\
\text { subjetivos (multimodalidade); }\end{array}$ & $\begin{array}{l}\text { - Repositório de objetos } \\
\text { educacionais; } \\
\text { - Repositório de histórico de } \\
\text { relatos; } \\
\text { - Protótipo desenvolvido e } \\
\text { testado; } \\
\text { - Software } \\
\text { adquiridos; } \\
\text { - Ambiente pronto para o teste } \\
\text { piloto; }\end{array}$ \\
\hline Teste Piloto & $\begin{array}{l}\text { - Protótipo desenvolvido e } \\
\text { testado; } \\
\text { - Software e hardware } \\
\text { adquiridos; } \\
\text { - Ambiente pronto para o teste } \\
\text { piloto; } \\
\text { - check-list dos elementos } \\
\text { multimodais; }\end{array}$ & $\begin{array}{l}\text { - Relatório de uso do sistema } \\
\text { indicando as necessidades de } \\
\text { refinamento; } \\
\text { - chek-list dos elementos } \\
\text { multimodais atualizado; }\end{array}$ \\
\hline Refinamento & $\begin{array}{l}\text { - Relatório de uso do sistema } \\
\text { indicando as necessidades } \\
\text { de refinamento; } \\
\text { - check-list dos elementos } \\
\text { multimodais atualizado; }\end{array}$ & $\begin{array}{l}\text { - Planejamento do refinamento } \\
\text { (vide artefatos de } \\
\text { planejamento); } \\
\text { - Implementação do refinamento } \\
\text { (vide artefatos de } \\
\text { Implementação); } \\
\text { - Ambiente Refinado; }\end{array}$ \\
\hline $\begin{array}{l}\text { Implantação e } \\
\text { Manutenção }\end{array}$ & - Ambiente Refinado; & $\begin{array}{l}\text { - Histórico das Manutenções } \\
\text { corretivas e adaptativas } \\
\text { - Registros dos índices de } \\
\text { satisfação dos usuários; }\end{array}$ \\
\hline Análise & $\begin{array}{l}\text { - Histórico das Manutenções } \\
\text { corretivas e adaptativas }\end{array}$ & - Sugestões de melhorias; \\
\hline
\end{tabular}




\begin{tabular}{|c|c|c|}
\hline Resultado & $\begin{array}{l}\text { - Registros dos índices de } \\
\text { satisfação dos usuários; } \\
\text { - Repositório de histórico de } \\
\text { relatos; }\end{array}$ & $\begin{array}{l}\text { - } \text { Boas práticas a serem } \\
\text { replicadas; } \\
\text { - Histórico de problemas } \\
\text { encontrados } \\
\text { - Sugestões para mitigar os } \\
\text { riscos em futuras execuções } \\
\text { do processo. } \\
\text { - Matriz de ponderação de } \\
\text { resultados; } \\
\text { - Repositório de histórico de } \\
\text { relatos atualizado; }\end{array}$ \\
\hline
\end{tabular}

Fonte: o autor

Ainda, entre os resultados identificados na reunião do grupo focal, temos como destaque a clara manifestação dos participantes da reunião na necessidade de outras reuniões para a continuidade da discussão dos assuntos contemplados no modelo proposto. Ficou evidente que esta pesquisa não esgotou as possibilidades do uso da Arquitetura da Informação e da Multimodalidade em ambientes colaborativos de ensino/aprendizagem.

Finalmente, diante das análises dos resultados e alterações propostas ao modelo inicial, podemos perceber que o DAIM:CSCL se tornou mais complexo e completo em relação a sua proposta inicial. A indicação dos atores e artefatos indica para a evolução do modelo de arquitetura multimodal para ambientes CSCL, em um processo que contempla a criação e evolução de ambientes CSCL, o que permite os resultados obtidos nesta tese, mais tangíveis de serem aplicados. Ou seja, os resultados obtidos estão mais factíveis de serem executados que a proposta inicial que o modelo previa. 


\section{CONCLUSÃo}

Essa tese teve como questionamento que norteou a pesquisa, buscar novas formas de atender às necessidades informacionais dos usuários, criando espaços informacionais que estimulam ou limitam as interações nos Ambientes CSLC para tornar esses ambientes mais relevantes aos estudantes.

Diante disso se buscou apresentar algumas contribuições da Arquitetura da Informação e da Multimodalidade para melhorar a interação dos estudantes em Ambientes Informacionais Colaborativos de Ensino-Aprendizagem apoiados em computador, tendo como norte os preceitos da Teoria da Relevância, que apresenta o princípio da relevância onde existe a predisposição de um indivíduo para determinado ato comunicativo em precedência a outro.

Para responder o questionamento inicial e atender o objetivo de pesquisa definidos para esse trabalho, foram estabelecidos três objetivos específicos conforme segue:

1. Identificar os conceitos e fundamentos da Arquitetura da Informação, da multimodalidade e teoria da relevância, bem como, alguns ambientes colaborativos de ensino/aprendizagem, segundo critérios pré-estabelecidos.

2. Estabelecer relações teóricas entre Arquitetura da Informação, Teoria da Relevância e Multimodalidade que fundamentam um modelo de Arquitetura da Informação multimodal.

3. Propor e discutir um modelo preliminar de Arquitetura da Informação Multimodal para Ambientes Colaborativos de Ensino Aprendizagem.

Quanto ao primeiro objetivo específico proposto, podemos observar que ele foi contemplado no capítulo 2, onde foi apresentado o referencial teórico que embasou a pesquisa. Foram identificados os conceitos e fundamentos da Arquitetura da Informação, da multimodalidade e da teoria da relevância. Os ambientes colaborativos de ensino/aprendizagem que foram identificados na pesquisa 
seguiram os seguintes critérios: a) são ambientes de groupware que estimulam a colaboração entre os seus membros; b) são ambientes desenvolvidos no Brasil, portanto estão voltados à realidade da educação nacional; c) são ambientes que estão em pleno uso e aperfeiçoamento; d) são ambientes livres e gratuitos.

O segundo objetivo específico dessa tese foi alcançado conforme podemos observar no item 2.6 que apresenta alguns artigos científicos sobre a Ciência da Informação, Arquitetura da Informação e Multimodalidade aplicadas em ambientes CSCL. Alguns desses artigos têm a autoria do pesquisador dessa tese.

O Item 4 complementa o segundo objetivo ao apresentar a base epistemológica do modelo de Arquitetura da Informação Multimodal, a proposta inicial do modelo e as definições para o grupo focal que fará a discussão desse modelo.

O terceiro objetivo específico, é contemplado no item 5 dessa tese onde a reunião do grupo focal é efetuada e os resultados dessa discussão acerca do modelo preliminar de Arquitetura da Informação Multimodal para Ambientes CSCL são identificados, derivando no refinamento desse modelo gerando uma proposta de processo que contempla a criação e evolução de ambientes CSCL, segundo os preceitos da Arquitetura da Informação e da Multimodalidade considerando o principio da relevância.

Finalmente, com os objetivos específicos alcançados, podemos observar que 0 objetivo geral desta tese foi atendido, indicando respostas ao questionamento inicial que norteou a pesquisa.

\subsection{SUGESTÕES DE TRABALHOS FUTUROS}

Dentre os trabalhos futuros derivados desta tese, podemos destacar:

1. O estudo e concepção dos novos artefatos sugeridos na concepção do modelo proposto. Dentre eles, podemos citar a matriz de ponderação de resultados sugerida para fase de análise dos resultados;

2. Relacionar os perfis dos atores sugeridos para a execução do modelo proposto com os artefatos a serem gerados ao longo do projeto. 
3. A execução de um projeto piloto conforme o modelo proposto para iniciarmos o ciclo de melhoria do modelo e do ambiente gerado com base nesse modelo;

4. Detalhar os fluxos de atividades de cada uma das fases do DAIM:CSCL.

Conforme a solicitação dos participantes do grupo focal quanto à realização de novas reuniões para a continuidade das discussões elencadas no reunião, fica a possibilidade de organização de novos grupos focais ou grupos de pesquisa que possam utilizar os resultados desta tese como ponto de partida para novas pesquisas nas áreas de Multimodalidade e Arquitetura da Informação aplicadas em ambientes CSCL. 


\section{REFERÊNCIAS}

AUDY, J. L. N.; ANDRADE, G. K. de; CIDRAL, A. Fundamentos de sistemas de informação. PortoAlegre/RS : Bookman, 2007.

BAKHTIN, M.. Estética da Criação Verbal. São Paulo: Martins Fontes, 1992.

BATEMAN, J. A. Multimodality and Genre: A Foundation for the Systematic Analysis of Multimodal Documents. ISBN-10: 0230002560. Palgrave Macmillan, London, 2008.

BATES, M. J. A Tour of Information Science through the Pages of JASIS. Journal of the American Society for Information Science. n 50. 1999. p. 975-993.

BERTALANFFY, L. V. Teoria geral dos sistemas. Petrópolis-RJ: Vozes, 1973.

BORKO, H. Information science: what is it? American Documentation, Jan. 1968.

CAPURRO, R. Epistemologia e Ciência da Informação. Anais do V Encontro Nacional de Pesquisa em Ciência da Informação. Belo Horizonte (Brasil), 10 de Novembro de 2003.

DUQUE, C. G. SiRILiCO: Uma Proposta para um Sistema de Recuperação de Informação baseado em Teorias da Lingüística Computacional e Ontologia. 2005. 120 f. Tese (Doutorado em Ciência da Informação), Escola de Ciência da Informação, Universidade Federal de Minas Gerais, Minas Gerais, 2005.

DUQUE, C. G.; CARVALHÊDO, S. do P. A Web Semântica, as Redes Sociais e o Futuro dos Profissionais da Informação. IX ENANCIB - Encontro Nacional de Pesquisa em Ciência da Informação. São Paulo - SP. 2008.

DUQUE, C. G. Ciência da Informação Estudos e Praticas. Brasília-DF. Centro Editorial. 2011.

FARIAS, M. A.; OBILINOVIC, K.; ORREGO, R. Pontos de possível diálogo entre aprendizyado Multimodal e Ensino-Aprendizado de Línguas Estrangeiras. Trab. Ling. Aplic., Campinas, 50(1): 133-151, Jan./Jun. 2011.

FELIPE, A. A. C. Ciência da informação e ambientes colaborativos de aprendizagem: um estudo de caso da plataforma Moodle-UFPB. Dissertação (Mestrado em Ciência da Informação) - Curso de Ciência da Informação, Universidade Federal da Paraíba, 2011.

FUKS, H.; RAPOSO, A.B.; GEROSA, M.A.; PIMENTEL, M. \& LUCENA, C.J.P. Suporte à Coordenação e à Cooperação em uma Ferramenta de Comunicação Textual Assíncrona: Um Estudo de Caso no Ambiente AulaNeT. Anais do I Workshop Brasileiro de Tecnologias para Colaboração (WCSCW 2004), Ribeirão Preto-SP, ISBN 85-7669-010-1. Outubro de 2004a. 
FUKS, H.; GeRosA, M. A.; RAPOSO, A. B. e LUCENA, C. J. P. O Modelo de Colaboração $3 C$ no Ambiente AulaNet. Informática na Educação: Teoria e Prática, v.7, n 1, UFRGS, ISSN 1516-084X, p. 25-48. Porto Alegre-RS, 2004b.

GIL, A. C. Como elaborar projetos de pesquisa. São Paulo: Atlas, 1991.

GIL, A. C. Métodos e técnicas de pesquisa social. São Paulo: Atlas, 1999.

GORDON, S. R.; GORDON, J. R. Sistema de Informação: uma Abordagem Gerencial. 3를 ed LTC, 2006, 408p.

GUO, L. Multymodality in a Biology Textbook. In:O'HALLORAM, Kay L. Multimodal discourse analysis: systemic-functional perspectives. Open Linguistics Series. Ed. Continuum. ISBN: 0-8264-7256-7, 2004.

HALLIDAY, M.A.K. An introduction to functional grammar. London: Edward Arnold. 1994.

HALLIDAY, M.A.K. (revised by) Christian M.I.M. Matthiessen. An Introduction to functional grammar. London: Arnold. 2004.

HSU, Yu-C. \& SHIUE, Ya-M. The Effect of Self - Directed Learning Readiness on Achievement Comparing Face-to-Face and Two-Way Distance Learning Instruction. International Journal of Instructional Media, v.32, 2005.

ISO/IEC, 13.407 Human-centred design processes for interactive systems, 1999: ISO/IEC 13407: 1999.

KITZINGER, J. Focus groups with users and providers of health care. In: POPE, C.; MAYS, N. (Org.). Qualitative research in health care. 2. ed. London: BMJ Books, 2000.

KRESS, G. Multimodality: a social semiotic approach to contemporary communication. London: Routledge, 2010.

KRESS, G.; LEITE-GARCIA, R., van LEEUWEN, T. Semiótica discursiva. In: van DIJK, T. A. El discurso como estructura y proceso. Barcelona: Gedisa Editorial, 2000.

KRESS, G.; VAN LEEUWEN, T. Front Pages: (The critical) analysis of newspaper layout. In: BELL, A, GARRETT, P. (Eds.). Approaches to media discourse. Oxford: Blackwell, 1998.

KRESS, G.; VAN LEEUWEN, T. Multimodal Discourse: The Modes and Media of Contemporary Communication. London: Hodder Arnold Publication. 2001.

KRESS, G.; VAN LEEUWEN, T. Reading Images: The Grammar of Visual Design. London and New York: Routledge, 2006. 
LE COADIC, Y. F. A. Ciência da informação. Briquet de Lemos, $2^{a}$ ed. Brasília, 2004.

LIMA-MARQUES, M. Outline of a theoretical framework of Architecture of Information: a School of Brasilia proposal. In: BEZIAU, J.-Y.; CONIGLIO, M. E. (Eds.) 2011.

LIMA-MARQUES, M.; MACEDO, F. L. O. Arquitetura da informação: base para a Gestão do Conhecimento. In: TARAPANOFF, K. O. (Ed.). Inteligência, informação e conhecimento. Brasília: IBICT, 2006. p. 241-255.

LORENS, E. M. Aspectos normativos da segurança da informação: um modelo de cadeia de regulamentação. Dissertação (Mestrado em Ciências da Informação e Documentação)-Universidade de Brasília, Brasília, 2007.

LYRA, Maurício Rocha. A contribuição da Arquitetura da Informação para o Gerenciamento de Serviços de TI. Tese (doutorado) - Universidade de Brasília, Faculdade de Ciência da Informação, 2012.

Mayer, R. E.; Moreno, R.; Aids to computer-based multimedia learning. In Learning and Instruction v. 12. 2002. p. 107-119 Disponível em: http://www.psychology.mcmaster.ca/bennett/psy720/readings/m1/m1r3.pdf

MONTE MÓR, W. M. Multimodalidades e Comunicação: Antigas e Novas Questões no Ensino de Línguas Estrangeiras. Revista. Let. \& Let. Uberlândia-MG, v.26, n.2, p.469-476, jul./dez. 2010.

MORREIRA, M. C. Ambientes Virtuais de Aprendizagem (AVA) e seus Diferentes Tipos. Última atualização: 17/10/2012 Disponível em: http://www.mar.mil.br/ciaga/ead/site/artigos sup mario.html. Acesso em: 05/2014.

NASCIMENTO, M. S. O. do. Proteção ao conhecimento: uma proposta de fundamentação teórica.181 f. Dissertação (Mestrado em Ciência da Informação)Universidade de Brasília, Brasília, 2008.

NERI, M. Motivos da Evasão Escolar. NERI, M. (Org.). O Tempo de Permanência na Escola e as Motivações dos Sem-Escola. Rio de Janeiro - RJ: FGV/IBRE, CPS p. $4-34,2009$.

NORRIS, S. Analyzing Multimodal Interaction: a methodological framework. New York: Routledge. 2004

OLIVEIRA, E. A.; TEDESCO, P. i-collaboration: Um modelo de colaboração inteligente personalizada para ambientes de EAD. Revista Brasileira de Informática na Educação, Volume 18, Número 1, 2010.

O'TOOLE, M. The Language of displayed art. London: Routledge Paperback, 2011. 
PEÓN ESPANTOSO, J. J. A arquitetura da informação na intranet os sítios do EME. 2001. 127 f. Dissertação (Mestrado em Ciência da Informação). Universidade de Brasília, Brasília, 2001.

POWELL, R. A.; SINGLE, H. M. Focus Groups. International Journal of Quality in Helth Care, v.8, n.5, p.499-504, 1996.

PRESSMAN, R. S. Engenharia de Software: Uma Abordagem Profissional. $6^{\mathrm{a}}$ ed São Paulo: Makron Books, 2006, 720p.

RAPOSO, A. B.; PIMENTEL, M.; GER OSA, M. A.; FUKS, H. \& LUCENA, C. J. P. Prescribing e-Learning Activities Using Workflow Technologies. Proceedings of 1st International Workshop on Computer Supported Activity Coordination (CSAC 2004). Porto - Portugal, 2004.

REZENDE, D. A.; ABREU, A. F. Tecnologia da informação aplicada a sistemas de informação empresariais: o papel estratégico da informação e dos sistemas de informação nas empresas. 9 ed. São Paulo: Atlas, 2013.

ROBREDO, J. Da ciência da informação revisitada aos sistemas humanos de informação. Brasília: Thesaurus Editora, 2003.

ROBREDO, J. Documentação de Hoje e de Amanhã. 4. ed. Brasília: Edição de autor, 2005.

ROCHA, E. C. de F.; DUARTE, A. B. S. Reflexões sobre os paradigmas de estudo da usabilidade na Ciência da Informação. DataGramaZero - Revista de Informação - v.14 n.4 (ARTIGO 03), agosto de 2013.

SANTORO, F. M.; GUERERRO, L. G.; ZAPATA, S; BORGES, M.; SANTOS, N. (2004). Evaluating Collaboration in CSCL Application Domain within the CSCW Lab, Proceedings of the 8th International Conference on Computer Supported Cooperative Work in Design Vol II, CSCWD'2004, Xiamen, China, May 2004, IEEE Press pp. 56-61

SARACEVIC, T. Interdisciplinary nature of information science. Ciência da Informação, v.24, n. 1, 1995.

SHI, W.; LEE, H.H.S.;GHOSH, M. LU,C. A Boldyreva High efficiency counter mode security architecture via prediction and precomputation. ACM SIGARCH Computer Architecture News 33 (2), 14-24, 2005.

SOMMERVILLE, I. Engenharia de software. 6. ed., São Paulo: Addison Wesley, 2003, 592p.

SPERBER, D.; WILSON, D. Relevance Theory. Proceedings of the Tokyo Conference on Psycholinguistics, 2002.

SPERBER, D.; WILSON, D. Relevance: communication and cognition. Oxford: Blackwell, 1995 (1st ed. 1986). 
STEINMETZ, E. H. R. Concepção de um ambiente de apoio ao autoplanejamento discente no seu processo de aprendizagem. Dissertação (Mestrado em Gestão do Conhecimento e da Tecnologia da Informação) Universidade Católica de Brasília, 2007.

STEINMETZ, E. H. R.; DUQUE, C. G. Algumas Contribuições da Arquitetura da Informação para Ambientes Colaborativos de Ensino/Aprendizagem. Anais XV Encontro Nacional de Pesquisa em Ciência da Informação: além das nuvens, expandindo as fronteiras da Ciência da Informação, 27-31 de outubro de 2014, em Belo Horizonte-MG. p. 3066 - 3072.

STEINMETZ, E. de F. P. da S.; STEINMETZ, E. H. R.; DUQUE, C. G.; OLIVEIRA, K. A Multimodalidade como ponte para o aluno ingressar na iniciação científica. VIII Congreso Internacional de La Asociación de Lingüística Sistémico-Funcional de América Latina (ALSFAL). Universidad Católica del Uruguay de Montevideo Uruguai, 27 al 29 de setiembre de 2012.

STEINMETZ, E. de F. P. da S.; STEINMETZ, E. H. R.; DUQUE, C. G.; COSTA, R. da S. Pontos Convergentes entre Ciência da Informação, Teoria da Relevância e Multimodalidade. VI ENCONTRO IBÉRICO EDICIC 2013 - Globalização, Ciência, Informação. Cidade do Porto - Portugal. 4 a 6 de novembro de 2013. ISBN 978-97236-1339-1. Disponível em: http://www.youblisher.com/p/745142-VI-Encontro-lbericoEDICIC-2013-Globalizacao-Ciencia-Informacao/

STEINMETZ, E. de F. P.S; STEINMETZ, E. H. R.; DUQUE, C. G. Competência Informacional: Uma reflexão sobre o papel social da Ciência da Informação e sua relação com a Competência Informacional dos discentes em IES privadas do DF. III CONGRESO INTERNACIONAL CIENCIAS, TECNOLOGÍAS Y CULTURAS. DIÁLOGO ENTRE LAS DISCIPLINAS DEL CONOCIMIENTO. MIRANDO AL FUTURO DE AMÉRICA LATINA Y EL CARIBE - SIMPOSIO DE ESTUDIANTES. 07 a 10 de enero de 2013. Santiago de Chile - Chile. Disponível em:

http://www.internacionaldelconocimiento.org/index.php?option=com content\&view=a rticle\&id=632:resumenes-simposio-de-estudiantes-de-pregrado\&catid=100:resumenes-de-los-simposios-55-a-68\&ltemid=101

STEINMETZ, E. de F. P.S; STEINMETZ, E. H. R.; DUQUE, C. G. Gramática Visual do Blog do PAPIC. III CONGRESO INTERNACIONAL CIENCIAS, TECNOLOGÍAS Y CULTURAS. DIÁLOGO ENTRE LAS DISCIPLINAS DEL CONOCIMIENTO. MIRANDO AL FUTURO DE AMÉRICA LATINA Y EL CARIBE. SIMPOSIO DE ESTUDIANTES. 07 a 10 de enero de 2013. Santiago de Chile - Chile. Disponível em:

http://www.internacionaldelconocimiento.org/index.php?option=com content\&view=a rticle\&id=632:resumenes-simposio-de-estudiantes-de-pregrado\&catid=100:resumenes-de-los-simposios-55-a-68\&ltemid=101

STEINMETZ, E. H. R.; DUQUE, C. G. Análise de Interfaces em Sistemas de Autoplanejamento Discente Utilizando padrões IHC para WEB. In: DUQUE, C. G. (Org.). Ciência da Informação Estudos e Praticas. Brasília - DF: THESAUROS Editora, 2011, v.1, p. 165-186. 
STEINMETZ, E. H. R.; STEINMETZ, E. de F. P. da S.; DUQUE, C. G. Ciência da Informação, Arquitetura da Informação e Multimodalidade: algumas relações teóricas. VIII Congreso Internacional de La Asociación de Lingüística SistémicoFuncional de América Latina (ALSFAL). Universidad Católica del Uruguay de Montevideo - Uruguai, 27 al 29 de setiembre de 2012.

STEINMETZ, E. H. R.; DUQUE, C. G. A Contribuição da Multimodalidade para a iniciação científica. III CONGRESO INTERNACIONAL CIENCIAS, TECNOLOGÍAS Y CULTURAS. DIÁLOGO ENTRE LAS DISCIPLINAS DEL CONOCIMIENTO. MIRANDO AL FUTURO DE AMÉRICA LATINA Y EL CARIBE - SIMPOSIO № 56: LA PRODUCCIÓN INTELECTUAL DE LOS DOCENTES UNIVERSITARIOS EN LATINOAMÉRICA. 07 a 10 de enero de 2013. Santiago de Chile - Chile. Disponível em:

http://www.internacionaldelconocimiento.org/index.php?option=com content\&view=a rticle\&id=596:simposio-no-56-la-produccion-intelectual-de-los-docentesuniversitarios-en-latinoamerica\&catid=100:resumenes-de-los-simposios-55-a$\underline{68 \& \text { Itemid }=101}$

STEINMETZ, E. H. R.; DUQUE, C. G. Ciência da Informação, Arquitetura da Informação e Multimodalidade: algumas relações teóricas. III CONGRESO INTERNACIONAL CIENCIAS, TECNOLOGÍAS Y CULTURAS. DIÁLOGO ENTRE LAS DISCIPLINAS DEL CONOCIMIENTO. MIRANDO AL FUTURO DE AMÉRICA LATINA Y EL CARIBE - SIMPOSIO № 56: LA PRODUCCIÓN INTELECTUAL DE LOS DOCENTES UNIVERSITARIOS EN LATINOAMÉRICA. 07 a 10 de enero de 2013. Santiago de Chile - Chile. Disponível em: http://www.internacionaldelconocimiento.org/index.php?option=com content\&view=a rticle\&id=596: simposio-no-56-la-produccion-intelectual-de-los-docentesuniversitarios-en-latinoamerica\&catid=100:resumenes-de-los-simposios-55-a68\&ltemid=101

STEINMETZ, E. de F. P.S; STEINMETZ, E. H. R.; DUQUE, C. G. Multimodalidade em Blog Acadêmico: um blog Multimodal como incentivo ao compromisso, à produção Intelectual e a divulgação do Conhecimento de graduandos em IES privada do Distrito Federal. III CONGRESO INTERNACIONAL CIENCIAS, TECNOLOGÍAS Y CULTURAS. DIÁLOGO ENTRE LAS DISCIPLINAS DEL CONOCIMIENTO. MIRANDO AL FUTURO DE AMÉRICA LATINA Y EL CARIBE SIMPOSIO DE ESTUDIANTES. 07 a 10 de enero de 2013. Santiago de Chile Chile. Disponível em: http://www.internacionaldelconocimiento.org/index.php?option=com content\&view=a rticle\&id=632:resumenes-simposio-de-estudiantes-de-pregrado\&catid=100:resumenes-de-los-simposios-55-a-68\&ltemid=101

TRAD, L. A. B. Grupos focais: conceitos, procedimentos e reflexões baseadas em experiências com o uso da técnica em pesquisas de saúde. Physis (UERJ. Impresso), v. 19, p. 777-796, 2009.

VEIGA, L.; GONDIM S. M. G. A utilização de métodos qualitativos na ciência política e no marketing político. Opinião Pública. v.2, n1, p. 1-15, 2001. 
VERGARA, S. Projetos e relatórios de pesquisa em administração. 9. ed. São Paulo: Atlas, 2007.

VERGARA, S. Métodos de coleta de dados no campo. São Paulo: Atlas, 2009.

VICKERY, B.; VICKERY, A. Information Science in Theory and Practice. BowkerSaur. 1993.

WfMC. The Workflow Reference Model: 10 years On. In Workflow Handbook 2004, by David Dave Hollingsworth. Workflow Management Coalition. Disponível em: http://www.wfmc.org/standards/docs/RefModel10yearsonHollingsworth.pdf. Acessado em: 01/2015.

WURMAN, R. S. Information architects. 2. ed. Lakewood: Watson-Guptill Pubns, 1997. 


\section{APÊNDICE A - CORREIO ELETRÔNICO ENVIADO AO GRUPO FOCAL}

Prezado(a) Senhor(a),

Sou aluno do doutorado da Universidade de Brasília em Ciência da Informação, e estou escrevendo uma tese intitulada "A contribuição da Arquitetura da Informação na construção e utilização de Ambientes Informacionais Colaborativos de Ensino/Aprendizagem.

Uma das etapas do desenvolvimento da minha tese implica na realização de um grupo focal. O grupo focal é método que consiste na discussão de conceitos e propostas por parte de um pequeno grupo de especialistas nas áreas de conhecimento abordadas na pesquisa. Trata-se de uma técnica qualitativa de coleta de dados, que faz uso das experiências, habilidades e conhecimentos conforme perfis previamente definidos pelo pesquisador. Informo que os dados pessoais colhidos no decorrer da pesquisa serão tratados com devido sigilo, não sendo expostos no texto final da tese.

Local, Data e Hora do grupo focal:

Instituto Federal de Brasília, sala 110, bloco A.

SGAN 610, Módulos D, E, F e G, Brasília/DF, CEP 70830-450 - Asa Norte Brasília DF.

Dia 19/10/2015 - segunda-feira - 19h às $20 \mathrm{~h} 30$

Roteiro da reunião do Grupo Focal:

O grupo será formado por até 10 especialistas, um mediador e um redator. Primeiramente o mediador solicitará que cada participante se apresente. Após, esclarecerá o objetivo da pesquisa. O mediador, então, apresentará uma questão para os participantes sobre o tema da pesquisa. Os participantes discutirão livremente a questão e cada um colocará seu ponto de vista. Essas observações serão todas registradas pelo mediador e farão parte da sua pesquisa. O processo é repetido para cada questão e, no final, o mediador fará o encerramento da sessão, toda a reunião será gravada para posterior análise por parte do pesquisador. (LYRA, 2012)

Sendo assim, gostaria de contar com a sua colaboração para realização desta pesquisa e conclusão de minha tese. Peço, por gentileza, a confirmação da participação até o dia 13/10/2015, pois no caso de impossibilidade de algum especialista, possa ser convidada outra pessoa e assim recomposto o grupo.

Desde já, agradeço a atenção e contribuição.

Atenciosamente,

Ernesto Henrique Radis Steinmetz

Doutorando em Ciências da Informação

Programa de Pós-Graduação em Ciência da Informação - FCl/UnB

(61) 9234-4045

ernesto.radis@gmail.com

ernesto.steinmetz@ifb.edu.br

LYRA, Maurício Rocha. A contribuição da Arquitetura da Informação para o Gerenciamento de Serviços de TI. Tese (doutorado) - Universidade de Brasília, Faculdade de Ciência da Informação, 2012. 


\section{APÊNDICE B - QUESTÕES PARA O GRUPO FOCAL}

1 - Observando o desenho do DAIM, quais seriam as sugestões de alteração da figura proposta?

2 - Sobre a fase de iniciação quais seriam os artefatos gerados nesta fase e os papeis indicados para executar essa fase?

3 - Sobre a fase de Planejamento quais seriam os artefatos gerados nesta fase e os papeis indicados para executar essa fase?

4 - Sobre a fase de Implementação quais seriam os artefatos gerados nesta fase e os papeis indicados para executar essa fase?

5 - Sobre a fase de Teste Piloto quais seriam os artefatos gerados nesta fase e os papeis indicados para executar essa fase?

6 - Sobre a fase de Implantação e Manutenção quais seriam os artefatos gerados nesta fase e os papeis indicados para executar essa fase?

7 - Sobre a fase de Analise dos Resultados quais seriam os artefatos gerados nesta fase e os papeis indicados para executar essa fase? 


\section{APÊNDICE C - O CONTEXTO DA PESQUISA}

\section{Prezados participantes do Grupo Focal,}

Este texto apresenta o contexto da pesquisa em questão e os resultados obtidos até o presente momento, que servem como ponto de partida para nossa discussão do dia 19 de outubro.

Solicito a gentileza de efetuarem a leitura do texto em anexo, bem como informo que no início da nossa reunião farei uma breve explanação de cerca de 15 minutos sobre este documento.

\section{INTRODUÇÃO}

A concepção de Ambientes Colaborativos de Ensino e Aprendizagem (CSCL Computer Supported Collaborative Learning) tem seu principal foco de estudo no contexto da Informática na Educação. Entretanto, existem alguns trabalhos sobre a relação/contribuição da Ciência da Informação e da Arquitetura de Informação em CSCL. Estes trabalhos são voltados para estudos de caso específicos, onde o aluno é visto como um usuário da informação e para gerar seu conhecimento precisa recuperar informações por meio de ambientes informatizados.

Considerando que a informação é um elemento essencial no processo de ensino e aprendizagem e que Arquitetura da Informação trata da sua organização e recuperação, entende-se que ela deve estar ou deveria estar presente no processo de elaboração e utilização de Ambientes CSCL. Para tanto, esta pesquisa investiga as contribuições da Ciência da Informação $(\mathrm{Cl})$ e da Arquitetura da Informação (Al) em Ambientes Colaborativos de Ensino/Aprendizagem, com foco nos preceitos da Multimodalidade e da Teoria da Relevância.

\section{REFERENCIAL TEÓRICO}

\section{Ciência da Informação}

Capurro (2003, p. 04), entende que a Ciência da Informação busca estudar "à produção, seleção, organização, interpretação, armazenamento, recuperação, disseminação, transformação e uso da informação". Nessa linha de pensamento, diversos estudos sobre Ciência da Informação abordam a questão do real 
significado das palavras: Dado, Informação e Conhecimento, ou o que determinada comunidade científica entende como o conceito destes termos.

Le Coadic (2004), afirma que um dos papéis da Ciência da Informação é a análise dos processos que se alimentam reciprocamente para conceber os sistemas, pela comunicação, uso e armazenamento da informação. Considera-se que, a necessidade de informação surge como um problema a ser resolvido, um objetivo a ser atingido e percebe-se então, que ela pertence à categoria das necessidades humanas básicas, conforme a figura 1.

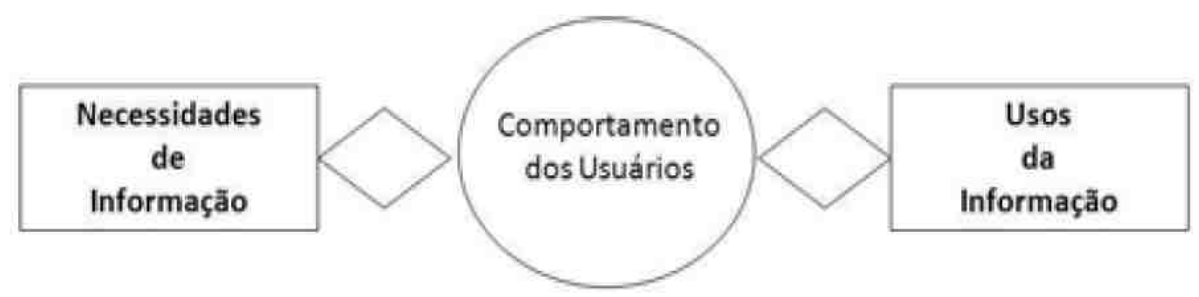

Figura 1: Usos e Necessidades da Informação (LE COADIC, 2004, p. 40).

\section{Arquitetura da Informação}

A ASSIT\& $T^{9}$ - American Society for Information Science and Technology define:
A Arquitetura da Informação como sendo a arte, ciência e negócio de organizar a informação de modo que faça sentido para quem a usa. $\mathrm{E}$ os arquitetos da informação são membros da equipe que coreografam os relacionamentos complexos entre os elementos que compõem um espaço da informação. (ASIS\&T, 2011).

Ainda, conforme o portal da ASIST\&T, a Arquitetura da Informação caracteriza-se pelo conjunto de atividades padronizadas e estruturadas para disponibilizar acesso a informações com o objetivo de organizar e disponibilizar conteúdos, facilitando a navegação e a sua recuperação.

Wurman (1997) apresentou uma definição para Arquitetura da Informação como a ciência e a arte de criar instruções para espaços organizados. Neste sentido o autor explica que a Arquitetura da Informação busca entender os problemas de reunião, organização e apresentação da informação para sanar as necessidades informacionais dos usuários.

Para Rosenfeld e Morville (2002) a Al é uma intersecção de três áreas:

9 


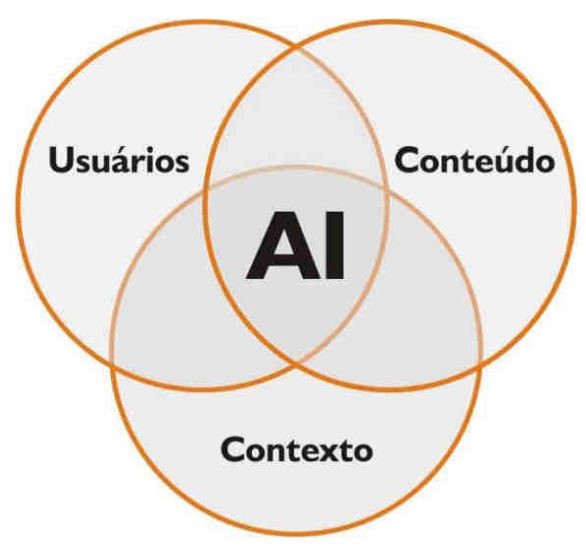

Figura 2: Intersecções da Al. (Rosenfeld e Morville, 2002).

Segundo Lima-Marques e Macedo (2006) a informação depende do comportamento dos usuários que farão uso dela e determinarão as suas necessidades. O uso da informação está no nível de aplicação que segundo o modelo de Arquitetura da Informação proposto por estes autores representa os processos básicos do ciclo da informação em três níveis, conforme podemos observar na Figura 3.

- Nível de meta-modelagem - análise do contexto ou do ambiente informacional para realização do planejamento estratégico do sistema de informação;

- Nível de modelagem - definição do conteúdo que irá ser armazenado, organizado e representado, por meio da captura, armazenamento, organização, representação e comunicação;

- Nível de aplicação - aplicação das teorias e modelos construídos a partir dos níveis anteriores na implementação de sistemas de informação. 


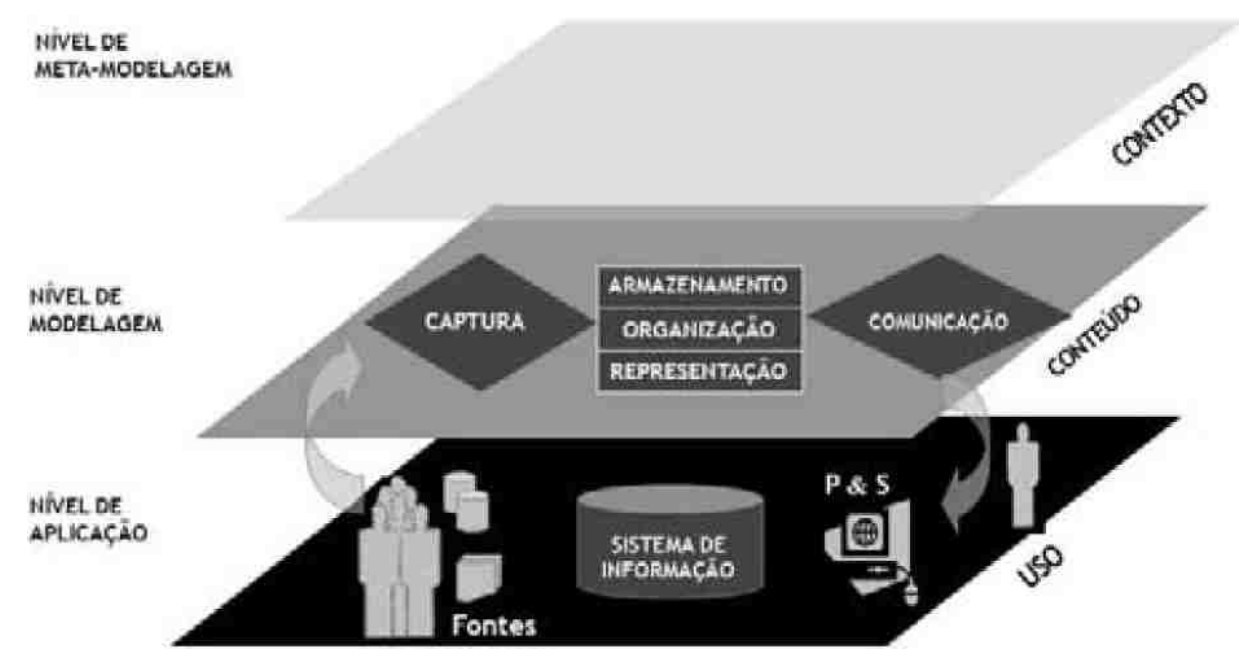

Figura 3: Proposta de Modelo de Arquitetura da Informação (LIMA-MARQUES; MACEDO, 2006, p 253).

\section{Ambientes Colaborativos de Ensino/Aprendizagem}

Dentre as formas de viabilizar o trabalho colaborativo, o groupware pode ser visto como uma tecnologia de apoio, definido pela WfMC (2002) como um exemplo de workflow com alto grau de colaboração e pouco estruturado.

Conforme podemos observar em Fuks et al. (2004), e Raposo et al. (2004), o conceito de workflow sob a forma de groupware, tem sido explorado no sentido de modelagem da coordenação de grupos de trabalho em aprendizagem colaborativa, de forma transparente ao usuário. O conceito de groupware nos remete ainda a outros dois conceitos estudados por esses autores, são eles: o Trabalho Colaborativo Apoiado por Computador (Computer Supported Collaborative Work CSCW) e por conseqüência, Aprendizagem Colaborativa Apoiada por Computador (Computer Supported Collaborative Learning - CSCL).

Steinmetz (2007), apresenta uma breve explicação da diferença entre os ambientes CSCW - Computer Supported Cooperative Work e CSCL - Computer Supported Collaborative Learning. Onde o autor explica que:

O foco no trabalho colaborativo, desenvolvido nas pesquisas de CSCW, derivou o conceito de aprendizagem colaborativa apoiada por computador (CSCL), onde a aplicação de sistemas de workflow tem sido estudada. Os dois conceitos, apesar de semelhantes, apresentam algumas características distintas. O CSCW possui a finalidade de facilitar a comunicação e a produtividade do grupo de trabalho, com foco no produto das interações. A CSCL almeja sustentar uma aprendizagem eficaz em grupo e seu foco é no processo de interação (STEINMETZ, 2007, p. 65) 


\section{Multimodalidade}

O termo Multimodalidade foi desenvolvido pelo autor Kress, e Van Leeuwen (2001), e está associado aos múltiplos modos existentes que podem ser utilizados como auxílio no processo comunicativo. Os trabalhos de Kress, Garcia e Van Leeuwen (2000) Kress, e Van Leeuwen (2001) explicam que a Análise Sociossemiótica Multimodal: está associada à significação, produção e recepção de mensagens tanto 0 autor quanto o leitor de uma determinada comunidade interpretativa. Os autores tratam da interpretação do significado do contexto e essa abordagem foca a análise de significados na interação entre os indivíduos, envolvendo também o produtor e o observador. Esses autores desenvolveram metodologias que permitem a análise de imagens (A Gramática do Designer Visual). Essa pesquisa se deu devido a novas tecnologias e ao uso de diversos recursos semióticos. O foco é o "Signo", o significado e a maneira como cada grupo interpreta em diferentes situações e contextos.

Considerando que a sociedade está cada vez mais baseada em padrões visuais, a multimodalidade possibilita através dos estudos sobre a Gramática Visual de Kress e Van Leeuwen (2006), compreender a relação e as maneiras como as imagens representam as relações entre as pessoas, os lugares e os objetos que nelas estão retratados em análise de textos multimodais com a noção teórica "Hallidayana ${ }^{10 "}$ de metafunções ideacional, interpessoal e textual.

Para tanto os autores propõem a decomposição visual de uma página de um documento multimodal que define nove possíveis composições de layout de acordo com o valor da informação no documento. A Figura 4 apresenta um destas composições de layout propostas, onde a informação é distribuída na pagina em setores e cada um dos quais atribui valores específicos para os elementos colocados dentro dele.

10 


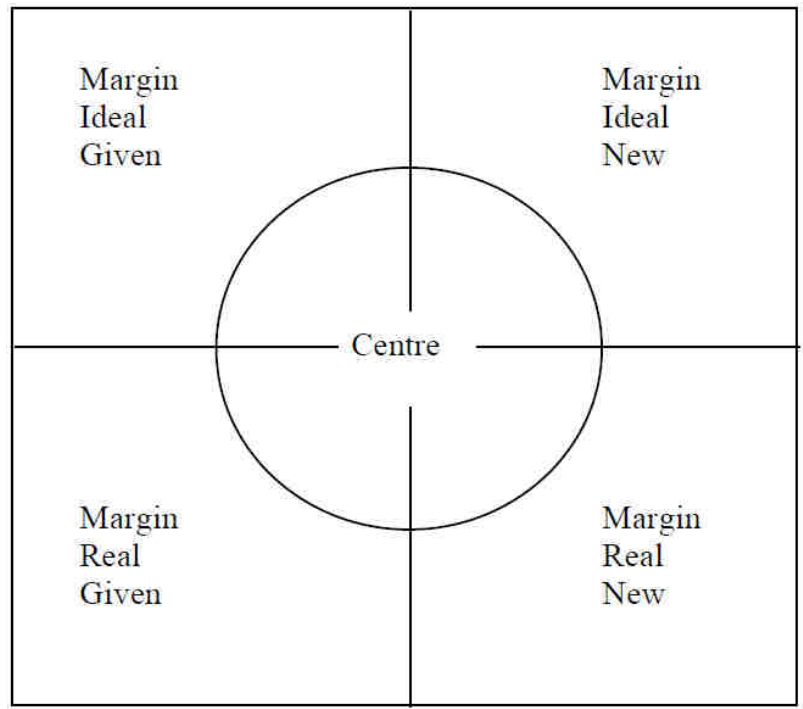

Figura 4: Proposta de Composição de Layout (KRESS e VAN LEEWEN, 2006, p 223).

Neste exemplo, o layout sugerido consiste em uma área central e quatro áreas marginais equivalentes aos quatro cantos da pagina, a informação que estiver no centro recebe um valor de importância maior, em relação ao resto nas margens.

\section{Teoria da Relevância}

A Teoria da Relevância proposta por Dan Sperber e Deirdre Wilson (1995, 2004), se propõe a explicar como ocorre o processamento de informações durante a comunicação humana. Os autores explicam que a comunicação humana se realiza por meio de dois mecanismos: o primeiro é baseado na codificação e decodificação de enunciados, e o segundo, baseado na ostensão por parte do falante e na inferência feita pelo ouvinte. Assim, a Teoria da Relevância pode ser vista como uma teoria fundamentada na Cognição e na Comunicação, sendo desenvolvida na interface entre a Comunicação e a Cognição.

$\mathrm{Na}$ inferência, o ouvinte utiliza um processo de raciocínio dedutivo que o permite gerar suposições e conclusões que estejam coerentes com a situação comunicativa. Na ostensão o falnate assume uma atitude que parte do seu comportamento quando este deixa explícita a intenção de manifestar algo, ou seja, é a atitude de fazer com que o ouvinte perceba sua intenção e chegue a uma interpretação relevante da mesma. Todo esse processo interpretativo é guiado pela busca da relevância.

Assim, podemos entender que a Teoria da Relevância é um modelo de comunicação e cognição humana que se propõe a explicar como a informação é 
representada mentalmente e processada de maneira inferencial em situações comunicativas intencionais da vida real. Essa abordagem é baseada nos princípios lógico e o cognitivo.

Sperber e Wilson $(1995,2004)$ defendem que a cognição humana tem uma tendência para a relevância. Assim, eles propõem o 'princípio de relevância', que explica a predisposição de um indivíduo para determinado ato comunicativo em precedência a outro. De acordo com o 'princípio de relevância' o cérebro/mente vai sempre na direção daquilo que para determinado indivíduo é mais relevante. Isso é descrito como o princípio abdutivo que busca explicar o processamento inferencial extremamente rápido da mente direcionado à comunicação humana para aquilo que é mais relevante em determinado momento.

\section{CIÊNCIA DA INFORMAÇÃO E ARQUITETURA DA INFORMAÇÃO EM AMBIENTES INFORMACIONAIS DE ENSINO/APRENDIZAGEM}

Steinmetz, Steinmetz, Costa e Duque (2013) apresentam uma base conceitual para uma Arquitetura da Informação Multimodal, para isso os autores identificam o estado da arte sobre os assuntos abordados no artigo e colocam algumas premissas que permitem estabelecer esta base conceitual relacionado a Arquitetura da Informação, a Multimodalidade, a Teoria da Relevância e as formas de representação e recuperação de informações. Neste mesmo sentido Steinmetz e Duque (2014) apresentam algumas contribuições da Arquitetura da Informação para ambientes colaborativos de ensino/aprendizagem, conforme o quadro resumo apresentado a seguir:

Quadro1: Resumo da Relação entre Arquitetura da Informação, a Multimodalidade, a Teoria da Relevância.

\begin{tabular}{|c|c|}
\hline Base conceitual & Pressuposto/Inferência \\
\hline $\begin{array}{l}\text { A Arquitetura da Informação têm como } \\
\text { objetivo gerar espaços informacionais } \\
\text { para atender as necessidades de } \\
\text { informação dos usuários, enquanto a } \\
\text { Multimodalidade está associada ao } \\
\text { estudo dos meios utilizados que levam a } \\
\text { compreensão de uma mensagem em um } \\
\text { determinado contexto. }\end{array}$ & $\begin{array}{l}\text { Partindo do pressuposto que um espaço de } \\
\text { informação pode ser multimodal, podemos } \\
\text { perceber que a Arquitetura da Informação e a } \\
\text { Multimodalidade são complementares no objetivo } \\
\text { de atender as necessidades informacionais das } \\
\text { pessoas. Onde, para a Arquitetura da Informação } \\
\text { este objetivo está explicito e para a } \\
\text { Multimodalidade isso acaba sendo uma } \\
\text { consequência da interação multimodal entre o } \\
\text { espaço de informação e o usuário. Ainda, } \\
\text { podemos inferir que a multimodalidade pode } \\
\text { influenciar no 'principio da relevância' melhorando } \\
\text { o processo transmissão da informação. }\end{array}$ \\
\hline
\end{tabular}




\begin{tabular}{|c|c|}
\hline $\begin{array}{l}\text { A Arquitetura da Informação é } \\
\text { considerada interdisciplinar agregando } \\
\text { áreas como a usabilidade e ergonomia. } \\
\text { A multimodalidade estuda os vários } \\
\text { modos de comunicação e/ou interação } \\
\text { entre os sujeitos e objetos. }\end{array}$ & $\begin{array}{l}\text { Considerando que a usabilidade e a ergonomia } \\
\text { podem influenciar a interação dos usuários com os } \\
\text { objetos informacionais, podemos inferir que a } \\
\text { Multimodalidade e a Arquitetura da Informação } \\
\text { tem objetivos de estudo semelhantes. }\end{array}$ \\
\hline \begin{tabular}{|l|} 
A Multimodalidade e a Gramática Visual \\
buscam compreender e prover múltiplas \\
formas de comunicação com o uso e a \\
organização de padrões visuais. A \\
Arquitetura da Informação busca prover \\
a organização, representação e \\
comunicação das informações.
\end{tabular} & $\begin{array}{l}\text { Ao assumirmos que um padrão visual pode ser um } \\
\text { design, pode ser uma forma de organização e } \\
\text { representação de informações utilizadas para } \\
\text { estabelecer uma comunicação, temos uma relação } \\
\text { direta entre a Multimodalidade/Gramática Visual } \\
\text { com a Arquitetura da Informação, pois nos dois } \\
\text { casos a organização do espaço informacional na } \\
\text { forma de uma representação que apóie a } \\
\text { comunicação é o principal objetivo. }\end{array}$ \\
\hline $\begin{array}{l}\text { A Arquitetura da Informação pode ser } \\
\text { vista como a integração entre contexto, } \\
\text { conteúdo e usuários, enquanto a } \\
\text { Multimodalidade busca tratar da } \\
\text { interpretação do significado do contexto } \\
\text { pelo sujeito. }\end{array}$ & $\begin{array}{l}\text { É possível deduzir que o estudo do contexto em } \\
\text { que o sujeito e a informação estão inseridos são } \\
\text { preocupações comuns tanto para Multimodalidade } \\
\text { quanto para Arquitetura da Informação. }\end{array}$ \\
\hline \begin{tabular}{|l|} 
A Multimodalidade foca na análise de \\
significados, na interação entre os \\
indivíduos, envolvendo o produtor e o \\
observador da informação. Na proposta \\
da Teoria Geral da Arquitetura da \\
Informação, o fenômeno da presença do \\
observador implica na mudança do \\
comportamento do objeto observado \\
determinando a diferença entre dado e \\
informação, sendo o conceito de \\
conhecimento resultado da abstração \\
que deriva da interação entre o \\
observador e o objeto observado.
\end{tabular} & $\begin{array}{l}\text { Neste ponto, se considerarmos a interação como } \\
\text { um fenômeno, temos uma sobreposição de } \\
\text { conceitos aplicados no desenvolvimento tanto da } \\
\text { Multimodalidade como da Arquitetura da } \\
\text { Informação, que apontam para definiçães } \\
\text { semelhantes sob pontos de vista diferentes. Pois, } \\
\text { podemos perceber uma relação entre a análise de } \\
\text { significados na interação e a definição de } \\
\text { conhecimento proposta na TGAl. }\end{array}$ \\
\hline $\begin{array}{l}\text { Sendo um documento visto como o } \\
\text { registro da informação. Considerando } \\
\text { que todo texto é multimodal e } \\
\text { documentos multimodais envolvem } \\
\text { combinações de informações que } \\
\text { empregam diferentes meios de } \\
\text { apresentação. }\end{array}$ & $\begin{array}{l}\text { Podemos inferir que documentos textuais são } \\
\text { documentos multimodais e ainda, podemos } \\
\text { perceber que a organização visual destas } \\
\text { informações no documento pode ser considerada } \\
\text { uma Arquitetura da Informação e, ainda, que esta } \\
\text { organização pode influenciar na relevância das } \\
\text { informações para o usuário. }\end{array}$ \\
\hline $\begin{array}{l}\text { Considerando que a Teria da Relevância } \\
\text { implica na predisposição de um } \\
\text { indivíduo para determinado ato } \\
\text { comunicativo em precedência a outro e } \\
\text { que a Arquitetura da Informação busca } \\
\text { organizar os espaços informacionais } \\
\text { para atender as necessidades dos } \\
\text { usuários, juntamente com a definição de } \\
\text { multimodalidade como o estudo os } \\
\text { vários modos de comunicação. }\end{array}$ & $\begin{array}{l}\text { Podemos inferir que um espaço informacional, } \\
\text { definido pela Arquitetura da Informação, pode ser } \\
\text { multimodal, bem como podemos utilizar a } \\
\text { multimodalidade para aumentar a relevância das } \\
\text { informações contidas neste espaço informacional, } \\
\text { melhorando o ato comunicativo em questão e } \\
\text { atendendo a necessidade de informação do } \\
\text { usuário de maneira mais eficiente. }\end{array}$ \\
\hline
\end{tabular}

Fonte: Steinmetz e Duque (2014) 
Considerando o que foi exposto até o momento, podemos inferir que é possível estabelecer um modelo para elaboração de uma Arquitetura de Informação Multimodal para Ambientes Informacionais Colaborativos de Ensino/Aprendizagem. Considerando que tanto a Ciência da Informação, a Arquitetura da Informação e a Multimodalidade podem contribuir na relevância do ambiente CSCL utilizado no processo de ensino/aprendizagem, melhorando assim o resultado deste processo.

Podemos observar que o significado que a informação assume para cada individuo pode ser singular, ou seja, a abstração que cada indivíduo faz do ambiente CSCL pode ser singular, devido ao contexto onde este indivíduo está inserido. Por conseqüência a colaboração destes indivíduos nos ambiente CSCL depende desta abstração, pois é com base na definição de conhecimento de Lima-Marque, (2011) a abstração será um dos requisitos para formação do conhecimento. A figura 5 explicita esta situação, conforme o fluxo a informação na comunicação de uma estudante com um Ambiente CSCL.

Fluxo da Informação em um Ambiente CSCL

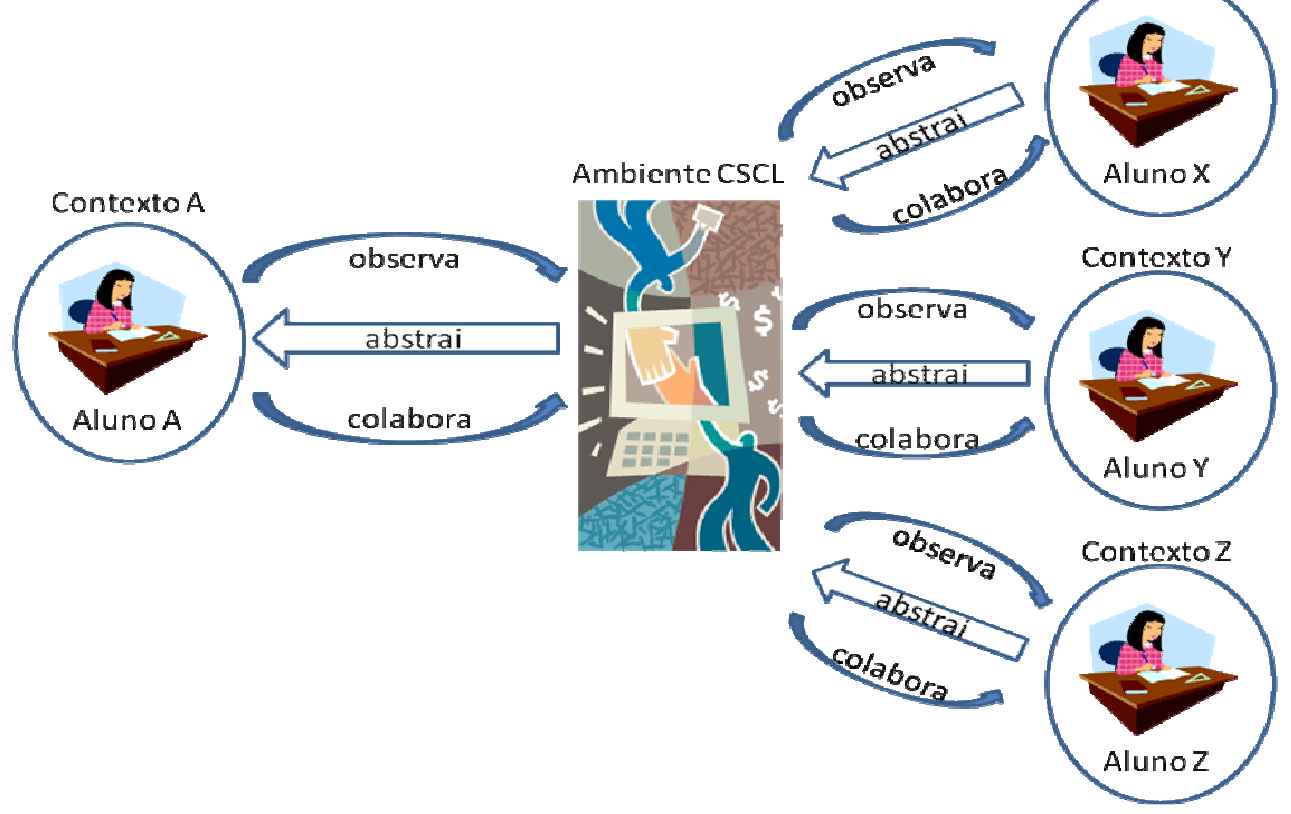

Figura 5: Fluxo da Informação em um Ambiente CSCL (Steinmetz e Duque, 2014).

Com o entendimento do Fluxo de Informações em um Ambiente CSLS podemos então partir para o estudo de um modelo para elaboração de uma Arquitetura de Informação Multimodal para Ambientes Informacionais Colaborativos de Ensino/Aprendizagem.

Neste sentido Rocha e Duarte (2013) explicam que a boa usabilidade de um sistema está diretamente ligada a como este ambiente é concebido, sendo que esta 
concepção deve partir de uma perspectiva centrada no usuário (Design Centrado no Usuário), de forma a reconhecer e atender às suas necessidades, a partir de processos que nem sempre são os mesmos da engenharia de software. Para isso os autores sugerem a norma ISO/IEC 13407/1999, que busca definir o design centrado em humanos através de ciclos iterativos, conforme a figura 6 :

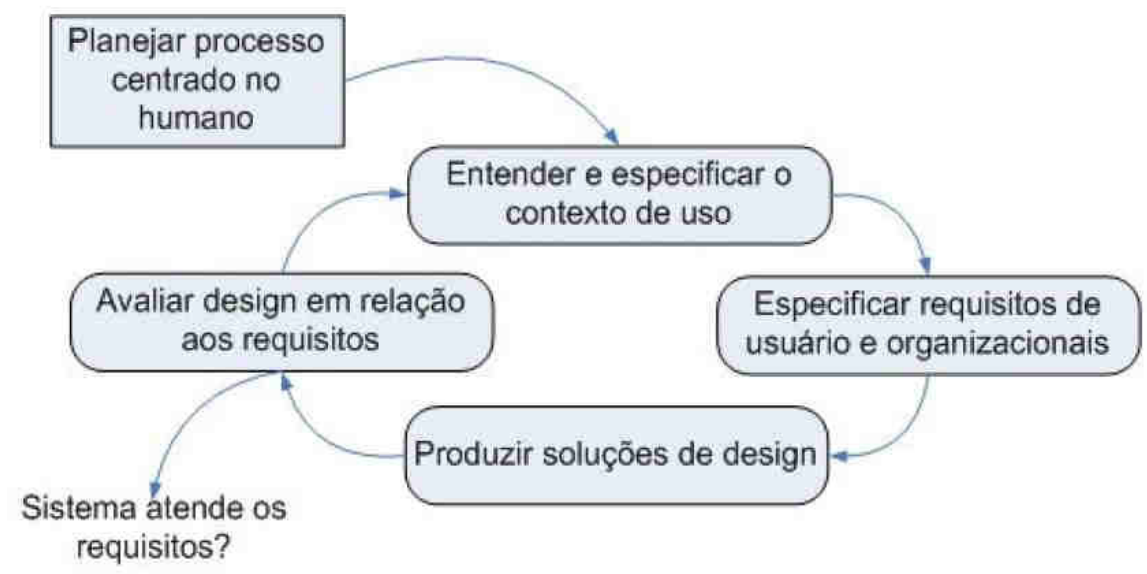

Figura 6: Design centrado no humano - (ISO/IEC 13407, 1999).

Assim, podemos identificar um conjunto inicial de características básicas que devem ser contempladas em uma ambiente CSCL concebido e utilizado a luz dos preceitos da multimodalidade e da teoria da relevância:

- O ambiente deve ser concebido/adaptado ao contexto dos estudantes/usuários.

- O ambiente deve oferecer vários modos comunicacionais, conforme prevê a definição do termo multimodalidade.

- O ambientes deve considerar a usabilidade e a ergonomia que podem influenciar a interação dos usuários.

- O ambiente deve apresentar uma Arquitetura da Informação que permita a inclusão, organização e recuperação das informações de forma simples e eficiente.

- Em complemento aos itens 3 e 4 o ambiente deve oferecer um Design centrado no humano.

\section{A PROPOSTA}

Considerando o Modelo de Ciclo de Vida do Desenvolvimento de Sistemas proposto por Gordon e Gordon (2006), temos:

- O levantamento das necessidades também chamado de análise de requisitos; 
- A análise de alternativas consiste na identificação e avaliação de sistemas alternativos;

- O projeto que trata da construção das especificações detalhadas para o sistema;

- O desenvolvimento que é codificação do software;

- O teste do novo sistema;

- A implantação que consiste na transferência do sistema para o real de uso;

- A manutenção que refere-se a todas as atividades relacionadas a um sistema depois que ele é implantado.

Juntamente as características básicas que devem ser contempladas em uma ambiente CSCL concebido e utilizado a luz dos preceitos da multimodalidade e da teoria da relevância propostas no item anterior, temos um Diagrama de fases para concepção de uma Arquitetura da Informação Multimodal para ambientes CSCL - DAIM:CSCL.

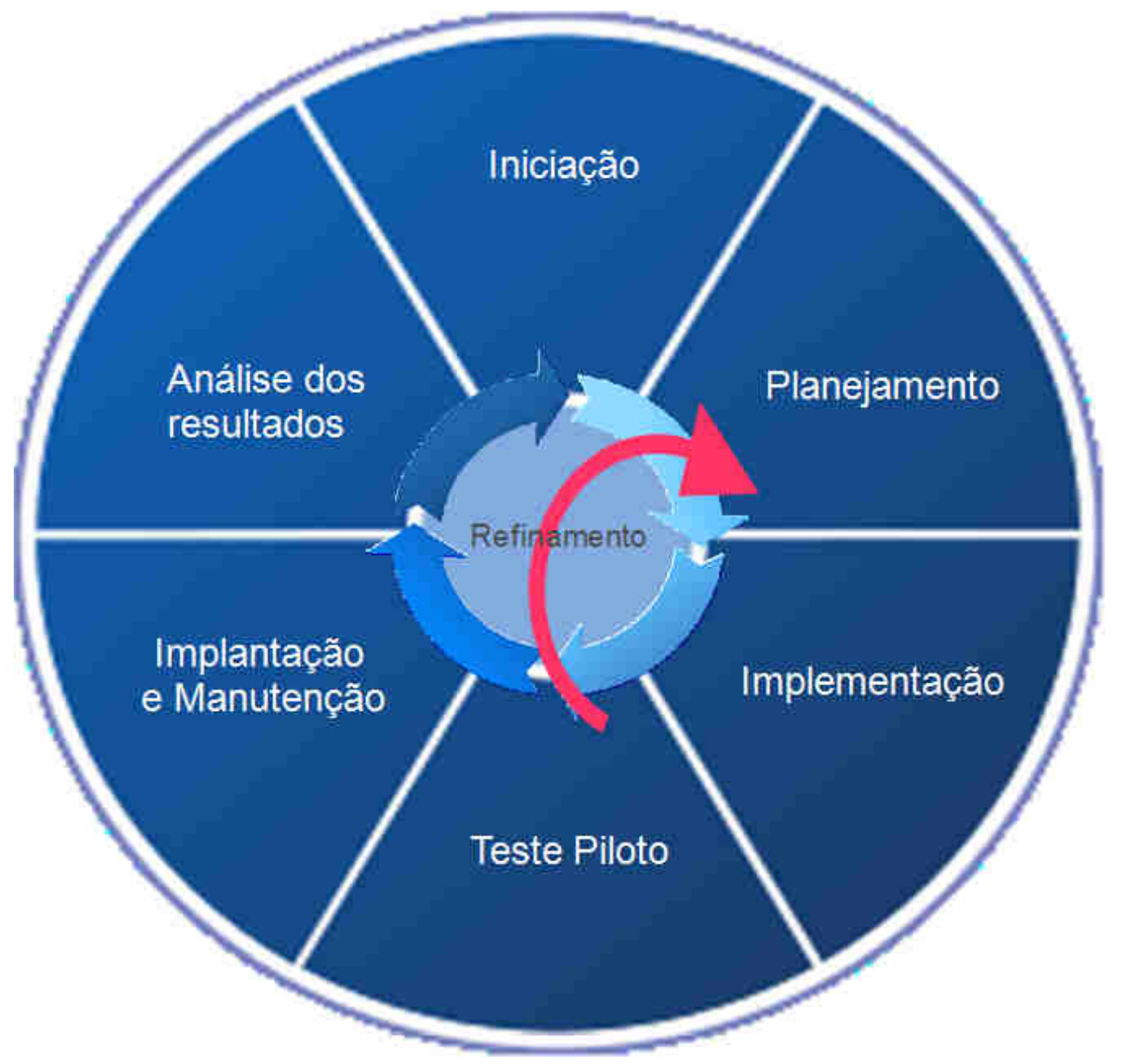

Figura 7: Diagrama de fases para concepção de uma Arquitetura da Informação Multimodal para ambientes CSCL - DAIM:CSCL 
Na figura 7 que apresenta o DAIM:CSCL, temos as seguintes fases:

- Iniciação: corresponde a fase da identificação da demanda, identificação do público alvo, identificação do contexto do público alvo, definição da equipe responsável pelo processo, levantamento inicial das necessidades, definição dos objetivos gerais a serem alcançados.

- Planejamento: trata da construção das especificações detalhadas para que os objetivos sejam alcançados. Tais como: projeto das interfaces que deve considerar recursos multimodais identificados segundo o contexto dos usuários; o projeto de banco de dados que devem atender os conceitos de precisão e revocação dos SRIs; o projeto transacional que deve comportar as solicitações postadas na interface retornando os resultados do banco de dados; e as características físicas do sistema. Sendo o conjunto das interfaces, banco de dados e transações os elementos que definem a Arquitetura da Informação Multimodal. Ainda, podemos considerar a possibilidade de aquisição de hardware e softwares necessários para viabilizar a execução do processo. Finalmente, devem ser preparados os testes do sistema.

- Implementação: consiste no desenvolvimento do ambiente segundo as especificações definidas na fase de planejamento, ocorre a codificação ou aquisição do software, a aquisição do hardware e o teste do novo sistema.

- Teste Piloto: esta fase ajuda a aprimorar o novo ambiente considerando que o trabalho já foi conceituado e planejado nas fases anteriores. Consiste em submeter o ambiente a um teste real com variáveis controladas, buscando o refinamento da Arquitetura da Informação Multimodal, já desenvolvida, com base nos preceitos do Design Centrado no Humano conforme apresentado na Figura 11. Neste momento o ambiente CSCL deve ser alimentado com as informações referentes ao curso a ser ministrado, sendo importante que estes conteúdos estejam adequados ao contexto dos usuários e aos modos comunicativos definidos nas etapas de iniciação e planejamento. 
- Implantação e Manutenção: Consiste na utilização do ambiente em larga escala, sendo efetuadas as manutenções corretivas e adaptativas pertinentes, bem como do registro histórico destas manutenções, dos índices de satisfação dos usuários e sugestões de melhorias.

- Analise dos Resultados: esta fase completa o ciclo de aprimoramento do processo buscando revisar os relatórios do que foi executado, se o esforço alcançou os objetivos pretendidos inicialmente e como podemos implementar futuras mudanças de forma a melhorar a qualidade, eficiência e eficácia, aprimorando a execução e corrigindo eventuais falhas. Esta fase pode ser vista também como uma fase de aprendizado para a equipe que executa o processo, sendo importante que os registros sejam mantidos através de todo o ciclo do processo.

Fazendo uma interseção entre o Diagrama de fases para concepção de uma Arquitetura da Informação Multimodal para ambientes CSCL - DAIM:CSCL (Figura 7), com o modelo de Modelo de Arquitetura da Informação (Figura 3) proposto por Lima-Marques e Macedo (2006). Podemos observar que o DAIM:CSCL otimiza a relação entre os níveis de meta-modelagem, modelagem e aplicação.

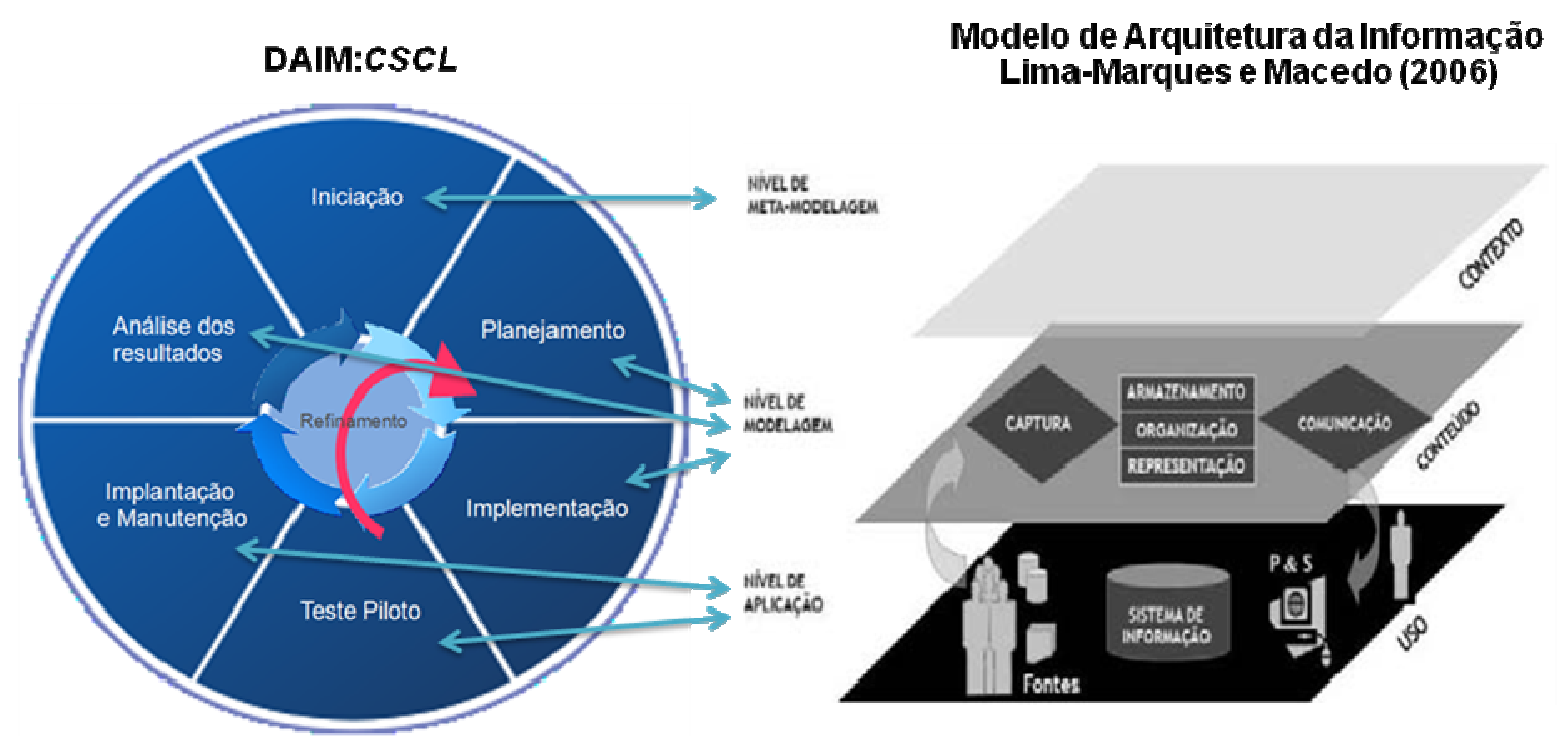

Figura 7: Interseção entre o DAIM:CSCL e o Modelo de Arquitetura da Informação 


\section{APÊNDICE D - APRESENTAÇÃO DA PROPOSTA PARA O GRUPO FOCAL}

$19 / 10 / 2015$

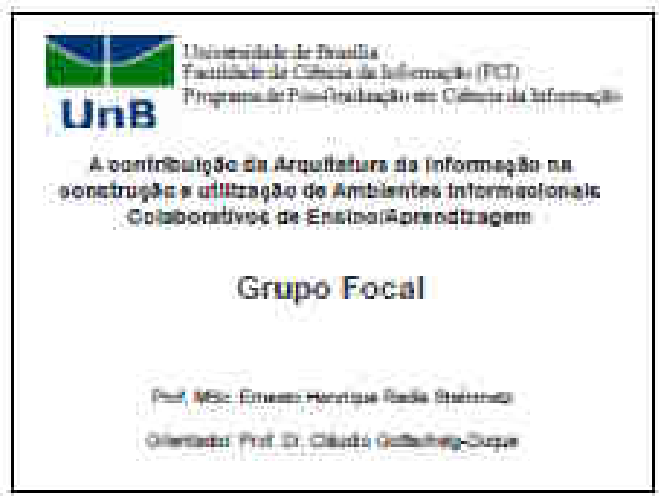

\section{ROTEIRO}

1 Recepelp dos dartipanes:

Z Enplica; to score of fiodoinamenth, chithos e regrn

relaclonodaic 20 grupo focal, durs; 50 zotal da gesquan e a

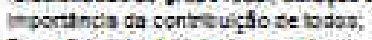

2. Ereve la's inpodutoca do pesoisadice erplicando or oojetived gera a as pescuas, as condiglea de mavac5s.

do stundo e as aspectos atcos sovotioou nao

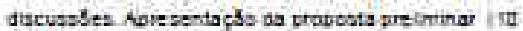
minutss

4 Esciarecimerto sebre o terts envage aos namponets:

contertualanac-ers a nemeto ta peagifita

3 inico do detase pelo pesoviador, acresentanap as

auesties prooustas no roters

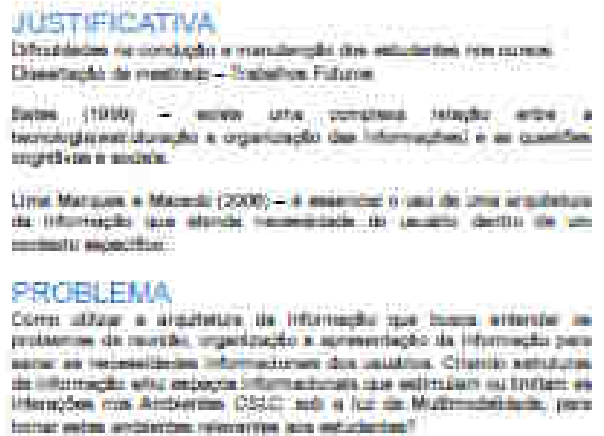

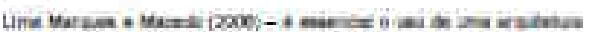

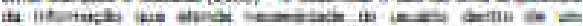
ereur meitin.

PRCELEMA

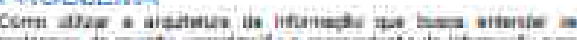

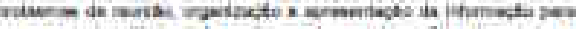

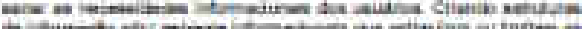

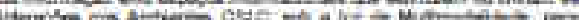




\section{CENETINOS}

onirmid armak.

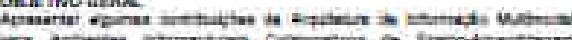

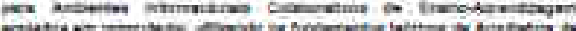

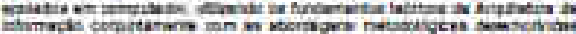

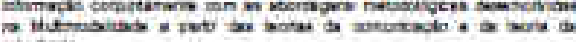
axomit

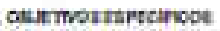

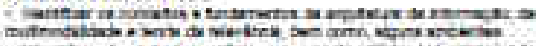

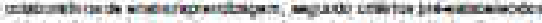

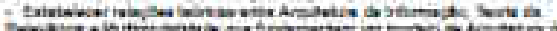

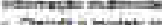

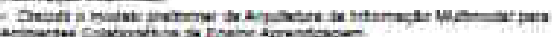

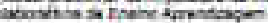

\section{REFERENICIAL TEÓRICO}

Cencos da irdormaça

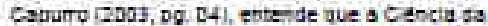

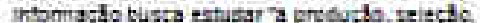

orpaniracto, interprstaclis, amianenamerts, recuperacho,

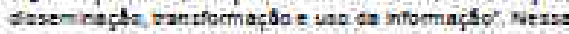

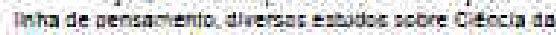

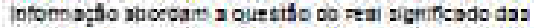

pasinar Dado, intomacalo e Conhecosento su o due

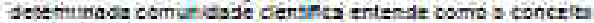

sestes temos.

\section{ARQUITETURA DA WFORMACTÁ}

Wurman (19g7) define Arquitetura da informacio cono a cencia e 3 arie de criar instrup̧os para espaços unganizados. Blusca entender os problemas de reinitáo, organizacíp e apresentapâo da

informacbo parta sanar as nesessidades informacionais dos usuatios.

Para Rosenteld e Morvile (2002) a A é uma nterseccẩn de três àreas

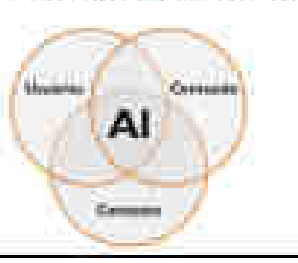




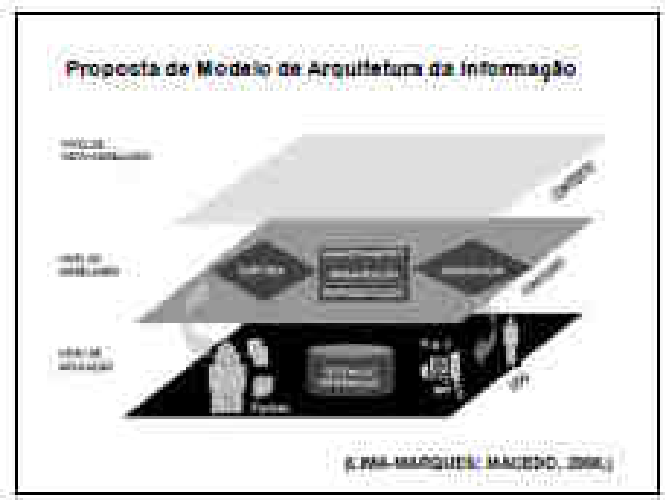

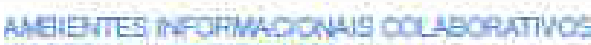
DE ENSINONFRENDIZAOEM

O toco no trobalts colaberatud, desenvelvido nas peequinas de OSOW, detivou o conceac of apcenciagem colaborativs apalade pot computador (EJCL) onae a seitracts de nistemss de soriscow

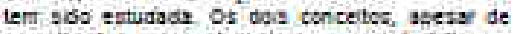

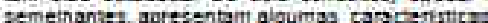

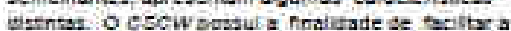

cominicaplo to onoduinidase do ondoo de trabaing, com

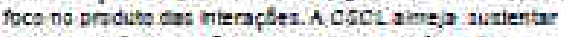

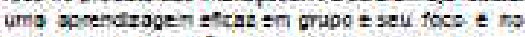

trocesuo of interaçb istentetr, soor, pla $6 \mathrm{E}$

Mutrimodalidarte

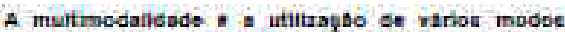
aemianieattvec durants unia interaşes ontre cujeitoc ou ortin kujettiot o doubmentes zendo o mide, ume forma de tstabeisoer a somunioapso i a mutfimodrlidade co raters ae uso do mais of un modo

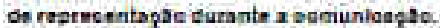

iKreat : Van Leewarn; 200 1) 
A Gramática do Designer Vtaual

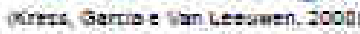

Tem cond focs 4 "Ibno", a Ilgnifodo e a manen cons zaos orupo inferprsta em therentes s tuaptete e comientes.

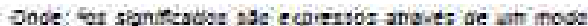

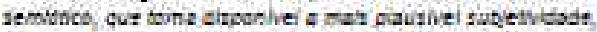

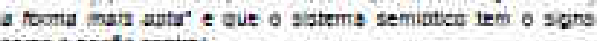
coina a napta centra:

4 GOV oonsicte na desamposięso vicunal de una Daging

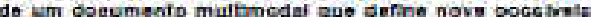

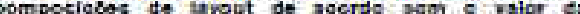

informapho bo doouminto

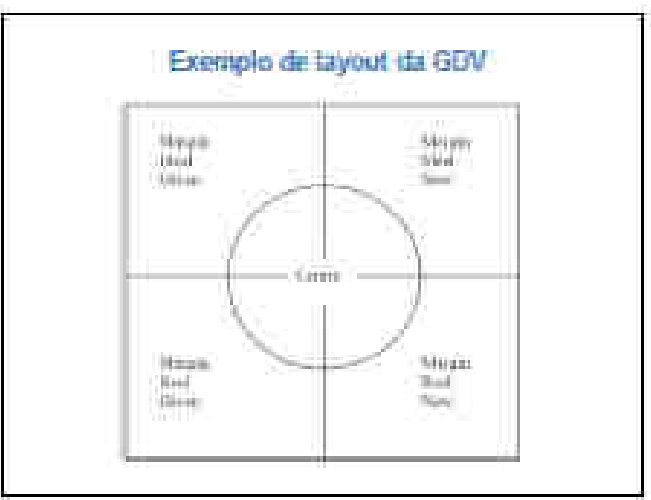

\section{Teoria da Retevāncia}

A Teoria da Releváncia proposta poc Dan Sperber e Derdre, Witson (1905, 2004)

A comunicacäo humana se reaila por meio de dois mecarismos o prinero e baseado na coddicacáo e decodif cacaio de enurncados, e o segundo, baseade na ostensio por parte do talinte en na inferéncla feita pelo ouvinte.

Propoben a principio de relevànciá, que é a predisposicaso de um individio para deterninado ate comurcative em precedéncia a outro. Atencia está serrpre voltada para o que é rais relevante 


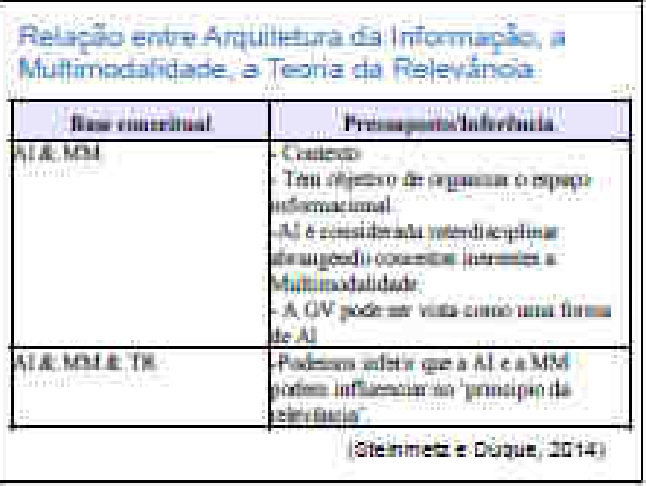

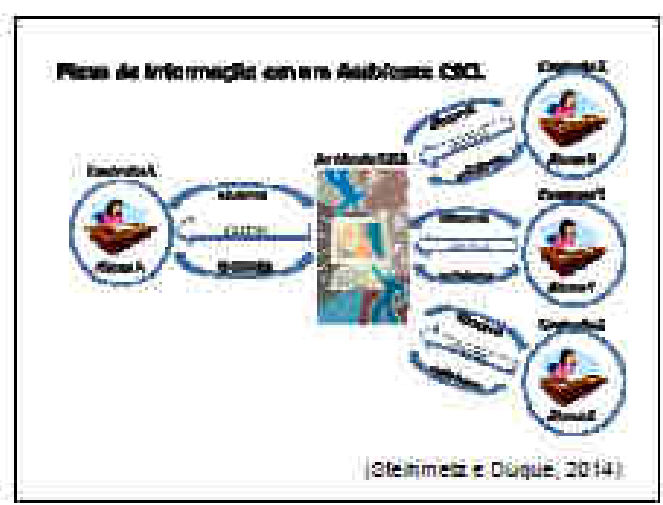

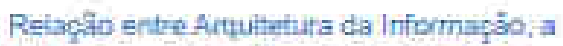
Mutimodalidate, a Tesria da Relevânos

\begin{tabular}{|c|c|}
\hline Hew cantritual & 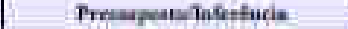 \\
\hline UENAM & 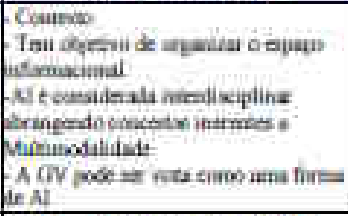 \\
\hline$M E B M=1 R$ & 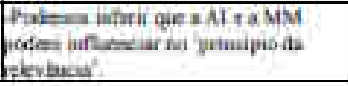 \\
\hline
\end{tabular}


Como Criar uma Al Muitimodal?

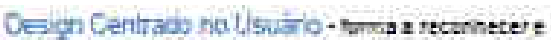

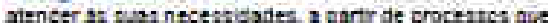

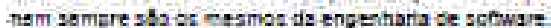

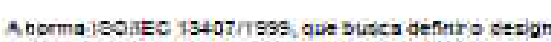
ceetrsob shi hum enos araver de docr lecation:

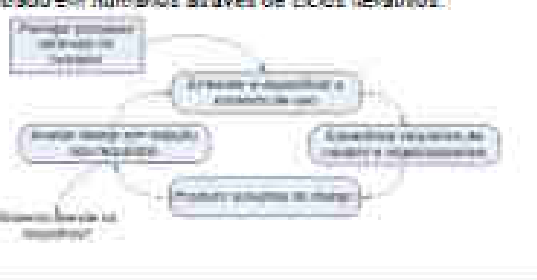

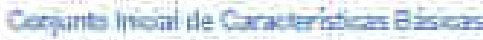

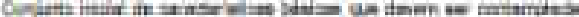

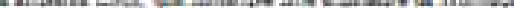

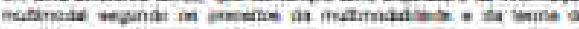
wimentar

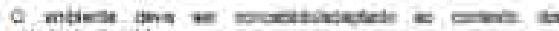

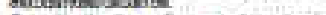

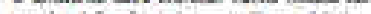

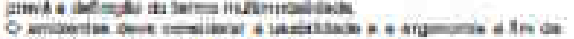

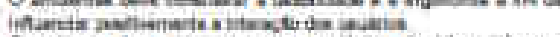

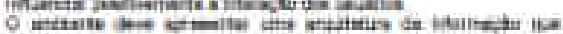

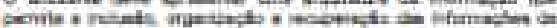

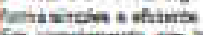

5. ET w Cogt intias in humate 


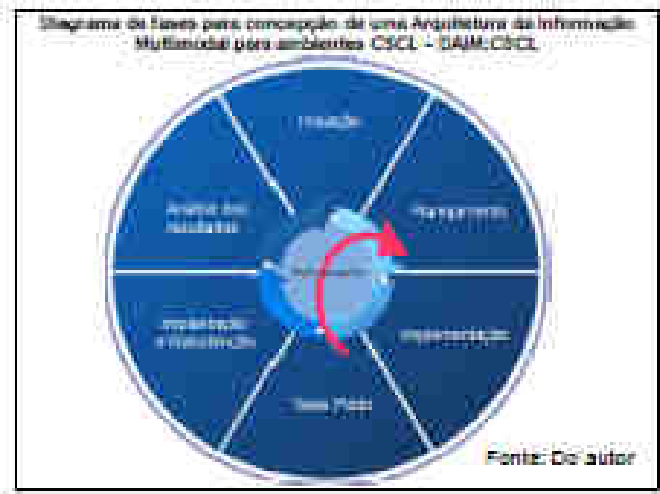

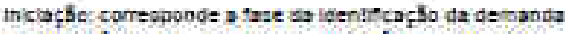
dentifcaçto do pcoico aso, denticap̧lo de conteria do poblico aivo, dennig bo oa ezupe rzagonsave peit avocesso, is astamienta inicai das necessidader. betniçs: des objetios geras o seftem aitconpasus. Garejaryente uba as erpechcaçbes eetainatas parn que

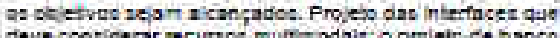
deve cootioerar recirnot muntrodais; o prujein de banco Je dades ait devem atender or conceloc sRis propets trocescionai \&ue de is eqrapotar as solictiaçles pootadao

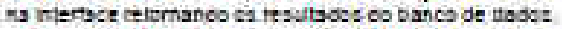

O conjuns das Inteffacsi, banco de cades = ranaactes oe

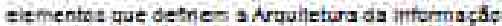

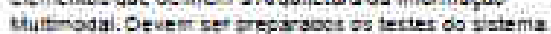

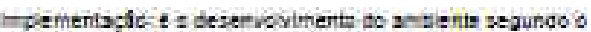
sanejanentb. procerve ce eqgentaris de :DW.

Teste fivth esta tase a vits a acheoraro norc ambierts

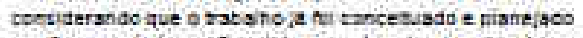

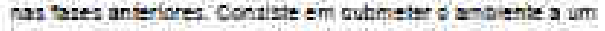
zeste reai com vanaveir controados, buacando o remartents As.Arutetura as informacibo Muttisodat, it desenvainida zomi bast cor preceitur do Derlon Cestruoo ao Hurcaso

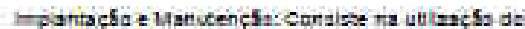

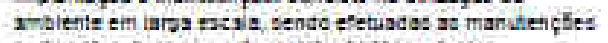

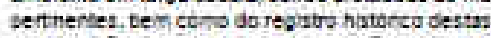

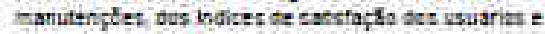
sugetiles de nehorias. 


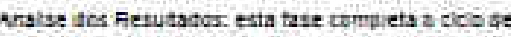

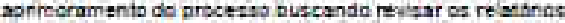

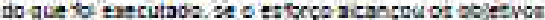

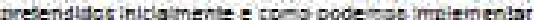

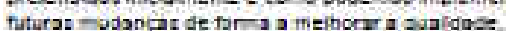

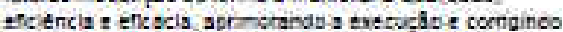

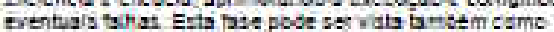

uma fase de apretdrado para a soope que erscula

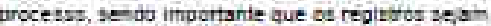

mantides airsuts ge toos te cclo de procezse.

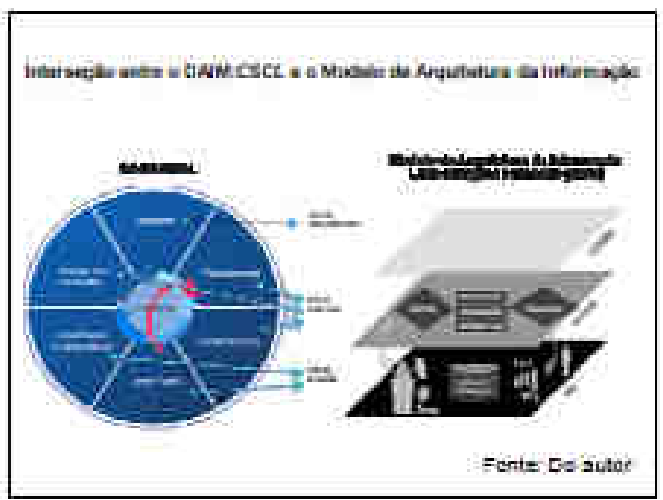

\section{OBRIGADO}

emesto steinmetrgitb.edu.tor 